\title{
Wahlmöglichkeiten und Wettbewerb in der niederländischen Krankenhausversorgung
}

\author{
Christina Walser
}

I. Grundlegendes

1. Das Gesundheitssystem der Niederlande - ein Überblick 277

2. Kernprobleme von Wettbewerb und Regulierung 279

2.1. Krankenhausversorgung $\quad 279$

2.2. Kosten der Krankenhausversorgung $\quad 279$

2.3. Normative Steuerung und politische Diskussion 281

2.3.1. Zusammenspiel von Staat und privaten Unternehmen 282

2.3.2. Flexibilisierung 283

3. Der Krankenhaussektor im Rahmen des Gesundheitssystems 284

3.1. Krankenhausversorgung 284

3.2. Organisationsstruktur des Krankenhaussektors 284

3.3. Gesetzlicher Rahmen 287

3.4. Strukturen und Institutionen der Krankenversicherungsträger 288

3.4.1. Struktur der Krankenversicherer nach dem Krankenkassengesetz bis 2005

3.4.2. Struktur der Krankenversicherer seit 2006

3.5 Rechtsverhältnisse zwischen Krankenversicherung, Leistungserbringer und Versichertem

4. Wettbewerb und Gesundheitsversorgung

4.1. Allgemeines Verständnis von Wettbewerb

4.2. Die Bedeutung von Wettbewerb im Gesundheitssystem

4.3. Gesetzlicher Rahmen

4.4. Institutionen der Wettbewerbskontrolle

II. Märkte - Wettbewerb und Regulierung in der Krankenhausversorgung 301

1. Der Verbraucher bei der Auswahl des Krankenhauses 301

$\begin{array}{ll}1.1 \text { Qualität } & 302\end{array}$

1.2. Preis $\quad 304$

2. Anreize für den Verbraucher bei der Wahl der Krankenversicherung 304

2.1 Das Recht zum Wechsel der Krankenversicherung 306

2.1.1 Preis als Anreiz $\quad 306$

2.1.2 Leistungen als Anreiz $\quad 307$

2.1.3 Zusatzversicherungen $\quad 311$

3. Das Verhältnis zwischen Krankenversicherung und Krankenhaus 312

3.1. Entwicklung der Kontrahierungsfreiheit zwischen Krankenhäusern und Krankenversicherern

$\begin{array}{ll}3.2 . & \text { Vertragsinhalt } \\ 3.313\end{array}$

$\begin{array}{ll}3.3 \text { Tarifgestaltung } & 313\end{array}$

4. Wettbewerb zwischen den Krankenhäusern $\quad 314$

$\begin{array}{ll}\text { 4.1. Rechtsform } & 314\end{array}$

4.2 Besonderheiten der selbständigen Behandlungszentren 315

$\begin{array}{ll}4.3 \text { Krankenhausplanung } & 316\end{array}$ 
4.4. Zulassungsverfahren $\quad 319$

4.5. Finanzierung $\quad 322$

4.6. Staatlicher Einfluss $\quad 325$

4.7. Wettbewerbswidrige Absprachen zwischen Krankenhäusern 326

5. Wettbewerb der Krankenversicherungen untereinander 327

5.1. Konkurrenz um die Versicherten $\quad 327$

5.2. Risikostrukturausgleich $\quad 330$

5.3. Zusatzversicherungen 331

5.4. Konzentration 331

III. Zusammenfassung der Ergebnisse bezogen auf die Funktion und Rolle des Wettbewerbs 


\section{Grundlegendes}

\section{Das Gesundheitssystem der Niederlande - ein Überblick}

Das Gesundheitssystem der Niederlande ist durch eine für alle Einwohner verpflichtende Krankenversicherung geprägt. Diese hat durch die Reform im Jahre $2006^{1}$ einen grundlegenden Wandel durchlaufen. Zwar ist die Dreigliedrigkeit der Struktur der medizinischen Versorgung beibehalten worden, nämlich die Versicherung für die notwendige medizinische Versorgung, die Versicherung für besondere Krankheitskosten als eine Pflegeversicherung und die privaten Krankenzusatzversicherungen, ${ }^{2}$ jedoch hat die Versicherung der notwendigen medizinischen Versorgung, wozu neben der hausärztlichen Versorgung auch die hier besonders relevante Krankenhausbehandlung gehört, eine grundlegende Neufassung erfahren. ${ }^{3}$ Die Versicherung für die medizinisch notwendige Versorgung, die ihre Grundlage im Krankenkassengesetz ${ }^{4}$ hatte, das vor der Reform 2006 galt, fand, war eine verpflichtende Arbeitnehmerversicherung für diejenigen, deren Einkommen unterhalb der Jahresarbeitsentgeltgrenze lag. Besserverdienende mussten sich privat versichern. Es gab keine Möglichkeit einer freiwilligen Versicherung im Krankenkassengesetz. Die Versicherung für besonders schwere Risiken war im Allgemeinen Gesetz über besondere Krankheitskosten ${ }^{5}$ geregelt. Es war keine Arbeitnehmerversicherung, sondern eine Volksversicherung, die für alle Einwohner der Niederlande verpflichtend war. Sie deckt diejenigen Risiken ab, die auf dem freien Markt

1 Zorgverzekeringswet (Krankenversicherungsgesetz) vom 16. Juni 2005, Stb. 2005, 358, letzte Änderung vom 22. Dezember 2005, Stb. 2005, 708.

2 Ausführlich: Noordam, Socialezekerheidsrecht, 7. Aufl. 2004, S. 268 ff; ders., Hoofdzaken Socialezekerheidsrecht, 3. Aufl. 2004, S. 74 ff; Walser, Die aktuellen Reformen der niederländischen Krankenversicherung - Anregungen für Deutschland?, ZFSH/SGB 2004, 410 (410 ff).

3 Zur Krankenversicherungsreform 2006: Beerepoot, De Zorgverzekeringswet en de Wet op de zorgtoeslag, Houten, 2006; Hamilton, Een zorgverzekering voor iedereen, 2005 Nr. 3; van Saase/Pruijssers, De nieuwe Zorgverzekeringswet, Kluwer 2006; van Westerlaak, De zorgverzekeringswet toegepast, Kluwer 2005; Walser, Die aktuellen Reformen der niederländischen Krankenversicherung - Anregungen für Deutschland?, ZFSH/SGB 2004, 410; diess., Neue Krankenversicherung der Niederlande, ZRP 2005, S. 273; diess., Nach der Gesundheitsreform in den Niederlanden: Eine neue Krankenversicherung für jeden, SozSich 2006, S. 87 ff; Hamilton, Kabinet kiest voor wettelijke geregelde privaatrechtelijke zorgverzekering, Zorg \& Financiering 2004, 12 ff; Schooneveld, De Zorgverzekeringswet en de Wet op de zorgtoesalg in vogelvlucht, TvG 2005, 3 ff; van der Most, De Zorgverzekeringswet en de selfverzekerde burger, TvG 2005, 17 ff.

4 Ziekenfondswet (Krankenkassengesetz) vom 15 Oktober 1964, Stb. 1964, 392, letzte Änderung in Stb. 2003, 203.

5 Algemene wet bijzondere ziektekosten (AWBZ), Gesetz vom 14 Dezember 1967, Stb. 1967, 617, letzte Änderung in Stb. 2002, 241. 
nicht wirtschaftlich zu versichern wären. ${ }^{6}$ Durch die jüngste Reform wurde sie nicht weitergehend berührt.

Durch Inkrafttreten des neuen Krankenversicherungsgesetzes ist die gesetzliche Krankenversicherung mit den privaten Vollversicherungen in der 2. Säule zu einer einheitlichen Basisversicherung verschmolzen, die für alle Einwohner der Niederlande verpflichtend ist, Art. 2 Abs.1 Krankenversicherungsgesetz. Die Krankenversicherung wird durch private Krankenversicherungen ausgeführt, die aber strengen gesetzlichen Rahmenvorgaben entsprechen müssen. Die wesentlichen gesetzlichen Vorgaben sind ein gesetzlich umschriebenes Basispaket an Leistungen (Art. 11 Krankenversicherungsgesetz i.V.m. Art. $2.1 \mathrm{ff}$ Beschluss Krankenversicherung, BZ ${ }^{7}$ ), ein Annahmezwang für die Krankenversicherungen hinsichtlich der Versicherten im Bereich der Basisleistungen (Art. 3 Krankenversicherungsgesetz), sowie ein morbiditätsorientierter Risikostrukturausgleich. Aber die Reform führte auch viele Gestaltungsräume für die Krankenversicherungen und die Versicherten ein. ${ }^{8}$ So dürfen die Unternehmen Gewinn erzielen, sie setzen einen Teil der Beiträge, nämlich die nominelle Prämie, selbständig fest und entscheiden über ihre Leistungsangebote (ausgenommen das Basispaket, dies ist verpflichtend) und Selbstbehalte, Art. 11 Abs. 2, 17 Abs.1, Art. 19 ff Krankenversicherungsgesetz. Durch diese Freiheiten soll eine Zunahme von effektivem Wettbewerb erreicht werden, von dem man sich eine Stabilisierung der Kosten bei gleichbleibender Leistungsqualität erhofft. 9

Sowohl nach dem alten Krankenkassengesetz (Art. 8) als auch nach Art. 11 des neuen Krankenversicherungsgesetz i.V.m. Art. 2.4 Beschluss Krankenversicherung haben die Versicherten neben dem Anspruch auf Behandlung durch Allgemeinärzte auch Anspruch auf Behandlung durch Spezialisten und insofern auch auf Krankenhausversorgung. An diesem Anspruch und auch an seinem Umfang hat die Reform nichts geändert. Es gab jedoch 2005 bereits Reformen im Bereich der Finanzierung von Krankenhausleistungen, auf die unten ${ }^{10}$ näher eingegangen wird.

6 Pruijssers/Siebers/Kolsteren/Mulder/van Scherpenzeel, Sociale verzekeringswetten Bd. 7, Fn. 13, AWBZ Anm. 1; Noordam, Socialezekerheidsrecht, 7. Aufl. 2004 S. 255.

7 Besluit zorgverzekeirng, Beschluss vom 28.06.2005 nr. 05.001638, im Internet unter: www.denieuwezorgverzekering.nl/Zorgverzekering/nieuwewet/Publicaties/.

8 de Groot, De zorgverzekeraar: spin in het web?, TvG 2005, 41 (51 ff); Schooneveld, De Zorgverzekeringswet en de Wet op de zorgtoeslag in vogelvlucht, TvG 2005, 3 (11 f); van der Most, De Zorgverzekeringswet en de zelfverzekerde burger, 2005, 17 (26 ff).

9 Kamerstukken II 29763 Nr. 3: Regeling van een sociale verzekering voor geneeskundige zorg ten behoeve van de gehele bevolking (Zorgverzekeringswet) - Memorie van toelichting, Gesetzesbegründung S. $2 \mathrm{f}$.

10 Unten II. 4.5. 


\section{Kernprobleme von Wettbewerb und Regulierung}

\subsection{Krankenhausversorgung}

Der Bereich der Gesundheitsversorgung im Krankenhaus stellt einen wesentlichen Pfeiler des niederländischen Gesundheitssystems dar. Der Aufgabenbereich der Krankenhäuser ist im internationalen Vergleich in den Niederlanden sehr breit gefasst, indem die Krankenhäuser auch den Mittelpunkt der fachärztlichen Versorgung bilden. ${ }^{11}$ Insofern ist eine Entwicklung zu beobachten, die von den ,gasthuisen“ im 18. Jahrhundert als Vorläufer der Krankenhäuser ausging. Diese wurden lediglich von den Ärmsten der Bevölkerung aufgesucht. ${ }^{12}$ Im Gegensatz dazu sind die Krankenhäuser heutzutage Zentren der Spitzenmedizin. Die gegenwärtige Bedeutung der Krankenhäuser lässt sich auch an den finanziellen Mitteln ablesen, die für Ihre Gründung, den Betrieb und die Modernisierung aufgewendet werden. Sie beliefen sich 2004 auf 7,1\% des Bruttoinlandprodukts und belaufen sich auf ca. 33\% der gesamten Ausgaben im Gesundheitsbereich. ${ }^{13}$ Noch im Jahr 2003 betrugen die Kosten lediglich 5,8\%. Seit 1995 ist sogar eine Kostensteigerung um $70 \%$ zu beobachten ${ }^{14}$, aber sie hat seit 2004 wieder abgenommen und pendelt sich auf rund $30 \%$ der Gesamtkosten der Gesundheitsversorgung ein. ${ }^{15}$

Aber auch anhand der vermehrten Inanspruchnahme der Krankenhäuser lässt sich ihre Bedeutung ablesen. Seit 1995 hat die Anzahl der im Krankenhaus aufgenommenen Personen einen Zuwachs von $10 \%$ zu verzeichnen. 16

\subsection{Kosten der Krankenhausversorgung}

Im Gesundheitssystem der Niederlande wurden in den vergangenen Jahren fortwährend steigende Kosten verzeichnet. Während die Ausgaben für den Gesundheitssektor im Jahr 1990 noch rund 24 Milliarden EUR betrugen, beliefen sie sich 2004 bereits auf knapp 60 Milliarden EUR. ${ }^{17}$ Die Ausgaben steigen nicht kontinuierlich an, sondern es lassen sich Einbrüche sowie sprunghafte Steigerungen infolge gesetzlicher Reformmaßnahmen beobachten. So sind die Ausgaben gemessen am Bruttoinlandsprodukt 2001

11 Vandermeulen, Ziekenhuisen: medisch bedrijven, III 2.1-4 in: Breit/Elsinga/Kasdrop/San-ders/Vandermeulen/Weevers, Handboek Structuur en financiering gezondheidszorg Bd. 3 2005; Ribbens, De positie van de huisarts in de gezondheidszorg, III 1.3-5 in: Breit/Elsinga/Kasdrop/San-ders/Vandermeulen/Weevers, Handboek Structuur en financiering gezondheidszorg Bd. 3 2005; Maarse, Marktwerking in de ziekenhuiszorg, Maastricht 2002, S. 52f.

12 Scherpenisse/Verbeek, Gezondheidszorg, 2002, S. 70.

13 Centraal Bureau voor de Statistiek, Gezondheid en zorg in cijfers 2007, S. 97.

14 Centraal Bureau voor de Statistiek, Gezondheid en zorg in cijfers 2005, S. 57.

15 Centraal Bureau voor de Statistiek, Gezondheid en zorg in cijfers 2007, S. 96 f.

16 Centraal Bureau voor de Statistiek, Gezondheid en zorg in cijfers 2005, S. 24.

17 Centraal Bureau voor de Statistiek, Gezondheid en zorg in cijffers 2005, S. 11, 13; CVZorgzijfers 1998-2003, S. 11. 
rapide angestiegen. 2000 beliefen sie sich noch auf rund 42 Milliarden EUR und 2001 bereits auf rund 47 Milliarden. ${ }^{18}$ Dies ist auf den „Aktieplan Zorg verzekerd“ zurückzuführen, in dessen Rahmen staatliche Mittel zur Verfügung gestellt wurden, um der Wartezeitenproblematik zu begegnen. ${ }^{19}$ Dagegen sind die relativen Ausgaben 2004 gegenüber dem Vorjahr mit 4,3\% nur gering gestiegen. Ursächlich sind vermehrte Einsparmaßnahmen wie die Einengung des Leistungsumfangs des Krankenkassengesetzes, aber auch das Einfrieren der Tarife für die ärztliche Versorgung. ${ }^{20} 2006$ sind die Kosten der Krankenhausversorgung um 5,4\% gegenüber dem Vorjahr gestiegen, was auf eine Zunahme der Leistungsnachfrage und ein Ansteigen der Lohnkosten zurückgeführt wird. ${ }^{21}$

Die Bedeutung des Krankenhaussektors für die Ausgaben im Gesundheitssystem wird dadurch deutlich, dass im Jahr 2000 rund 10 Milliarden EUR und 2004 bereits rund 14,5 Milliarden EUR auf diesen Bereich entfielen. ${ }^{22} 2006$ lagen die Ausgaben der Krankenhausversorgung bereits bei knapp 19 Milliarden EUR. ${ }^{23}$ Mit der fachärztlichen Versorgung zusammen, die zwar grundsätzlich im Krankenhaus stattfindet, aber in Ausnahmefällen wie zahnärztlicher Versorgung, eben auch in niedergelassenen Facharztpraxen, entfällt ca. 1/3 der Gesamtausgaben im Gesundheitssektor auf die Krankenhäuser. ${ }^{24}$ Ein weiterer Anteil, der ca. 1/5 der Gesamtausgaben ausmacht, trifft die Pflegeheime und Einrichtungen der Versorgung zu Hause. Daneben machen auch die Arznei-, Heil- und Hilfsmittel, niedergelassene Ärzte (außer Fachärzten) und gemeindliche Gesundheitsdienste wesentliche Bereiche der Gesamtausgaben im Gesundheitsbereich aus. 25

Aufgrund der stetig steigenden Kosten hat der niederländische Gesetzgeber insbesondere im Krankenhaussektor immer wieder Reformmaßnahmen verabschiedet. So wurde 2005 die Krankenhausfinanzierung auf eine neue Grundlage gestellt ${ }^{26}$ und 2006 wurde die gesetzliche Krankenversicherung grundlegend reformiert. 27 Dabei wird als entscheidendes Mittel die Wirkung des Wettbewerbs zur Kostensenkung oder zumindest zu ihrer Stabilisierung im Verhältnis zu seiner Regulierung zum Zwecke einer sozialen Krankenversicherung angesehen. Diesen Bereich berühren die Reformen der vergangenen Jahre ebenso wie auch die gegenwärtigen Erneuerungsbestrebungen. Die Kernelemente bei dem Ansatz, eine Steigerung des Wettbewerbs im Krankenhaussektor herbeizuführen und so zu einer Kostenstabilität beizutragen, sind zum einen eine Erhöhung der Anzahl möglicher Konkurrenten und zum anderen die Schaffung größerer

18 Centraal Bureau voor de Statistiek, Gezondheid en zorg in cijffers 2005, S. 111.

19 Centraal Bureau voor de Statistiek, Gezondheid en zorg in cijffers 2005, S. 13.

20 Centraal Bureau voor de Statistiek, Gezondheid en zorg in cijffers 2005, S. 13.

21 Centraal Bureau voor de Statistiek, Gezondheid en zorg in cijffers 2007, S. 95.

22 Centraal Bureau voor de Statistiek, Gezondheid en zorg in cijffers 2005, S. 111.

23 Centraal Bureau voor de Statistiek, Gezondheid en zorg in cijffers 2007, S. 125.

24 Centraal Bureau voor de Statistiek, Gezondheid en zorg in cijffers 2007, S. 94 f.

25 Centraal Bureau voor de Statistiek, Gezondheid en zorg in cijffers 2007, S. 94.

26 Eingehend unten II. 4.5.

27 I. 3.4.2. 
Spielräume bei der Gestaltung vor allem der Preise, aber auch des Leistungsspektrums in diesem Bereich. Zur Erhöhung der Konkurrenzsituation tragen die Zulassungen von Selbstbehandlungszentren, der sog. selbständigen Behandlungszentren (Zelfbehandeling Center), einer Art Tagesklinik, bei, 28 während die Konzentration im Krankenhausbereich in den vergangenen Jahrzehnten diesem Trend wieder entgegenwirkt. Während es 1951 noch 253 Krankenhäuser gab, waren es 2001 gerade noch 112, also weniger als die Hälfte. ${ }^{29}$ Auch die Anzahl der Betten pro Einwohner hat abgenommen. 1951 waren es 4,4 und 2001 noch 3,6. Dagegen hat die Anzahl der Betten pro Krankenhaus erheblich zugenommen, was auf die Konzentrationsbewegung zurückzuführen ist. Während ein Krankenhaus 1951 im Durchschnitt 178 Betten hatte, waren es 2001511 Betten. ${ }^{30}$

Ein weiterer Reformschritt im Rahmen der Kostendämpfung war die Freigabe der Preise bei bestimmten Leistungen, die zunächst ca. 10\% der gesamten Krankenhausleistungen ausmachten und seit 2008 sogar 20\%. In diesem sog. B-Segment stehen die Tarife zur freien Verhandelbarkeit der Parteien, so dass eine flexiblere Preisgestaltung erreicht werden kann. ${ }^{31}$

Desweiteren wurde auch die Finanzierung der Krankenhauskosten in den letzten Jahren umgestellt. 2005 wurde das bisherige Budgetierungssystem zugunsten von Fallpauschalen, sog. Diagnose Behandeling Combinaties (DBC`s) abgelöst, die eine pauschale Festsetzung des Entgelts für bestimmte Indikationen vorsehen.

\subsection{Normative Steuerung und politische Diskussion}

Da das niederländische Gesundheitssystem sich durch die gegenwärtige Reform des gesamten Systems der Krankenversicherung im Umbruch befindet, kommt den normativen und politischen Vorgaben eine besondere Bedeutung zu. Durch Einführung des Krankenversicherungsgesetzes ist es zu einer Verschiebung der Aufgaben und Rollen der Beteiligten Akteure gekommen. Zwar kommt dem Staat nach wie vor eine sichernde Rolle zu, so durch die gesetzliche Vorgabe der verpflichtenden Basisversicherung, aber auch den Krankenversicherungsunternehmen und den Versicherten werden im Zuge der neuen Wettbewerbsorientierung vermehrt Spielräume gelassen.

28 Ausführlich zu den Selbstbehandlungszentren unten II. 4.2.

29 Vandermeulen, Ziekenhuizen: medisch bedrijven in:

Breit/Elsinga/Kasdrop/Sanders/Vandermeulen/Weevers, Handboek Structuur en financiering gezondheidszorg, III 2.1-3.

30 Vandermeulen, Ziekenhuizen: medisch bedrijven in:

Breit/Elsinga/Kasdrop/Sanders/Vandermeulen/Weevers, Handboek Structuur en financiering gezondheidszorg, III 2.1-3.

31 Eingehend unten II. 4.5. 


\subsubsection{Zusammenspiel von Staat und privaten Unternehmen}

Durch die Reform von 2006 sollte sich der Staat aus seiner Gestaltungsfunktion im Gesundheitswesen mehr und mehr zurückziehen, so war es jedenfalls vorgesehen. ${ }^{32}$ Während er unter dem Krankenkassengesetz bis 2006 nicht nur die gesetzlichen Grundlagen der Krankenversicherung geschaffen und diese beaufsichtigt und kontrolliert hat, sondern auch vielfältige Gestaltungsfunktionen, insbesondere in der Preisgestaltung und Krankenhausplanung, übernommen hat, soll sich diese Funktion ändern. Zwar schafft der Staat auch unter dem neuen Krankenversicherungsgesetz die gesetzliche Grundlage der Basisversicherung und stellt in diesem Zusammenhang hoheitliche Rahmenvorgaben auf wie beispielsweise die Versicherungspflicht für alle Einwohner der Niederlande, den Kontrahierungszwang für die Versicherungsunternehmen und das Verbot der Risikoselektion aufgrund des Gesundheitszustandes. Hinsichtlich der Ausführung der Versicherung zieht sich der Staat aber zunehmend zurück. Aus diesem Grund hat man sich auch für die Trägerschaft der Krankenversicherung durch private Versicherungsunternehmen und nicht durch öffentlich-rechtliche Krankenkassen entschieden. ${ }^{33}$ Diese sollen die Krankenversicherung im Rahmen der gesetzlichen Vorgaben aufgrund der Marktgegebenheiten und der aufgestellten Anreize gestalten. Um diese Möglichkeit zu schaffen sind vielfältige Flexibilisierungen, insbesondere im Rahmen der Preisgestaltung, aber auch hinsichtlich des Leistungsumfangs, soweit dieser über das verpflichtende Basispaket hinausgeht, vorgenommen worden, auf die unten noch näher eingegangen wird.

Durch diese Zunahme an Freiheiten der privatrechtlich organisierten Beteiligten entsteht ein Bedarf an entsprechender Kontrolle und Aufsicht. ${ }^{34}$ Aus diesem Grund ist auch der institutionelle Rahmen der stattlichen Aufsicht über den Gesundheitsmarkt erneuert worden. Vor der Reform war diese Aufgabe noch geteilt. Sowohl der Rat für die Aufsicht über Krankenversicherungen (College Toezicht Zorgverzekeringen, CTZ), ein öffentlich-rechtliches Aufsichtsorgan, als auch der Krankenversicherungsrat (College voor Zorgverzekeringen, CVZ), das vor allem Aufgaben im Rahmen der Finanzierung des Gesundheitssystems wahrnimmt, und die niederländische Wettbewerbsbehörde (Nederlandse Mededingingsautoriteit, NMa) sowie das niederländische Gesundheitsministerium nahmen Funktionen der Aufsicht und Kontrolle wahr. In 2006 wurde ein neues Kontrollorgan die niederländische Gesundheitswettbewerbsbehörde (Nederlandse Zorgautoriteit, NZa), geschaffen, das Kompetenzen des öffentlich-rechtliches Auf-

32 Kamerstukken II 29763 Nr. 3: Regeling van een sociale verzekering voor geneeskundige zorg ten behoeve van de gehele bevolking (Zorgverzekeringswet) - Memorie van toelichting, S. 8 ff; Kamerstukken II 27855 Nr. 2: Vernieuwing van het zorgstelsel, Nota Vraag aan bod, S. 22 ff.

33 Kamerstukken II 29763 Nr. 3: Regeling van een sociale verzekering voor geneeskundige zorg ten behoeve van de gehele bevolking (Zorgverzekeringswet) - Memorie van toelichting, S. $20 \mathrm{ff}$.

34 Kamerstukken II 29763 Nr. 3: Regeling van een sociale verzekering voor geneeskundige zorg ten behoeve van de gehele bevolking (Zorgverzekeringswet) - Memorie van toelichting, S. $51 \mathrm{ff}$. 
sichtsorgans und der Wettbewerbsbehörde in sich vereint und darüber hinaus noch über weitere Befugnisse verfügt. ${ }^{35}$

Für das Entstehen und Verstärken von Wettbewerb, aber vor allem für seine Auswirkungen in einem sozialen System der Krankenversicherung ist die Ausgestaltung der Kontrolle von eminenter Bedeutung. Ein System, das derart auf Freiheiten der privatrechtlich organisierten Beteiligten setzt, wie das niederländische Gesundheitssystem nach der Reform 2006, ist davon bedroht, dass die Chancen und Möglichkeiten deswegen nicht zum Tragen kommen, weil Freiheiten ausufern und ausgenutzt werden und demzufolge kein System der Gleichgewichte zwischen den Beteiligten, also den Krankenversicherungen, den Krankenhäusern als Stellvertreter der Leistungserbringer und natürlich auch der Versicherten, erreicht werden kann. Dies zu verhindern, also die Einhaltung der gesetzlichen Vorgaben, aber auch gegebenenfalls deren Anpassung oder Erweiterung, sind Aufgabe der Kontrolle des Marktes im Bereich des Gesundheitswesens.

Ein weiterer Bereich, in dem der Staat sich zunehmend zurückzieht ist die Krankenhausplanung, also die Entscheidung, wo Krankenhäuser gebaut werden und welche Krankenhäuser wie erweitert werden sollen. In der Vergangenheit hatte der Staat durch die Provinzen im Bereich der Krankenhausplanung eine erhebliche Gestaltungsfunktion im, aus der sich in der Praxis die Provinzen bereits ein Stück weit zurückgezogen haben. Für die Zukunft ist geplant, den Krankenhäusern immer mehr Entscheidungsspielräume zu überlassen. 36

\subsubsection{Flexibilisierung}

Ebenfalls Bedeutung für die wettbewerblichen Zusammenhänge, Möglichkeiten und letztlich auch deren Auswirkungen haben die Gestaltungsmöglichkeiten der Beteiligten. An erster Stelle ist die Freiheit der Krankenversicherungen, mit Leistungserbringern, die dies anstreben, Leistungsverträge abzuschließen, zu nennen, Art. 12 Krankenversicherungsgesetz. Diese Verpflichtung ist für den Bereich der ambulanten Leistungen entfallen und gilt mittlerweile auch nicht mehr für die vertragliche Bindung von Krankenhäusern. ${ }^{37}$

Weitere Möglichkeiten der Flexibilisierung und damit der Unterscheidbarkeit von Konkurrenten bestehen bei der Gestaltung des Leistungsumfangs. Insofern ist das Basispaket der Leistungen zwar gesetzlich vorgeschrieben, Art. 10 Krankenversicherungsgesetz, insofern greift also hoheitliche Steuerung, darüber hinaus können jedoch eine Vielzahl von Zusatzversicherungen angeboten werden. Ebenfalls bei der Prämiengestaltung bestehen durch Selbstbehalte, Gruppenversicherungen und Rückzahlungsmodalitäten bei Nichtinanspruchnahme nach dem Krankenversicherungsgesetz Freiräume, die

35 Ausführlich unten I. 4.4.

36 Ausführlich zur Krankenhausplanung unten: II. 4.3.

37 Ausführlich unten II. 3. 
von den Krankenversicherern genutzt werden können, um sich voneinander abzugrenzen und in Konkurrenz zueinander zu treten. ${ }^{38}$

\section{Der Krankenhaussektor im Rahmen des Gesundheitssystems}

Der Krankenhausversorgung kommt in den Niederlanden eine erhebliche Bedeutung zu, umfasst sie doch nahezu die gesamte fachärztliche Versorgung der Versicherten. 39 Fachärztliche Versorgung durch niedergelassene Ärzte bildet eine Ausnahme, etwa bei Zahnärzten. Insofern sind effizient organisierte Krankenhäuser, die medizinische Versorgung auf hohem Niveau bieten, ein wichtiger Bestandteil eines funktionierenden Gesundheitssystems.

\subsection{Krankenhausversorgung}

Bis zu den 70iger Jahren gab es keine klaren Grenzen zwischen Krankenhausversorgung und solcher durch niedergelassene Ärzte. Zu dieser Zeit fand aber eine Neuordnung statt, die eine strenge Unterteilung in die Versorgung durch niedergelassene Ärzte (,eerste lijn“) und die Versorgung im Krankenhaus und anderen Einrichtungen (,tweede lijn") vorsieht. ${ }^{40}$ Nachdem diese Trennung zunächst strikt durchgesetzt wurde, hat sich in den letzten Jahren wieder eine Lockerung dieser strengen Grenzen durch die integrierte Versorgung ergeben. ${ }^{41}$ Aus Gründen der Effektivität werden die sektoralen Grenzen überschritten, so dass beispielsweise auch der Hausarzt die Räume und Geräte von Krankenhäusern nutzen darf, ohne seine Patienten zu überweisen. Dieser Bereich der sektorübergreifenden Versorgung gewinnt immer mehr an Bedeutung.

\subsection{Organisationsstruktur des Krankenhaussektors}

Der maßgebliche Ausgangsbegriff für den Anspruch der Versicherten auf Krankenhausversorgung ist nach dem Krankenversicherungsgesetz die „Einrichtung“42. In den Regelungen des Leistungsinhalts wird zwar der Leistungserbringer nicht angesprochen, sondern lediglich die Art der zu beanspruchenden Leistungen (funktionale Umschrei-

38 Art.18, 19, 22 Krankenversicherungsgesetz.

39 Maarse/Groot/Merode/Mur-Veeman/Paulus, Marktwerking in de ziekenhuiszorg, Maastricht 2002, S. 52f; van der Heyden, De ontwikkelingen en veranderingen in de uitvoerende praktijk van medisch specialisten in: Breit/Elsinga/Kasdrop/Sanders/Vandermeulen/Weevers, Handboek Structuur en financiering gezondheidszorg, III 2.2-1 ff; Mackenbach/van der Maas, Volksgezondheid en gezondheidszorg, 3. Aufl. Maarssen 2005, S. 200, 204.

40 Scherpenisse/Verbeek, Gezondheidszorg, S. 77.

41 Boot/Knapen, Nederlandse Gezondheidszorg, 2005, S. 126 f; Scherpenisse/Verbeek, Gezondheidszorg, S. 77.

42 Instelling 
bung der Ansprüche ${ }^{43}$ ), jedoch erfolgt die Nennung in Art. 12 Abs. 3 Krankenversicherungsgesetz, der Auf Artikel 1 1) Krankenversicherungsgesetz verweist. Danach ist eine Einrichtung eine solche nach dem Zulassungsgesetz für Krankenhäuser (Wet toelating zorginstellingen) ${ }^{44}$. In Art. 1 Abs. 1 f) Zulassungsgesetz für Krankenhäuser wird eine Einrichtung als ein organisatorischer Verband definiert, der eine Zulassung nach dem Zulassungsgesetz für Krankenhäuser hat.

In Artikel 5 Zulassungsgesetz für Krankenhäuser wird das Erfordernis der Zugehörigkeit des organisatorischen Verbandes zu einer der Kategorien, die durch ministeriellen Beschluss bestimmt werden sollen, aufgestellt. Hinzu kommt die Zulassung durch den Rat für Krankenversicherungen (College voor zorgverzekeringen), Art. 5 Abs. 1 Zulassungsgesetz für Krankenhäuser. Bislang gibt es auch noch keine ausführenden Beschlüsse, so dass die soeben genannten Kategorien noch nicht bekannt sind. Es steht aber zu erwarten, dass diese weit gefasst werden, denn es ist das Ziel der Reform, mehr Wettbewerbselemente einzuführen, wofür es eine Voraussetzung ist, dass es eine Vielzahl von Leistungserbringern gibt, die sich auch voneinander unterscheiden können. ${ }^{45}$

Das alte Gesetz (Wet ziekenhuisvoorzieningen) kannte einen Ausführungsbeschluss ${ }^{46}$, der als Einrichtung zum einen Krankenhäuser wie allgemeine Krankenhäuser, kategoriale Krankenhäuser und Einrichtungen, in denen nur eine Untersuchungsoder Behandlungsart ausgeübt wird, und andere bestimmt und zum anderen Einrichtungen, die Leistungen nach dem Beschluss Krankenversorgungsansprüche AWBZ (Besluit zorgaanspraken $A W B Z$ ) erbringen. Schon dieses Begriffsverständnis ist sehr weitgehend und es ist davon auszugehen, dass mit der Reform keine Einengung durchgeführt werden sollte, sondern allenfalls eine Ausweitung.

Inhaltlich umfasst Krankenhausversorgung in den Niederlanden sowohl stationäre als auch ambulante fachärztliche Versorgung der Versicherten. Für die ambulante Versorgung sind spezielle Abteilungen vorgesehen, in denen die Versicherten untersucht und behandelt werden. ${ }^{47}$ Anschließend wird der Patient wieder nach Hause entlassen, eine Übernachtung ist im Rahmen der ambulanten Versorgung nicht möglich, dann müsste eine stationäre Aufnahme ins Krankenhaus erfolgen. Die Krankenhausversorgung wird definiert als Versorgung, bei der eine Aufnahme und ein Verbleib in einer Einrichtung,

43 Ausführlich zu der erst vor kurzem eingeführten Art der Anspruchsumschreibung: Walser, Die aktuellen Reformen der niederländischen Krankenversicherung - Anregungen für Deutschland?, ZFSH/SGB 2004, 410 S. 413 f; van der Most, Funktiegerichte verstrekking-omschrijving, TvG 1991, S. 464 ff; ders., Vraaggestuurde zorg als recht vanuit verzekeringsperspectief (ZFW en AWBZ), TvG 2003, 2 (10f).

44 Kamerstukken I 27 659: Vereenvoudinging van het stelsel van overheidsbemoeienis met het aanbod van zorginstellingen (Wet toelating zorginstellingen) - gewijzigd voorstel van wet van 22 september 2004.

45 Ministerie van Volksgezondheid, Welzijn en Sport, Beleidsvisie Wet toelating zorginstellingen (Zulassungsgesetz für Krankenhäuser) vom 3. Juni 2005, S. 6.

46 Besluit van 1 augustus 1979, tot aanwijzing van inrichtingen voor gezondheidszorg als bedoelt in art. 1, eerste lid, Wet ziekenhuisvoorzieningen.

47 Mackenbach/van der Maas, Volksgezondheid en gezondheidszorg, 3. Aufl. Maarssen 2005, S. 202. 
beispielsweise einem Krankenhaus, von mindestens einer Nacht erfolgt, Art. 1 b und c Regelung Versorgungsansprüche AWBZ.

Man kann ein Krankenhaus umschreiben als ein fachärztliches Zentrum mit einem Fokus auf Diagnose, Behandlung und Verpflegung und mit Notfallaufnahme. ${ }^{48}$ Darüber hinaus spielt es aber auch eine zentrale Rolle bei der Ausbildung von Ärzten und nichtärztlichem Personal.

Hinsichtlich des inhaltlichen Wirkungskreises von Krankenhäusern wird üblicher Weise zwischen allgemeinen Krankenhäusern, Universitätskliniken und kategorialen Krankenhäusern unterschieden: 49

Die allgemeinen Krankenhäuser bieten die umfassende Versorgung mit Krankenhausleistungen. Dabei wird unterschieden zwischen sog. Basiskrankenhäusern und solchen mit zusätzlichen Spezialfunktionen. ${ }^{50}$ Die sog. Basiskrankenhäuser gewähren die Versorgung mit den regulären Leistungen, die typischer Weise häufig von Patienten in Anspruch genommen werden. Andere Krankenhäuser haben darüber hinausgehend noch bestimmte Spezialfunktionen, allerdings nicht solche, die eine besondere Genehmigung 51 erfordern wie beispielsweise Organtransplantationen oder Stammzelltransplantationen.

Die Universitätskliniken sind organisatorisch zu den jeweiligen Universitäten zugehörig und dienen neben der Versorgung von Patienten auch der Forschung und Lehre. ${ }^{52}$ In Ihnen werden auch besondere Leistungen angeboten, für die wegen des Erfordernisses einer speziellen Genehmigung ausschließlich von Universitätskliniken erbracht werden dürfen.

Die kategorialen Krankenhäuser sind in der Regel kleinere Einrichtungen, die keine umfassende Versorgung anbieten, sondern sich auf bestimmte Bereiche spezialisiert haben. 53

Von den Krankenhäusern ist das Selbständige Behandlungszentrum (Zelfstandig behandelcentrum, Zbc) zu unterscheiden. In Art. 1 Abs. 1 h) Zulassungsgesetz für Krankenhäuser ist es definiert als ein organisatorischer Verband, der kein Teil eines Krankenhauses ist oder einem Krankenhaus zuarbeitet und deas fachärztliche Versorgung anbietet.

Definitionsgemäß ist das Selbständige Behandlungszentrum also kein Krankenhaus, auch kein Teil eines Krankenhauses und es arbeitet auch nicht für ein solches. Sein

48 Mackenbach/van der Maas, Volksgezondheid en gezondheidszorg, 3. Aufl. Maarssen 2005, S. 200.

49 Nederlandse Mededingingsautoriteit (NMa), Concurrentie in de ziekenhuissector, 2004, S.5; College bouw ziekenhuisvoorzieningen, Curatieve Basiszorg: Vraag, Aanbod en infrastructuur, 2005, S. 27; Nobels, Prijsconcurrentie tussen ziekenhuis en ZBC, 2005, S. 26; Scherpenisse/Verbeek, Gezondheidszorg, 6. Aufl. 2002, S.73; Boot/Knapen, De nederlandse gezondheidszorg, 2005, S. $120 \mathrm{ff}$.

$50 N M a$, Concurrentie in de ziekenhuissector, 2004, S. 49.

51 Wet Bijzondere Medische Verrichtingen (WBMV), (Gesetz über besondere medizinische Behandlungen).

$52 N M a$, Concurrentie in de ziekenhuissector, 2004, S. 5.

$53 \mathrm{NMa}$, Concurrentie in de ziekenhuissector, 2004, S. 5. 
Aufgabenbereich weist jedoch Parallelen zum Krankenhaus auf, nämlich die Tätigkeit von Fachärzten und gerade nicht von Hausärzten. Hinsichtlich der Finanzierung lassen sich Parallelen bei der Honorierung der Fachärzte ziehen, die sich nicht ändert, wenn es sich um solche in einem Selbständigen Behandlungszentrum handelt. Auch staatliche Förderungen beim Bau eines Krankenhauses kann ein Selbständiges Behandlungszentrum beantragen, weil es durch die Regelung Selbständige Behandlungszentren (Regeling Zelfstandige Behandelcentra) ${ }^{54}$ als Einrichtung definiert wird.

Den Versicherten standen 2006 in den Niederlanden 88 allgemeine, 8 akademische und 2 kategoriale Krankenhäuser zur Verfügung. ${ }^{55}$ Hinzu kommen ca. 57 selbständige Behandlungszentren. ${ }^{56}$ Im Durchschnitt verfügt ein Krankenhaus über 505 Betten. ${ }^{57}$

\subsection{Gesetzlicher Rahmen}

Der für die Krankenhausversorgung relevante gesetzliche Rahmen teilt sich in drei Bereiche auf: die sozialrechtlichen Vorschriften für die Krankenversicherung, die unmittelbar krankenhausbezogenen Normen des Verwaltungsrechts und schließlich die Wettbewerbsregelungen, die in immer stärkerem Maße auch das Krankenhauswesen prägen.

Das Krankenversicherungsgesetz wendet sich mit seinen Vorschriften vor allem an die Krankenversicherungsunternehmen und legt ihnen Pflichten auf wie beispielsweise den Kontrahierungszwang mit allen Versicherten unabhängig von ihrem Gesundheitszustand $^{58}$ und das Anbieten einer hinsichtlich des Leistungsumfangs vorgeschriebenen Basisversicherung ${ }^{59}$, gewährt aber gleichzeitig auch Rechte wie das Aufstellen verschiedener Vertragsmodelle etwa der Kostenerstattung, der Sachleistung oder einer Kombination hiervon ${ }^{60}$. Es wird konkretisiert durch den Beschluss zur Krankenversicherung61, der den Inhalt der Leistungsansprüche der Versicherten in der Basisversicherung näher festlegt sowie durch die Regelung Krankenversicherung ${ }^{62}$, die die inhaltliche Bestimmung der Leistungen noch weiter führt.

Hinsichtlich der verwaltungsrechtlichen Vorschriften mit Krankenhausbezug kommt dem Zulassungsgesetz für Krankenhäuser eine zentrale Aufgabe zu. Es enthält die Re-

54 Van 11 februari 1998, Stcr 1998, nr. 30, S. 9.

55 Nederlandse Zorgautoriteit, Monitor ziekenhuiszorg 2007, S.16.

56 Nederlandse Zorgautoriteit, Monitor ziekenhuiszorg 2007, S.16.

57 CTG/Zaio, Visiedocument ziekenhuiszorg, Analyse en aanbevelingen voor concurrentie in het Bsegment, 2005, S. S. 37.

58 Art. 3 Krankenversicherungsgesetz.

59 Art. 10 ff Krankenversicherungsgesetz.

60 Art. 11 Abs. 1 und 2 Krankenversicherungsgesetz.

61 Besluit zorgverzekering, Beschluss vom 28. Juni 2005, Stb. 2005, 389, letzte Änderung vom 15. Dezember 2005, Stb. 2005, 690.

62 Regeling Zorgverzekering, Beschluss vom 1. September 2005, Stcrt. 2005, 171, letzte Änderung vom 15. Dezember 2005, Stcrt. 2005, 249. 
gelungen über die Krankenhausplanung sowie über die Zulassung und steuert damit den Marktzugang für Krankenhäuser. Eine Konkretisierung dieses Gesetzes, insbesondere hinsichtlich des Zulassungserfordernisses, findet sich im Ausführungsbeschluss ${ }^{63}$.

Der Wettbewerb im Gesundheitssektor wird zentral durch das Wettbewerbsgesetz gesteuert, das, wie noch zu zeigen sein wird ${ }^{64}$, nach der neueren Rechtsprechung auch in diesem nicht in erster Linie ökonomisch geprägten Bereich Anwendung findet. Daneben gibt es aber noch ein spezielles Gesetz für den Wettbewerb im Gesundheitssektor, das vor allem die Kompetenzen der Gesundheitswettbewerbsbehörde regelt das Marktordnungsgesetz für den Gesundheitsbereich. Gerade das Zusammenspiel dieser beiden Wettbewerbsgesetze und entsprechend auch der zugehörigen Behörden, der Wettbewerbsbehörde und der Gesundheitswettbewerbsbehörde, prägen die Wettbewerbsverhältnisse im Gesundheitssektor ganz wesentlich.

\subsection{Strukturen und Institutionen der Krankenversicherungsträger}

Die Struktur der Krankenversicherer hat sich durch die Reform 2006 wesentlich geändert, weswegen zunächst kurz die alte Rechtslage geschildert wird und sodann ausführlicher auf die aktuellen Gegebenheiten eingegangen wird.

\subsubsection{Struktur der Krankenversicherer nach dem Krankenkassengesetz bis 2005}

Das bis 2006 geltende Krankenkassengesetz wurde durch die Krankenkassen ausgeführt. 65 Diese waren in privatrechtlichen Rechtsformen organisiert, in privatrechtliche Stiftungen 66 , Art. 2: 285 ff Bürgerliches Gesetzbuch 67 und Versicherungsgesellschaften auf Gegenseitigkeit 68 , Art. 2: 53 ff Bürgerliches Gesetzbuch, Art. 34 Abs. 3 Krankenkassengesetz. Die Anzahl der Krankenkassen belief sich landesweit auf ungefähr 30. ${ }^{69}$ Die Krankenkassen waren also auch vor der Reform schon in privaten Rechtsformen organisiert und der Staat hielt auch nicht die Anteile an den Gesellschaften. Gerade der Einfluss von religiösen Vereinigungen ist aber hervorzuheben. ${ }^{70}$ Die Krankenkas-

63 Uitvoeringsbesluit WTZi (Ausführungsbeschluss WTZi).

64 Vgl. unten 3.4.

65 Ausführlich zur alten Rechtslage: Walser, die aktuellen Reformen der niederländischen Krankenversicherung - Anregungen für Deutschland?, ZFSH/SGB 2004, S. 410 ff; Noordam, Socialezekerheidsrecht, 6. Aufl. 2002, S. 269 ff; ders. Hoofdzaken socialezekerheidsrecht, 2. Aufl. 2002, S. 71 ff; Kötter, Von alten und neuen Rezepten, Radikalkuren und Wechselbädern - die Reformen des niederländischen Gesundheitssystems, ZIAS 1998, $391 \mathrm{ff.}$

66 Stichtingen.

67 Burgerliijk wetboek, BW, Stb. 1976, 395, letzte Änderung in Stb. 2003, 203.

68 Onderlinge waarborgmaatschappijen.

69 Noordam, Socialezekerheidsrecht, 7. Aufl. 2004, S. 266.

70 Okma, Studies on Dutch Health Politics, Policies and Law, 1997, S. 87 ff; Maarse, Privitisation in European Health Care, 2004, S. 100 ff. 
sen erhielten durch den Krankenversicherungsrat ${ }^{71}$ eine Zulassung, Art. 8a Krankenkassengesetz, die sie ermächtigte, die öffentliche Aufgabe der gesetzliche Krankenversicherung auszuführen. Diese Zulassung wurde nur unter bestimmten Voraussetzungen erteil, Art. 34 Abs. 3 Krankenkassengesetz. Die beiden bedeutsamsten waren, dass die Krankenkasse keine Gewinnerzielung beabsichtigen durfte und dass sie sicherstellen musste, dass die Versicherten einen angemessenen Einfluss auf die Verwaltung der Gesellschaft haben. Der Krankenversicherungsrat ist seit 1999 der Nachfolger des Krankenkassenrats 72 . Es ist ein Verwaltungsorgan, das dem niederländischen Gesundheitsministerium unterstellt ist, Art. 1b Abs. 1 und Art. 1e Krankenkassengesetz. Seine Aufgaben lagen neben der Erteilung der Zulassungen in der Kontrolle der Krankenkassen, in ihrer Steuerung und Finanzierung. ${ }^{73}$

Die einzelnen Krankenkassen standen in einem regulierten Wettbewerb zueinander. ${ }^{74}$ Die Krankenkassen trugen zwar grundsätzlich das finanzielle Risiko, was eine Voraussetzung für das Entstehen von Wettbewerb ist, jedoch gab es einige Ausgleichsmechanismen, die diesen Wettbewerb regulierten. ${ }^{75}$ So werden Ausgaben, die für einen einzelnen Versicherten eine festgelegte Grenze überschreiten, aus einer gemeinsamen Kasse der Krankenkassen ausgeglichen. Zu einem gewissen Prozentsatz erfolgt ein genereller Ausgleich zwischen den Kassen. Dieser knüpft an die risikoabhängige Zuweisung von Kopfpauschalen des Krankenversicherungsrates an die Krankenkassen an. Je differenzierter diese Risikoberechnung der Versicherten einer Krankenkasse desto geringer erfolgte der pauschale Ausgleich. 76

Neben den Krankenkassen führten aber auch noch andere Organisationen die Krankenversicherung aus. Insofern wurde unterschieden zwischen den privaten Krankenversicherungsunternehmen 77 und den öffentlich-rechtlichen Krankenversicherungsunternehmen ${ }^{78}$. Erstere bedurften ebenso wie die Krankenkassen einer Zulassung durch den Krankenversicherungsrat, um das Krankenkassengesetz ausführen zu dürfen. Dagegen ist diese Zulassung für die öffentlich-rechtlichen Krankenversicherungen nicht erforderlich, eine bloße Anmeldung ist ausreichend. ${ }^{79}$ Ihnen obliegt die Versicherung der Angehörigen des öffentlichen Dienstes.

71 Das College voor zorgverzekeringen - CVZ.

72 Ziekenfondsraad (ZFR).

73 Pruijssers/Siebers/Kolsteren/Mulder/van Scherpenzeel, Sociale Verzekeringswetten Bd. 8, Fn. 12, Algemeen Nr. 3.

74 Ausführlich zum Wettbewerb zwischen den Krankenkassen in den Niederlanden: Greß, Krankenversicherung und Wettbewerb, Das Beispiel Niederlande, 2002, S. $89 \mathrm{ff}$.

75 Greß, Das Beispiel Niederlande, 2002, S. 90.

76 Greß, Das Beispiel Niederlande, 2002, S. 91.

77 Particuliere ziektekostenverzekeraars.

78 Publiekrechtelijke ziektekostenverzekeraars.

79 Noordam, Socialezekerheidsrecht, 7. Aufl. 2004, S. 280. 
Für das Verhältnis zwischen den gesetzlichen und den privaten Krankenversicherungen kam dem sog. MOOZ ${ }^{80}$-Beitrag eine wesentliche Rolle zu. Diesen Beitrag müssen die privaten Krankenversicherungen an die gesetzliche Krankenversicherung zahlen. Er diente zum Ausgleich des höheren Anteils kostenintensiver Rentner in der gesetzlichen Krankenversicherung. Dazu wurde der Anteil an gesetzlich Versicherten ab 65 Jahren festgestellt, der über den amtlichen Durchschnitt in den Niederlanden hinausgeht (dieser wird vom Centraal Bureau voor de Statistiek berechnet), Art. 4 Abs. 1 MOOZ. In einem zweiten Schritt wurden die durchschnittlichen Kosten des Vorjahrs dieser hochbetagten Versicherten festgestellt, Art. 4 Abs. 2 MOOZ. Aus der Multiplikation dieser Ergebnisse ergab sich der MOOZ-Beitrag, den die privaten Krankenversicherungen an die gesetzlichen Krankenkassen zu zahlen hatten und der vom Gesundheitsministerium in Übereinstimmung mit dem Finanzministerium, dem Wirtschaftsministerium und dem Sozialministerium festgestellt wurde, Art. 4 Abs. 3 MOOZ. Das MOOZ verlor mit Inkrafttreten des Krankenversicherungsgesetzes 2006 seine Gültigkeit.

\subsubsection{Struktur der Krankenversicherer seit 2006}

Mit der Reform von 2006 hat sich das System der Krankenversicherungen durch das Inkrafttreten des Krankenversicherungsgesetzes wesentlich verändern. Die Grundidee der neuen Krankenversicherung ist, dass die Aufspaltung in ein gesetzliches und ein privates Krankenversicherungssystem entfällt. ${ }^{81}$ Dadurch soll ein einfaches System und mehr Transparenz für die Versicherten geschaffen werden. ${ }^{82}$ Alle Einwohner der Niederlande sollen in dem gleichen Versicherungssystem gegen das Risiko Krankheit versichert sein und ihnen sollen alle Versicherungsunternehmen offen stehen.

Die Verschmelzung der beiden Krankenversicherungssysteme, nämlich der gesetzlichen Krankenkassen und der privaten Krankenversicherungen, stellt die Konsequenz der Probleme mit der ehemals bestehenden Dualität dar. Angestrebt ist es, die Vorteile, die beide Systeme bieten, in die neue Krankenversicherung zu übernehmen, dabei aber die Nachteile auszuschalten. ${ }^{83}$ Als nachteilig gestaltete sich der Verwaltungsaufwand beispielsweise beim Wechsel der Versicherten vom gesetzlichen in den privaten Versicherungsschutz. Dagegen soll die Flexibilität der Prämien und Leistungen, die die bisherige private Krankenversicherung auszeichnet, auch Bestandteil der neuen Versicherung werden. Die solidarischen Elemente wie etwa die teilweise einkommensabhängige

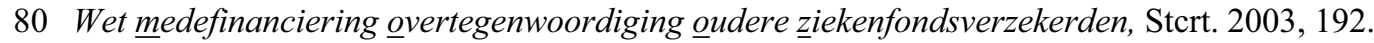

81 Noordam, Socialezekerheidsrecht, 7. Aufl. 2004, S. 268 ff; ders. (2004) Hoofdzaken Socialezekerheidsrecht, 3. Aufl. 2004, S. 74 ff; Walse,r Die aktuellen Reformen der niederländischen Krankenversicherung - Anregungen für Deutschland?, ZFSH/SGB 2004, 410 (410ff).

82 Kamerstukken II 2004, 29763 Nr. 3: Regeling van een sociale verzekering voor geneeskundige zorg ten behoeve van de gehele bevolking (Zorgverzekeringswet) - Memorie van toelichting, S. 4 .

83 Kamerstukken II 2004, 29763 Nr. 3: Regeling van een sociale verzekering voor geneeskundige zorg ten behoeve van de gehele bevolking (Zorgverzekeringswet) - Memorie van toelichting, 6; Hamilton, Zorgverzekering, 2005, S. 23 ff. 
Berechnung der Beiträge dagegen soll von der gesetzlichen Krankenversicherung übernommen werden, wenn auch der weit höhere Teil des Versicherungsbeitrags pauschal berechnet wird.

Die Versicherungspflicht trifft alle Einwohner der Niederlande, also auch die Selbständigen und Beamten, Art. 2 Abs. 1 Krankenversicherungsgesetz. ${ }^{84}$ Diese Regelung wird durch eine Anlehnung an die Krankenversicherung für besondere Krankheitskosten, das Algemene Wet Bijzondere Ziektekosten (AWBZ) erreicht. Diese ist bereits eine Volksversicherung. Nach Art. 5 Abs. 1 AWBZ sind alle Einwohner der Niederlande pflichtversichert und ebenso diejenigen, die zwar nicht in den Niederlanden wohnen, aber dort der Lohsteuer unterworfen sind. Durch diese Angleichung an das AWBZ wird schon ein erster Schritt gemacht, um später, wenn sich das Krankenversicherungsgesetz bewährt hat, auch die Versicherung für besonders schwere Risiken in das Krankenversicherungsgesetz zu integrieren. Dieses Vorhaben ist zwar nicht in der jetzigen Gesetzesbegründung angesprochen, wohl aber in dem oben bereits erläuterten Bericht des Parlaments von 2001 zur Ausgestaltung einer Gesundheitsreform. ${ }^{85}$ Insofern kann man davon ausgehen, dass langfristig die Vereinheitlichung der gesamten Krankenversorgung in einem Versicherungssystem angestrebt wird.

Die zweite wesentliche Änderung durch das Krankenversicherungsgesetz, die für die Struktur der Träger der Krankenversicherung eine elementare Bedeutung entfaltet, ist die Ausgestaltung der Krankenversicherung durch privatrechtlich organisierte Versicherungsunternehmen, allerdings im Rahmen von öffentlich-rechtlichen Vorgaben. 86 Solche Vorgaben sind beispielsweise der Annahmezwang hinsichtlich der Versicherten unabhängig von ihrem Gesundheitszustand, Basisleistungspaket und öffentlichrechtlicher Aufsicht durch die Gesundheitswettbewerbsbehörde. Die Krankenversicherungsunternehmen sind in den Rechtsformen von Aktiengesellschaften oder Versicherungsvereinen auf Gegenseitigkeit organisiert, einige auch als Genossenschaften. ${ }^{87}$ Es gibt ungefähr 35 Krankenversicherungsunternehmen in den Niederlanden. ${ }^{88}$ Als private Krankenversicherer sind es Schadenversicherungen im Sinne der Ersten Schadenrichtlinie $^{89}$. Als Schadenversicherung benötigen sie eine Genehmigung der Niederländischen Bank, die grundsätzlich auch Unternehmen aus anderen Mitgliedstaaten offen steht.

84 Ausführlich zur Versicherungspflicht: van der Most, De Zorgverzekeringswet en de zelfverzekerde burger, TvG 2005, S. 17 (21 ff); Hamilton, Zorgverzekering, 2005 S. 29 ff; Hermans, Zorgverzekeringswet, 2005, S. 33 f; Beerepoot, Zorgverzekeirngswet, 2006, S. 65 f; van Saase/Pruijssers, Zorgverzekeringswet, 2006, S. 18 f; Westerlaak, Zorgverzekeringswet, 2005, S. 31 ff; KronenburgWillems, Sociale Zekerheid, 2006, S. 376.

85 Kamerstukken II 2001, 27855 Nr. 2: Vernieuwing van het zorgstelsel, Nota Vraag an bod, S. 49 f.

86 Ausführlich zur privatrechtlichen Organisation der Krankenversicherungen: Hamilton, Zorgverzekering, 2005 S. 43ff; Hermans, Zorgverzekeringswet, 2005, S. 25 ff; Beerepoot, Zorgverzekeirngswet, 2006 S. 25 ff; Westerlaak, Zorgverzekeringswet, 2005 S. 18 ff.

87 Noordam, Socialezekerheidsrecht, 8. Aufl. 2006, S. 289; Hamilton, Een zorgverzekering voor iedereen, 2005, S. $143 \mathrm{ff}$.

88 Noordam, Socialezekerheidsrecht, 8. Aufl. 2006, S. 289.

89 Richtlinie Nr. 73/239/EG des Rates vom 24. Juli 1973, Amtsbl. EG 1973, L 228/3. 
Bislang hat jedoch kein nicht niederländisches Unternehmen beantragt, auf dem niederländischen Markt als Krankenversicherer tätig werden zu dürfen.

Der privatrechtliche Charakter der Krankenversicherungen betrifft in erster Linie das Zustandekommen der Versicherung und weniger die Ausführung, denn auch in einer öffentlich-rechtlichen Krankenversicherung kann die Ausführung durch private Versicherungsunternehmen erfolgen, wie bei den ehemaligen Krankenkassen zutraf.

Während bei einer Versicherung auf öffentlich-rechtlicher Grundlage das Versicherungsverhältnis von Rechts wegen zustande kommt, wenn die gesetzlichen Voraussetzungen erfüllt werden, also beispielsweise ein Beitritt erfolgt oder der Versicherte ein Einwohner der Niederlande ist (so beim AWBZ), kommt eine Krankenversicherung auf privatrechtlicher Grundlage durch Vertragsschluss zustande. 90

Eine relevante Auswirkung der Privatisierung ist auch der Rechtsschutz für den Bürger. Da es sich im Prozessfall um einen Rechtsstreit zwischen Privaten handelt, sind die Zivilgerichte zuständig und nicht die Verwaltungsgerichte. ${ }^{91} \mathrm{Da}$ der Gang zu den ordentlichen Gerichten als Hürde angesehen wird, insbesondere aufgrund der fälligen Gerichtsgebühren, die der Kläger zu entrichten hat, sollen die Versicherungsunternehmen verpflichtet werden, eine unabhängige Instanz einzurichten, die Streitigkeiten vorgerichtlich klären kann, Art.113 Krankenversicherungsgesetz. ${ }^{92}$

Die Entscheidung der Regierung für das privatrechtliche Modell hat aber auch durchaus Kritik erfahren. So hat der Raad van State in seinem Bericht ${ }^{93}$ Zweifel bekundet, ob eine derart weitgreifende Umstrukturierung erforderlich sei und überhaupt den erwünschten Effekt erzielen würde. Es gäbe keine Erfahrungen aus den Niederlanden oder aus anderen Ländern mit einem derartigen Krankenversicherungssystem, so dass die Wirkungsweise ungewiss sei. Es sollten vielmehr Möglichkeiten der Verkleinerung des Leistungspakets erwogen und geprüft werden.

Die Regierung hat sich in ihrem Gesetzesentwurf für das privatrechtliche Modell entschieden, um den beteiligten Akteuren, also den Versicherten, den Versicherern und den Leistungserbringern, möglichst viele Freiheiten und damit einhergehend auch mehr Verantwortung zuzusprechen. ${ }^{94}$ Dies soll eine freiere Entwicklung der Marktkräfte ermöglichen, so dass über eine Zunahme von Wettbewerb eine kostengünstige und gleichzeitig zweckgerichtete, effektive und qualitativ hochwertige medizinische Versorgung ermöglicht wird. Für ein solches System ist die privatrechtliche Grundlage, bei der

90 Hamilton, Zorgverzekering, 2005 S. 43 ff, 67 f; Hermans, Zorgverzekeringswet, 2005, S. 25; Beerepoot, Zorgverzekeirngswet, 2006 S. 25 f.

91 Van Schooneveld, 2005 S. 3 (14f).

92 Vgl. van Schooneveld, 2005, S. 15; Nolen, Rechtsbescherming van Verzekerden in den nieuwe Zorgverzekeringswet, Zorg \& Financiering 2004, 10 (12); van der Most, De zorgverzekeringswet en de zelfverzekerde burger, TvG 2005, 17 (36f).

93 Raad van State, Advies Zvw, 2004, S. 3 f.

94 Kamerstukken II 2004, 29763 Nr. 3: Regeling van een sociale verzekering voor geneeskundige zorg ten behoeve van de gehele bevolking (Zorgverzekeringswet) - Memorie van toelichting, S. 2; Hamilton, Zorgverzekering (2005) S. 43 ff. 
auch die Versicherten bereits zu Beginn durch den Vertragsschluss eine aktive Rolle und entsprechende Verantwortung übernehmen müssen, die angemessene Form.

\subsection{Rechtsverhältnisse zwischen Krankenversicherung, Leistungserbringer und Ver- sichertem}

Im Bereich des Gesundheitsmarktes gibt es drei Beziehungen, die für die Beurteilung der rechtlichen Verhältnisse, insbesondere bei Thematisierung der Bereiche Wettbewerb und Markt, maßgeblich sind. ${ }^{95}$ Diese sind das Verhältnis zwischen Krankenversicherung und Leistungserbringer, das zwischen Krankenversicherung und Versichertem und schließlich zwischen Leistungserbringer und Versichertem.

Im Verhältnis zwischen Krankenversicherung und Leistungserbringer werden Verträge geschlossen, um die Versorgung der Versicherten sicherzustellen. Damit werden die Krankenversicherungen ihrem Sicherstellungsauftrag (Art. 8 Abs. 5 Krankenkassengesetz und Art. 11 Abs. 1 Krankenversicherungsgesetz) gerecht. Bislang wurden auf Landesebene Modellverträge zwischen den Dachorganisationen der Krankenkassen und der Ärzteschaft geschlossen, die einer Billigung durch den Krankenversicherungsrat bedurften. Dadurch fehlte aber Flexibilität für die Anpassung an die regionalen Gegebenheiten. ${ }^{96}$ So ist es denkbar, dass Absprachen über Dinge getroffen werden müssen, die in der bestimmten Region keine Rolle spielen. ${ }^{97}$ Diese Modellverträge ${ }^{98}$ sind durch das HOZ ${ }^{99}$ abgeschafft worden. Die Krankenkassen und Leistungserbringer können jetzt direkt auf regionaler Ebene Verträge schließen, die ihren Bedürfnissen entsprechen.

Darüber hinaus ist auch die Kontrahierungsfreiheit der Parteien vergrößert worden. Während bislang die Krankenversicherungen verpflichtet waren, zwar nicht mit allen einzelnen Leistungserbringern, 100 jedoch mit allen interessierten Einrichtungen einen Versorgungsvertrag zu schließen, wird dieser Kontrahierungszwang im Rahmen der Gesundheitsreform zwar nicht völlig aufgehoben, aber wesentlich gelockert. Vor der Reform galt nach Art. 44 Abs. 1 Krankenkassengesetz, dass Krankenkassen generell Verträge mit Leistungserbringern schließen müssen, um ihrem Versorgungsauftrag

95 Boot/Knapen, Nederlandse Gezondheidszorg, 2005, S. 192; Scherpenisse/Verbeek, Gezondheidszorg 2005, S. 196; Nota vraag aan bod, S. 21.

96 Kamerstukken II 28994 Nr. 3: Wijziging van de Ziekenfondswet, de Algemene Wet Bijzondere Ziektekosten en enkele andere wetten, in verband met herziening van het overeenkomstenstelsel in de sociale ziektenkostenverzekering alsmede enkele andere wijziging (Wet herziening overeenkomstenstelsel zorg) - Memorie van toelichting, S. 4; auch: 96 Kamerstukken II 2004, 29763 Nr. 3: Regeling van een sociale verzekering voor geneeskundige zorg ten behoeve van de gehele bevolking (Zorgverzekeringswet) - Memorie van toelichting, S. $32 \mathrm{f}$.

97 Hermans/van Donk, Herziening overeenkomstenstelsel zorg, 2004, S. 33.

98 landelijke uitkomsten van overleg en modelovereenkomsten.

99 Wet herziening overeenkomstenstelsel zorg vom 9 Dezember 2004, Stb. 2005, 27.

100 Noordam, Hoofdzaken Socialezekerheidsrecht, 3. Aufl. 2004, S. 78. 
nachzukommen, aber keine Verpflichtung besteht, mit jedem Leistungserbringer zu kontrahieren. Eine derartige Verpflichtung ergab sich jedoch hinsichtlich der Einrichtungen, also vor allem Krankenhäusern, mit einer wichtigen Ausnahme aus Art. 47 Abs. 1 Krankenkassengesetz. Danach konnte durch allgemeine Verwaltungsvorschrift für bestimmte Kategorien von Einrichtungen oder bestimmte Versorgungsformen geregelt werden, dass dieser Kontrahierungszwang nicht galt.

Nach der neuen Rechtslage besteht kein - auch kein grundsätzlicher - Kontrahierungszwang mehr für Krankenhäuser, Art. 12 Krankenversicherungsgesetz. Es ist lediglich vorgesehen, dass durch ministerielle Verordnung einzelne Einrichtungen von dieser Kontrahierungsfreiheit ausgenommen werden können, Art. 12 Abs. 2 Krankenversicherungsgesetz. Dies ist bislang jedoch nicht geschehen und es sind auch keine diesbezüglichen Bestrebungen bekannt. ${ }^{101}$

Das Verhältnis zwischen Leistungserbringer und Versichertem wird wesentlich durch die Wahlfreiheit der Versicherten geprägt. Er kann grundsätzlich die Leistungserbringer, die er in Anspruch nehmen möchte, nach seinem freien Ermessen bestimmen. Lediglich bei Sachleistungspolicen muss er sich an die vertraglich an die Krankenversicherung gebundenen Leistungserbringer halten. ${ }^{102}$ Bei der Wahl eines Kostenerstattungstarifs dagegen müssen die Leistungserbringer, die konsultiert werden sollen, nicht zwingend vertraglich an die Krankenversicherung gebunden sein. In diesem Zusammenhang ist auch die Möglichkeit des Wechsels der Versicherung zu erwähnen, der einmal im Jahr zulässig ist. 103

Die rechtliche Grundlage für das Verhältnis der Versicherten zur Krankenversicherung findet sich hinsichtlich der Basisversicherung im Krankenversicherungsgesetz. Die darüber hinausgehenden privaten Zusatzversicherungen werden dagegen am 7. Buch des Bürgerlichen Gesetzbuches unter Titel 17 die Versicherungsverträge umfassend geregelt. ${ }^{104}$ Die Aufsicht über den Bereich der Lebens- und Schadenversicherungen ist im Gesetz über die Aufsicht der Versicherungsunternehmen geregelt ${ }^{105}$.

101 Hamilton, Een zorgverzekering voor iedereen, 2005, S. 101.

102 Kamerstukken II 2004, 29763 Nr. 3: Regeling van een sociale verzekering voor geneeskundige zorg ten behoeve van de gehele bevolking (Zorgverzekeringswet) - Memorie van toelichting, S. 28 f, $36 \mathrm{ff}$.

103 Kamerstukken II 2004, 29763 Nr. 3: Regeling van een sociale verzekering voor geneeskundige zorg ten behoeve van de gehele bevolking (Zorgverzekeringswet) - Memorie van toelichting, S. 35 .

104 Vgl. ausführlich: Wansink/Blom/van Garderen-Groenveld/van Ardenne-Dick/Kalkman, Juridisch Zakboek, Bd. IIIA XIVA.1 ff.

105 Wet Toezicht Verzekeringsbedrihf (WTV) vom 1. Juni 1987. 


\section{Wettbewerb und Gesundheitsversorgung}

\subsection{Allgemeines Verständnis von Wettbewerb}

Miteinander zu konkurrieren und im Wettbewerb zu stehen, ist ein häufiges und wohl auch wichtiges Erscheinungsbild in unserer Gesellschaft. Entsprechend kommt ihm auch im wirtschaftlichen Gefüge eine besondere Rolle zu. In diesem Bereich hat der Gesetzgeber aufgrund seiner normativen Entscheidungsbefugnis bestimmte Regelungen aufgestellt, nach denen Wettbewerb funktionieren soll. Statt die Marktkräfte völlig frei wirken zu lassen, sollten sie in bestimmter Weise reguliert werden. Dies gilt schon seit dem Inkrafttreten des ersten Wettbewerbsgesetzes von 1956.106 Das Verständnis von Wettbewerb in diesem ökonomischen Sinn, und allein hierauf kommt es in der vorliegenden Studie an, geht weit auseinander. Es haben sich mit der Zeit eine ganze Zahl von Wettbewerbstheorien herausgebildet. So gibt es die Auffassung, dass es sich um eine Erscheinungsform handelt, die ausschließlich die Konkurrenz zwischen Unternehmungen betrifft. Daneben wird Wettbewerb auch als die Gesamtheit der Handlungen verstanden, die darauf zielen, den Gewinn eines Unternehmens zu vergrößern. Bei diesen Theorien fällt auf, dass sie allein auf Unternehmen abstellen und schon insoweit nicht weit genug greifen, als sie beispielsweise die Verbraucher oder sogar deren Organisationen außer acht lassen. ${ }^{107}$ Die wohl verbreitetste Auffassung vom Wettbewerbsbegriff und die für diesen Bericht am geeignetsten, weil am weitesten gefasst, ist die Definition mittels des Marktes. Danach ist Wettbewerb die Gesamtheit der Verhaltensweisen aller Teilnehmer am Marktverkehr, die auf das Erlangen einer günstigen Marktposition gerichtet sind. ${ }^{108}$ Hierbei drängt sich nahezu zwingend die Frage der Definition des Marktes auf, da nach dieser Auffassung von diesem Begriff das ganze Wettbewerbsverständnis abhängt. Als Markt wird dabei der räumliche Bereich bezeichnet, in dem sich Angebot und Nachfrage gegenüberstehen und in dem Konkurrenten aufeinanderstoßen. ${ }^{109}$ Der Feststellung des relevanten Marktes kommt deshalb eine so erhebliche Bedeutung zu, weil die Bestimmung der Marktmacht je nach Zuschnitt des relevanten Marktes unterschiedlich ausfallen kann. ${ }^{110}$ Allgemein gefasst wird der Markt nach seinen jeweiligen Besonderheiten und nach den Anbietern und Nachfragern und natürlich nach den Produkten oder Diensten abgegrenzt. ${ }^{111}$ Es wird also festgestellt, ob es beispielsweise nur eine geringe Anzahl von Abnehmern gibt oder starke Abhängigkeiten von der Konjunktur. Desweiteren spielt es eine Rolle, ob es in dem Bereich eine weitgehende hoheitliche Steuerung gibt und welche Zutrittshemmnisse für neue Marktteilnehmer beste-

106 Wet economische mededinging (Wem).

107 Van der Kooij/Mulder, Hoofdzaken mededingingsrecht, 3. Aufl. 2001, S. 1.

108 Van der Kooij/Mulder, Hoofdzaken mededingingsrecht, 3. Aufl. 2001, S. 1.

109 Korsten, Memo Mededinging 2004/05, 3. Aufl. 2004, S. 17.

110 Korsten Memo Mededinging 2004/05, 3. Aufl. 2004, S. 20.

111 Korsten, Memo Mededinging 2004/05, 3. Aufl. 2004, S. 21. 
hen. Insgesamt erfolgt die Abgrenzung also nicht anhand von juristischen Kriterien, sondern vielmehr ist die ökonomische Realität maßgeblich. ${ }^{112}$ Welche Umstände zu berücksichtigen sind, ist detailliert im Besluit gegevensverstrekkingen Mededingingswet $^{113}$ geregelt. Im Einzelfall sind diese Abgrenzungen nicht einfach zu treffen, wie beim Gesundheitsmarkt zu zeigen sein wird.

\subsection{Die Bedeutung von Wettbewerb im Gesundheitssystem}

Das Gesundheitssystem weist einige Besonderheiten auf, die für die Beurteilung sowohl des Wettbewerbs als auch seiner Steuerung zu berücksichtigen sind. So wird im niederländischen Recht und in der Ökonomie das Gesundheitswesen als nichtökonomisch eingestuft, worüber man in Anbetracht der erheblichen Umsätze beispielsweise im Bereich der Krankenhaus- oder der Arzneimittelversorgung zweifeln könnte. 114

Der Gesundheitsmarkt generell, aber auch speziell im Bereich der Krankenhausversorgung, weist einige Besonderheiten auf. Dabei muss, wenn man sich das bereits dargestellte Leistungsdreieck vor Augen ruft, zwischen zwei relevanten Märkten unterschieden werden 115: zum einen den Markt für Krankenversicherungen, der zum einen durch die Beziehungen zwischen den Krankenversicherern und den Versicherten und zum anderen durch die Beziehungen zwischen den verschiedenen Versicherungsunternehmen bestimmt wird und zum anderen durch den Leistungsmarkt, der durch die Verhältnisse zwischen den Leistungserbringern und den Krankenversicherern sowie zwischen den Leistungserbringern und den Versicherten und schließlich zwischen den Leistungserbringern untereinander bestimmt wird. Das Hauptproblem im Bereich des Gesundheitsmarktes ist, dass die Versicherten nicht unmittelbar für die in Anspruch genommenen Leistungen zahlen. Anders als im üblichen Marktgeschehen erfolgt also keine Preis-Leistungs-Abwägung die das Zusammenspiel von Angebot und Nachfrage steuert. ${ }^{116}$ Selbst für den interessierten Nachfrager/Versicherten ist es ausgesprochen schwierig, sich über das Verhältnis von Leistung und Qualität zum Preis zu informieren. Durch die fehlende Unmittelbarkeit der Zahlungsverpflichtung für die Versicherten, neigen diese den Preisgesichtspunkt bei der Inanspruchnahme völlig außer acht zu lassen.

112 Korsten, Memo Mededinging 2004/05, 3. Aufl. 2004, S. 23.

113 Besluit van 17 oktober 1997, Stb. 485, letzte Änderung vom 27. April 2000, Stb. 222.

114 So Kist, Inleiding: De nederlandse mededingingsautoriteit en het waarborgen van niet-economische belangen in: van de Gronden/Mortelmans, Mededinging en niet-economische belangen, 2001, S. 1.

115 Gaasbeek in: van de Gronden/Mortelmans, Mededinging en niet-economische belangen, 2001, S. 72.

116 Gaasbeek in: van de Gronden/Mortelmans, Mededinging en niet-economische belangen, 2001, S. 73. 
Das Verhältnis zwischen Leistungserbringern und Versicherten wird in erster Linie bestimmt durch eine Informations- und Wissensasymetrie. ${ }^{117}$ Während sich die Leistungserbringer mit den Leistungen und deren Notwendigkeit und wohl auch Kosten auskennen, kann der Versicherte in der Regel nicht beurteilen, welche Leistungen notwendig sind oder selbst welche Leistungserbringer tätig werden sollten. Darüber hinaus können die Versicherten auch nicht steuern, ob sie Leistungen in Anspruch nehmen wollen, denn ob sie krank werden, liegt nicht in ihrem Einflussbereich. Diese Verhältnisse führen dazu, dass die Versicherten ihre Rolle als Nachfrager nicht aktiv ausfüllen können. Sie können das Qualitäts-Preis-Verhältnis nicht ausreichend beurteilen. ${ }^{118}$ Angebot und Nachfrage können sich nicht frei austarieren, weil die Anbieter selbst in dem meisten Fällen die Notwendigkeit der Nachfrage bestimmen. Hierbei besteht die Gefahr, dass Leistungserbringer die Nachfrage im Sinne ihrer ökonomischen Interessen, Freizeit oder Ansehen beeinflussen. 119

Eine wichtige Rolle spielt auch, dass der Preis von Gesundheitsleistungen für die Nachfrager keine bedeutende Rolle spielt, weil aus sozialpolitischen Gründen der Bedarf an Gesundheitsleistungen nur in geringem $\mathrm{Ma} ß$ an finanzielle Ausgaben geknüpft sein soll. ${ }^{120}$ Aus diesem Grund erfolgt die Bezahlung von Gesundheitsleistungen im Wesentlichen durch Dritte, die gesetzlichen oder privaten Krankenversicherungen. Dadurch wird das Interesse der Nachfrager an einem Vergleich der angebotenen Leistungen und ihres Preis-Leistungs-Verhältnisses beschränkt. Es besteht die Gefahr, dass Versicherte bei der Inanspruchnahme von Gesundheitsleistungen von vornherein mit in Betracht ziehen, dass für sie keine oder lediglich geringe Kosten entstehen (Moral hazard).

Auch das Verhältnis zwischen den Versicherten und den Krankenversicherungen wird bestimmt durch die vorgenannten Gegebenheiten. Da der Leistungsinhalt der gesetzlichen Krankenversicherung im Zorgverzekeringswet vorgeschrieben ist und sich auch die Prämien lediglich in ihrem nominellen Anteil unterscheiden dürfen, gibt es für die Versicherten keine hinreichenden Anreize, um sich eingehend über die verschiedenen Krankenversicherungen zu informieren, sie zu vergleichen und sich diejenige mit dem besten Preis-Leistungs-Verhältnis auszuwählen. Einige wenige sehr engagierte Versicherte werden diesen Vergleich vornehmen, aber die weitgehende Mehrheit wird den erforderlichen Aufwand weit höher einschätzen als den zu erzielenden Nutzen.

Die aufgezeigten Besonderheiten führen dazu, dass die Marktkräfte sich nicht frei entfalten können und es so nicht das Ergebnis eines ausgewogenen Preis-LeistungsVerhältnis erzielt wird, wie es sich in einem freien Markt einstellen würde. Ein freier Markt hätte im Bereich der Gesundheitsversorgung aber unerwünschte Folgen. So würde die Konkurrenz dazu führen, dass die Krankenversicherungen ihre Prämien mög-

117 Lapré/Rutten/Schut, Algemene economie van de gezondheidszorg, 2001, S. 14.

118 Lapré/Rutten/Schut, Algemene economie van de gezondheidszorg, 2001, S. 220.

119 Lapré/Rutten/Schut, Algemene economie van de gezondheidszorg, 2001, S. 15.

120 Lapré/Rutten/Schut, Algemene economie van de gezondheidszorg, 2001, S. 15. 
lichst niedrig halten würden, was soweit erstrebenswert ist, aber sie würden auch ein Verhältnis der Prämie zum versicherten Risiko herstellen, also zum Gesundheitszustand des Versicherten. Diese Risikoselektion widerspricht aber den gesetzgeberischen Vorgaben, die eine solche gerade ausschließen möchten, und auch der gesellschaftliche Konsens geht dahin, dass eine für jeden zugängliche und bezahlbare Krankenversicherung bestehen muss. ${ }^{121}$ Aus diesem Grund muss ein Gesundheitsmarkt und ein Krankenhausmarkt mit seinen kostenintensiven Leistungen gesetzlich reguliert werden. Inwieweit diese Regulierung notwendig ist, liegt im gesetzgeberischen Ermessen, das sich in den Niederlanden durch das Bestreben nach einer Verringerung des Maßes an gesetzlicher Regulierung auszeichnet.

\subsection{Gesetzlicher Rahmen}

Das niederländische Wettbewerbsrecht ist im Wettbewerbsgesetz (Mededingingswet) ${ }^{122}$ geregelt. Wie bereits dargestellt, sind im niederländischen Gesundheitswesen mit der Zeit immer mehr Wettbewerbselemente eingeführt worden, so dass sich folgerichtig die Frage nach der Anwendbarkeit des Wettbewerbsrechts in diesem nicht ökonomisch geprägten Bereich stellt. Von der niederländischen Wettbewerbsbehörde (Nederlandse Mededingingsautoriteit, NMa) wurde diese Frage in drei grundlegenden Entscheidungen ${ }^{123} \mathrm{im}$ Wesentlichen bejahrt. ${ }^{124} \mathrm{Zu}$ den Einzelheiten hat sich eine verzweigte Kasuistik herausgebildet. So werden die Zusammenschlüsse von Krankenhäusern oder Krankenkassen am Wettbewerbsrecht gemessen. Zentral steht dabei der Unternehmensbegriff, für dessen Auslegung Art. $1 \mathrm{f}$ Wettbewerbsgesetzt auf Art. 81 Abs.1 EG verweist. ${ }^{125}$

Im Rahmen der wettbewerblich orientierten Gesundheitsreform 2006 wurde neben dem Wettbewerbsgesetz ein Gesetz verabschiedet, das speziell auf die Regelung des Wettbewerbs im Gesundheitssektor zugeschnitten ist, das Gesetz zur Marktordnung im Bereich der Gesundheitsversorgung (Wet Marktordening Gezondheidszorg, WMG). Ausgangspunkt dieses Gesetzes ist die Regelung der Aufgaben und Befugnisse der neu gegründeten niederländischen Gesundheitswettbewerbsbehörde (Nederlandse Zorgautoriteit, NZa). Hierzu gehören die Marktaufsicht über den Gesundheitsmarkt, die Marktentwicklung sowie die Tarif- und Preisregulierung und die Aufsicht über die Ausführung des Krankenversicherungsgesetz, Art. 16 Gesetz zur Marktordnung im Bereich

121 Lapré/Rutten/Schut, Algemene economie van de gezondheidszorg, 2001, S. 221.

122 Gesetz vom 22.05.1997, Stb. 1997, 242, letzte Änderung vom 07.07.2006, Stb. 2006, 415.

123 Besluit van de d-g NMa in zaak 165, Sophia Ziekenhuis/Verpleeghuis de Weezenlanden, d.d. 5 juni 1998; Besluit van de d-g NMa in zaak1165, ANOZ Verzekeringen- ANOVA - ZAO, d.d. 29 december 1998; Besluit van de d-g- NMa in zaak 407/882, Amicon, d.d. 18 juni 1999.

124 Ausführlich: Gaasbeek, Mededingingswet en de zorgsector in: van de Gronden/Mortelmans, Mededinging en niet-economische belangen, 2001, S. $66 \mathrm{ff}$.

125

Im Einzelnen unten II. 4.7. 
der Gesundheitsversorgung. Für die klassischen Felder des Wettbewerbsrechts, wie das Verbot von horizontalen und vertikalen Wettbewerbsabsprachen (Art. 6 Wettbewerbsgesetz), Missbrauch einer ökonomischen Machtposition (Art. 24 Wettbewerbsgesetz), gilt aber weiterhin das Wettbewerbsgesetz.

\subsection{Institutionen der Wettbewerbskontrolle}

Durch die Reformen der vergangenen Jahre und insbesondere auch durch die Gesundheitsreform 2006 wurden verstärkt Wettbewerbselemente in das Gesundheitssystem implementiert. Damit diese ausgeweiteten Freiheiten aber nicht ausarten und den öffentlichen Belangen der Krankenversicherung zuwiderlaufen, ist eine ausgeprägte Kontrolle erforderlich. ${ }^{126}$ Diese Kontrolle umfasst verschiedene Aspekte, wie die Kartellaufsicht, die Aufsicht und die Förderung des Wettbewerbs auf dem Gesundheitsmarkt, die Aufsicht über die Erfüllung der gesetzlichen Rahmenvorgaben und gesundheitssektorspezifische Verhaltensaufsicht insbesondere hinsichtlich des Informationsverhaltens zugunsten der Versicherten hinsichtlich der verschiedenen Vertragsangebote der Krankenversicherungen. ${ }^{127}$

Diese Aufgaben werden von zwei Organisationen wahrgenommen: der Wettbewerbsbehörde und der neu geschaffenen Gesundheitswettbewerbsbehörde. Diese Splittung der Wettbewerbsaufsicht auf zwei Organisationen folgt dem niederländischen Vorbild des Telekommunikationsmarktes. ${ }^{128}$

Die Gesundheitswettbewerbsbehörde (Nederlandse Zorgautoriteit, NZa) ist aus dem Rat für Tarife im Gesundheitsbereich (College tarieven gezondheidszorg, CTG) und dem Rat für die Aufsicht über Krankenversicherungen (College van toezicht op de zorgverzekering, CTZ) hervorgegangen ist, als das Wet Marktordening Gezondheidszorg in Kraft getreten ist, Art. 3 Gesetz über die Marktordnung im Gesundheitsbereich $^{129}$.

Die Gesundheitswettbewerbsbehörde ist als eine öffentlich-rechtliche Einrichtung mit eigener Rechtspersönlichkeit vorgesehen, die durch ihren Vorsitzenden nach innen und außen repräsentiert wird, Art. 3 Gesetz zur Marktordnung im Bereich der Gesundheitsversorgung. Die drei Mitglieder des Verwaltungsrates werden vom Gesundheitsministerium auf maximal vier Jahre ernannt, Art. 4 Gesetz zur Marktordnung im Bereich der Gesundheitsversorgung. Das Gesundheitsministerium ist auch in inhaltlichen Fragen

126 Wet Marktordening Gezondheidszorg - Memorie van toelichting, S. 1, 3; Steyger, Marktwerking in oprichting: de bevoegdheden van Zorgautoriteit en Nma en der werking in de praktijk, TvG 2006, 2 (3).

127 Art. 16 u. 37 WMG (Entwurf); Hamilton, Een zorgverzekering voor iedereen, 2005 Nr. 3, S. 33.

128 Steyger, Marktwerking in oprichting: de bevoegdheden van Zorgautoriteit en Nma en der werking in de praktijk, TvG 2006, 2 (4).

129 Wet houdende regels inzake marktordening, doelmatigheid en beheerste kostenontwikkeling op het gebied van de gezondheidszorg (Wet Marktordening Gezondheidszorg) vom 7. Juli 2006, Stb. 2006, 415, letzte Änderung vom 30.11.2006, Stb. 2006, 644. 
weisungsbefugt, Art. 7 Gesetz zur Marktordnung im Bereich der Gesundheitsversorgung.

Durch das Gesetz zur Marktordnung im Bereich der Gesundheitsversorgung erhält die Gesundheitswettbewerbsbehörde weitreichende Befugnisse, die über diejenigen des Rates für Tarife im Gesundheitsbereich (CTG) und des Rates für die Aufsicht über Krankenversicherungen (CTZ), wie der Aufsicht und Regulierung der Tarife, hinausgehen. ${ }^{130}$ So darf sie einer Partei mit beachtlicher Marktmacht spezielle Verpflichtungen auferlegen, um den Leistungseinkaufsmarkt als einen Teilmarkt mit freier Preisgestaltung zu etablieren, Art. $40 \mathrm{ff}$ Gesetz zur Marktordnung im Bereich der Gesundheitsversorgung. Darüber hinaus darf sie allgemeine Regeln aufstellen, um die Transparenz des Marktes für die Versicherten zu gewährleisten. Insofern ist sie auch befugt, selbst Informationen zu veröffentlichen, Art. 20 Gesetz zur Marktordnung im Bereich der Gesundheitsversorgung.

Die Gesundheitswettbewerbsbehörde hat also recht weitreichende Kompetenzen in den Teilmärkten, in denen freie Preise etabliert werden sollen. ${ }^{131}$ Dem liegt das gesetzgeberische Ziel der Wettbewerbsverstärkung zugrunde, für das die Unterscheidbarkeit von Preisen und deren freie Gestaltung eine wichtige Grundlage darstellt.

Demgegenüber übt die Wettbewerbsbehörde nach wie vor die herkömmliche Wettbewerbsaufsicht aus, worunter die Überwachung des Verbots von vertikalen und horizontalen Kartellabsprachen (Art. 6 Wettbewerbsgesetz) fällt, aber auch das Einschreiten bei Missbrauch einer ökonomischen Machtposition (Art. 24 Wettbewerbsgesetz) sowie die Konzentrationsaufsicht. 132

Für die Abgrenzung der Befugnisse der Wettbewerbs- und der Gesundheitswettbewerbsbehörde ist also vor allem der zeitliche Aspekt maßgeblich. Die Gesundheitswettbewerbsbehörde wird bereits tätig, sobald sie eine ökonomische Machtposition feststellt, ohne dass es zu einem Verstoß gekommen sein muss, dagegen wird die Wettbewerbsbehörde immer erst ex post, also nach einem Verstoß gegen das Wettbewerbsgesetz tätig. ${ }^{133}$ Die Tätigkeitsbereiche der beiden Behörden überschneiden sich folglich in der Feststellung von ökonomischen Machtpositionen im Gesundheitsbereich. ${ }^{134}$ Um für die Praxis keine Probleme durch die eng beieinanderliegenden Befugnisse der Wettbewerbs- und der Gesundheitswettbewerbsbehörde zu schaffen, regelt Art. 18 des Gesetzes zur Marktordnung im Bereich der Gesundheitsversorgung, dass Anspruchsteller sich im Zweifel zuerst an die Gesundheitswettbewerbsbehörde wenden sollen.

130 Wet Marktordening Gezondheidszorg - Memorie van toelichting, S. 4.

131 Scheerder, De Wet Marktordening Gezondheidszorg, Zorg \& Financiering 2005, 25 (32).

132 Steyger, Marktwerking in oprichting: de bevoegdheden van Zorgautoriteit en Nma en der werking in de praktijk, TvG 2006, 2 (4).

133 Steyger, Marktwerking in oprichting: de bevoegdheden van Zorgautoriteit en Nma en der werking in de praktijk, TvG 2006, 2 (14, 16); Nederlandse Zorgautoriteit, Consultatiedocument Aanmerkelijke Marktmacht (AMM) in de Zorg, 2006, S. 13.

134 Nederlandse Zorgautoriteit, Consultatiedocument Aanmerkelijke Marktmacht (AMM) in de Zorg, 2006, Beilage 2, S 113. 
Durch das Zusammenfassen der Aufsicht über den Gesundheitsmarkt, die vorher durch verschiedene Organisationen ausgeübt wurde, in einer Hand, nämlich der Gesundheitswettbewerbsbehörde, erhofft man sich gerade in der Zeit des Veränderungsprozesses zu einem regulierten Wettbewerb eine effizientere Kontrolle. ${ }^{135}$ Die Einführung des verstärkten Wettbewerbs wird in den verschiedenen Teilmärkten nicht homogen verlaufen, dennoch beeinflussen sich die Entwicklungen in diesen Teilmärkten gegenseitig. Aus diesem Grunde wird eine Aufsicht aus einer Hand als sinnvoll erachtet.

\section{Märkte - Wettbewerb und Regulierung in der Krankenhausversorgung}

Der Krankenhaussektor bildet keinen einheitlichen Markt, vielmehr beinhaltet er verschiedene Teilmärkte, die sich nach den beteiligten Akteuren bestimmen. So werden die Verhältnisse der Versicherten zu den Krankenhäusern, der Versicherten zu den Krankenversicherungen, den Krankenhäusern untereinander, den Krankenhäusern zu den Krankenversicherungen und den Krankenversicherungen untereinander nachfolgend einzeln behandelt.

\section{Der Verbraucher bei der Auswahl des Krankenhauses}

Das Verhältnis der Versicherten zu den Leistungserbringern, im Rahmen dieser Untersuchung insbesondere der Krankenhäuser, ist zum einen von gesetzlichen Rahmenbedingungen wie dem Überweisungserfordernis, und zum anderen von der Freiheit in Bezug auf die Wahl des behandelnden Krankenhauses geprägt.

Die Versicherten dürfen nicht allein aus eigenem Antrieb, sondern nur nach Überweisung ein Krankenhaus aufsuchen, Art. 14 Abs. 2 Krankenversicherungsgesetz. ${ }^{136}$ Diese Einschränkung ist umso bedeutender als auch die Fachärzte weitgehend in den Krankenhäusern tätig sind und entsprechend lediglich nach Überweisung durch einen Hausarzt aufgesucht werden dürfen. 137 Jeder Niederländer muss sich bei einem Hausarzt einschreiben, worin die Grundlage für die feste Bindung zwischen Hausarzt und

135 Wet Marktordening Gezondheidszorg - Memorie van toelichting, S. 11; Scherder (Fn.131) S. 29; Steyger, Marktwerking in oprichting: de bevoegdheden van Zorgautoriteit en NMa en der werking in de praktijk, TvG 2006, $2(3,4)$.

136 Schrijvers, Een kathedraal van zorg, 2001, S. 98; van Rooij/Kodner/Rijsemus/Schrijvers, Health and Health Care in the Netherlands, 2002, S. 69; Boot/Knapen, Nederlandse Gezondheidszorg, 2005, S. 102.

137 Vandermeulen, Ziekenhuisen: medisch bedrijven, III 2.1-4 in: Breit/Elsinga/Kasdrop/Sanders/Vandermeulen/Weevers, Handboek Structuur en financiering gezondheidszorg Bd. 3 2005; Ribbens, De positie van de huisarts in de gezondheidszorg, III 1.3-5 in: Breit/Elsinga/Kasdrop/ Sanders/Vandermeulen/Weevers, Handboek Structuur en financiering gezondheidszorg Bd. 3 2005; Maarse, Marktwerking in de ziekenhuiszorg, Maastricht 2002, S. $52 \mathrm{f}$. 
Patient gesehen wird. 138 Dieser verweist generell zur fachärztlichen Versorgung, er entscheidet aber nicht darüber, welches Krankenhaus oder welchen Facharzt der Versicherte aufsuchen darf. Diese Entscheidung liegt beim Versicherten. Allerdings ist er bei Sachleistungspolicen an die durch die Krankenversicherung kontrahierten Einrichtungen gebunden, bei Kostenerstattungsverträgen kann er frei wählen, auch wenn in der Praxis diese Wahl häufig durch die örtlichen Gegebenheiten vorbestimmt wird, wenn es in der Umgebung nämlich nur ein geeignetes Krankenhaus gibt oder wenn in Notfallsituationen das am schnellsten zu erreichende Krankenhaus aufgesucht werden muss. Hier findet dann kein Wettbewerb mehr statt, sondern es folgt eine regionale Zuordnung.

Auf der anderen Seite gibt es für die Krankenhäuser keine allgemeine Verpflichtung zur Aufnahme von Patienten, lediglich im Rahmen von Sachleistungskontrakten müssen die gebundenen Einrichtungen aufgrund der Verträge die Versicherten versorgen. ${ }^{139}$

\subsection{Qualität}

Aber auch wenn der Versicherte Zeit hat, seinen Krankenhausaufenthalt zu planen, fehlen ihm häufig die notwendigen Informationen, um eine sachlich begründete Entscheidung treffen zu können. Insofern kann von einer Wissensasymetrie gesprochen werden, während die Ärzte im Krankenhaus über Behandlungsmöglichkeiten und -abläufe gut informiert sind, fehlt dieses Wissen bei den Versicherten. ${ }^{140}$ Häufig werden subjektive Gründe zur Wahl des Krankenhauses führen. Dies sind zum einen die örtliche Erreichbarkeit, zum anderen Empfehlungen aus dem Bekanntenkreis oder auch die konfessionelle Zugehörigkeit. Gerade die örtliche Erreichbarkeit ist hierbei hervorzuheben, denn de facto versorgt jedes Krankenhaus seine Region, so dass der Wettbewerb nur eine eingeschränkte Rolle spielt. ${ }^{141}$ Mit der zunehmenden Nutzung des Internets als Informationsplattform auch für medizinische Fragen, hat sich das Verhältnis der Patienten zu den Leistungserbringern etwas verschoben. Sie sind besser informiert, „mündiger", jedoch treten mit zunehmendem Wissen auch vermehrte Fragen auf, die an den Arzt gerichtet werden, so dass seine Beratungsfunktion gestärkt wird. ${ }^{142}$ Das Recht auf

138 Ribbens, De positie van de huisarts in de gezondheidszorg, III 1.3-2 in: Breit/Elsinga/Kasdrop/Sanders/Vandermeulen/Weevers, Handboek Structuur en financiering gezondheidszorg Bd. 32005.

139 Noordam, Socialezekerheidsrecht, 2006, S. 304.

140 Schipaanboord, De rol van de consument in de gezondheidszorg, I 2.1-9 in: Breit/Elsinga/Kasdorp/Sanders/Vandermeulen/Weevers, Handboek Structuur en financiering gezondheidszorg, Looseblatt, Stand 2004.

141 Schipaanboord, De rol van de consument in de gezondheidszorg, I 2.1-9 in: Breit/Elsinga/Kasdorp/Sanders/Vandermeulen/Weevers, Handboek Structuur en financiering gezondheidszorg, I 2.113.

142 Schipaanboord, De rol van de consument in de gezondheidszorg, I 2.1-9 in: Breit/Elsinga/Kasdorp/Sanders/Vandermeulen/Weevers, Handboek Structuur en financiering gezondheidszorg I 2.113. 
Information des Patienten resultiert aber aus dem Behandlungsvertrag, art. 7:448 Bürgerliches Gesetzbuch und erstreckt sich auf Informationen über die Behandlungsmöglichkeiten sowie deren Risiken. ${ }^{143}$ Für die stärkere allgemeine Information insbesondere über Krankenhäuser und deren Leistungen und Qualität setzen sich vermehrt Patientenverbände ein. So gibt es einen von der Patientenvereinigung aufgestellten Vergleich von 42 niederländischen Krankenhäusern hinsichtlich der Patientenzufriedenheit. ${ }^{144}$ Eine Verpflichtung der Krankenhäuser zur Veröffentlichung eines umfassenden Qualitätsberichtes gibt es jedoch nicht. In der „NVZ-Datenbank Qualität“145 werden eine Vielzahl von Indikatoren hinsichtlich der Qualität gesammelt und aufbereitet. Es geht um die Patientensicherheit, -zufriedenheit, die personelle Organisation, die finanzielle Position und das Qualitätssystem der Einrichtungen. Die Daten hinsichtlich des Versorgungsinhalts sind in erster Linie bestimmt für die Ausführung der Aufsicht der Inspectie voor de Gezondheidszorg (GZI), eine Vielzahl von Daten werden aber auch an die Patientenorganisationen weitergegeben und sind im Internet abrufbar. ${ }^{146}$

Schließlich ist noch die freiwillige Akkreditierungsmöglichkeit der Krankenhäuser über das Niederländische Institut für die Akkreditierung von Krankenhäusern (NIAZ, Nederlands Instituut voor Accreditatie van Ziekenhuizen) zu nennen, mit der die Einrichtungen werben können. ${ }^{147}$

Ein wesentlicher Umstand, der zunehmend an Bedeutung gewinnt, ist die Teilnahme an Formen integrierter Versorgung. Derartige Vernetzungsstrukturen der Krankenhäuser mit der Versorgung durch Niedergelassene - transmurale zorg, also Versorgung über die Mauern des Krankenhauses hinaus - hat sich zu Beginn der 90iger Jahre entwickelt und seitdem zunehmend verstärkt. ${ }^{148}$ Ursache und zugleich Zielrichtung ist die Überwindung der sektoralen Grenzen zwischen der Versorgung durch die Hausärzte und die Fachärzte, die, wie oben bereits dargelegt, in den Krankenhäusern angesiedelt sind. Mittlerweile gibt es eine Vielzahl von Projekten der transmuralen Versorgung unter Beteiligung der Krankenhäuser auf der Grundlage von Art. 11 Krankenversicherungsgesetz, eine spezielle Rechtsgrundlage gibt es nicht. Diese Verträge werden auf die allgemeine Vorschrift zur Versorgung durch die Krankenversicherungen gestützt. ${ }^{149}$ Bei-

143 Ausführlich: Leenen, Rechten van mensen in de gezondheidszorg, Deel I, 2000, S. $191 \mathrm{ff}$.

144 Schipaanboord, De rol van de consument in de gezondheidszorg, I 2.1-9 in: Breit/Elsinga/Kasdorp/Sanders/Vandermeulen/Weevers, Handboek Structuur en financiering gezondheidszorg, I 2.118.

145 Nederlandse Vereniging Ziekenhuizen (NVZ) - databank Kwaliteit.

146 www.kiesbeter.nl.

147 Im Internet unter: www.niaz.nl.

148 Van der Linden/Rosendal, The Birth of Transmural Care in the 1990 in: van Rooij/Kodner/Rijsemus/Schrijvers, Health and Health Care in the Netherlands, Maarssen 2002, S. 191.

149 Art. 11 Krankenversicherungsgesetz enthält den Versorgungsauftrag für die Krankenversicherungen. Hierzu kann auch der Abschluss von Leistungsverträgen gehören, wenn die jeweilige Versicherung auch Policen mit Sachleistungen anbietet. Gehören zu ihrem Versicherungspaket lediglich Policen mit Kostenerstattung, muss sie keine Leistungsverträge abschließen. 
spiele für derartige Projekte sind die über 90 Kooperationen, die die Stichting Ziekenhuisverplaatste zorg (Stiftung krankenhausverlagerte Versorgung) ins Leben gerufen hat und die vor allem Krebspatienten, Bypässe, Schmerz- und Ergotherapie sowie Diabetiker betreffen. 150 Über die Teilnahme an solchen Projekten können Krankenhäuser beispielsweise übers Internet informieren und so einen gewissen Qualitätswettbewerb beginnen. Gerade für chronisch kranke Versicherte kann das Angebot von derartigen Versorgungsstrukturen durchaus ein Anreiz zur Wahl gerade für die Wahl eines bestimmten Krankenhauses, das an einem solchen Netzwerk teilnimmt, sein.

\subsection{Preis}

Im Verhältnis des Versicherten zum Krankenhaus spielt Preiswettbewerb nur eine untergeordnete Rolle. Zwar gibt es fortschreitende Bestrebungen in den Niederlanden die Preisgestaltung im Krankenhaussektor in die Hände der Krankenhäuser und Krankenversicherungen zu legen, wie es bei ca. 20\% der Leistungen bereits der Fall ist. Darüber hinaus wurde die Finanzierung 2005 auf DBC's umgestellt wie oben ${ }^{151}$ ausführlich erläutert. Jedoch betrifft diese Preisgestaltung nicht die Versicherten, denn sie zahlen lediglich ihre Prämie oder finanzieren die Kosten bei Kostenerstattungstarifen vor. Die Preise sind für sie nur in engen Ausnahmefällen relevant. Denn selbst wenn Selbstbehalte vereinbart werden, erreichen Krankenhaustarife doch meist eine Höhe, in der der Selbstbehalt in voller Höhe gezahlt werden muss, unabhängig davon ob der Behandlungspreis etwas höher oder niedriger ist. Ein derartiger Selbstbehalt in Höhe von 155 EUR im Jahr wurde 2008 verpflichtend eingeführt und löste den Anspruch auf Prämienrückerstattung bei Nichtinanspruchnahme der Versicherung ab. ${ }^{152}$ Hinzu kommt, dass die niederländische Krankenhausvereinigung (NZV) bei den freigegebenen Preisen einen großen Einfluss hat, so dass es gar nicht zu einer Differenzierung zwischen den einzelnen Krankenhäusern kommt. Dies ist auf der einen Seite sinnvoll, weil ein einzelnes Krankenhaus - jedenfalls eines von den kleineren - keine ausreichende Verhandlungsposition gegenüber den Krankenversicherungen hat. Auf der anderen Seite fehlt es dann an der für das Entstehen von Preiswettbewerb nötigen Differenzierung.

\section{Anreize für den Verbraucher bei der Wahl der Krankenversicherung}

Neben der Auswahl des Krankenhauses durch die Versicherten, die wie soeben dargelegt, nur beschränkt zu Wettbewerb führt, da die Anzahl der Krankenhäuser beschränkt ist und die Versicherten häufig nicht nach finanziellen oder qualitativen Krite-

150 Beusmans/Zutphen, Vormen van transmurale zorg in: Spreeuwenberg/Pop/Beusmans/Winkens/Zutphen, Handboek transmurale zorg, 2000, S- $118 \mathrm{f}$.

151 Unten II. 4.5.

152 Pressebericht der Regierung vom 16. Mai 2007, im Internet unter: www.regering.nl. 
rien auswählen, sondern auf persönliche Empfehlungen abstellen oder auf örtliche Gegebenheiten, kommt der Auswahl der Krankenversicherung eine entscheidende Bedeutung zu. Die Steuerung des Krankenversicherungssystems basiert ganz entscheidend auf dem Vermögen der Versicherten durch ihre Wahlentscheidungen und ihre Wechselbereitschaft zwischen den einzelnen Krankenversicherungen den Wettbewerb zwischen den Versicherungen $\mathrm{zu}$ ermöglichen und zu verstärken. ${ }^{153}$ Umso erfreulicher waren dann auch die ersten Untersuchungen der niederländischen Gesundheitswettbewerbsbehörde, die im Jahr 2006 eine sehr hohe Wechselbereitschaft feststellen konnten. Während der Wechsel 2001 in der gesetzlichen Krankenversicherung lediglich bei 2,6\% lag und in der privaten Krankenversicherung bei 6,6\% und im Jahr 2005, also unmittelbar vor der Reform, in der gesetzlichen Krankenversicherung bei 4,5\% und in der privaten Krankenversicherung bei 8,7\%, so lag die Anzahl der Versicherten 2006, die ihre Krankenversicherung gewechselt haben bei $18 \% .{ }^{154}$ Auch wenn man berücksichtigt, dass die Wechselbereitschaft im ersten Jahr nach einer derart grundlegenden Reform sicher höher ist als in den Folgejahren, wenn die Marktanteile verteilt sind, so waren diese Zahlen dennoch hoch. Leider war 2007 ein deutlicher Rückgang bei der Wechselbereitschaft zu verzeichnen, die bei nur 4,4\% lag. ${ }^{155}$ Die Gesundheitswettbewerbsbehörde ist mit diesen Zahlen dennoch sehr zufrieden, was auf der Betrachtung derjenigen Versicherten gründet, die überlegt haben, ihren Versicherer zu wechseln, ohne dies auch tatsächlich zu tun. ${ }^{156}$ Diese Zahl liegt 2007 mit 11\% etwas über dem Niveau von 2005, aber deutlich unter den $44 \%$ von 2006. Aus dem Blickwinkel der Förderung von Wettbewerb könnte man jedoch Bedenken haben, ob diese Zahlen so zufriedenstellen sind, wie die Gesundheitswettbewerbsbehörde annimmt.

Da der Wettbewerb in diesem Bereich aus Sicht der Regierung nur dann funktionieren kann, wenn alle Teilnehmer aktiv mitwirken, hat der Gesetzgeber die Rolle der Beteiligten sowie die "Spielregeln“ an die sie gebunden sind, durch das Krankenversicherungsgesetz detailliert ausgestaltet. ${ }^{157}$ So ist beispielsweise die Wahlfreiheit der Versicherten hinsichtlich ihrer Krankenversicherung durch die Akzeptanzpflicht aller potentiellen Versicherten für die Versicherer gewährleistet, Art. 3 Krankenversicherungsgesetz. Darüber hinaus wird auch die Transparenz des Marktes für wesentlich erachtet, weshalb die Gesundheitswettbewerbsbehörde mit der Aufgabe der Überwachung der Informationsveröffentlichung der Krankenversicherungen über ihre Policeangeboten bedacht worden ist, Art. 32 Abs. 2 Gesetz zur Marktordnung im Bereich der Gesund-

153 Kamerstukken 2003-2004, 29763: Regeling van een sociale verzekering voor geneeskunduge zorg ten behoeve van de gehele bevolking (Zorgverzekeringswet) Nr. 3: Memorie van toelichting (Gesetzesbegründung), S. 2, 4, 9.

$154 N Z a$, De tussenstand op de zorgverzekeringsmarkt, 2006, S. 14.

$155 N Z a$, Monitor Zorgverzekeringsmarkt, 2007, S. 38.

156 NZa, Monitor Zorgverzekeringsmarkt, 2007, S. 38.

157 Kamerstukken 2003-2004, 29763: Regeling van een sociale verzekering voor geneeskundige zorg ten behoeve van de gehele bevolking (Zorgverzekeringswet) Nr. 3: Memorie van toelichting (Gesetzesbegründung), S. 9. 
heitsversorgung. ${ }^{158}$ Und schließlich soll die sektorspezifische Aufsicht durch die Gesundheitswettbewerbsbehörde dafür sorgen, dass die Marktteilnehmer sich wettbewerbsfreundlich und konform zum Krankenversicherungsgesetz verhalten. ${ }^{159}$

\subsection{Das Recht zum Wechsel der Krankenversicherung}

Das Krankenversicherungsgesetz sieht nicht nur das Recht zur Wahl einer Krankenversicherung vor, sondern vielmehr auch die Pflicht, Art. 2 Abs. 1 Krankenversicherungsgesetz. Alle Niederländer müssen eine Krankenversicherung abschließen. Es gibt nur zwei Ausnahmen von der Versicherungspflicht: Angehörige des Militärs und Menschen mit Bedenken aus Gewissensgründen. ${ }^{160}$ Auch Kinder müssen durch ihre gesetzlichen Vertreter versichert werden, Art. 2 Abs. 3 Krankenversicherungsgesetz. Allerdings zahlen Minderjährige bis 18 Jahre keine pauschale Prämie, Art. 16 Abs. 2 Krankenversicherungsgesetz. Die Versicherung für diese Gruppe wird aus dem Krankenversicherungsfonds finanziert.

Damit die Versicherten ihr Recht auf Wechsel und Auswahl der Krankenversicherung auch ausüben, was wie erörtert für das Funktionieren von Wettbewerb grundlegend ist, werden Anreize benötigt. Diese können einmal in finanzieller Hinsicht und dann in Angeboten besonderer Versorgungsformen bestehen.

\subsubsection{Preis als Anreiz}

Ein starker Anreiz für die Versicherten bei der Wahl ihrer Versicherung liegt sicherlich im Preis. ${ }^{161}$ Während der einkommensabhängige Beitrag hoheitlich vorgegeben wird und insofern nicht von den Versicherungen beeinflusst werden kann, steht die Höhe der pauschalen Prämie im Ermessen der Krankenversicherungen, Art. 17 Abs. 1 Krankenversicherungsgesetz. Hier erschließen sich dem Versicherten also tatsächlich Wahlmöglichkeiten. Dabei ist aber zu beachten, dass die Krankenversicherungen nicht nach dem Gesundheitszustand des Versicherten differenzieren dürfen. Es dürfen aber für unterschiedliche Leistungsverträge, also Sachleistungs-, Kostenerstattungs- oder Mischmodelle, auch verschiedene Prämien festgelegt werden. Über die bloße Höhe hinaus können die Krankenversicherungen ihren Versicherten eine Vielzahl von Wahltari-

158 Kamerstukken 2003-2004, 29763: Regeling van een sociale verzekering voor geneeskundige zorg ten behoeve van de gehele bevolking (Zorgverzekeringswet) Nr. 3: Memorie van toelichting (Gesetzesbegründung), S. 10.

159 Kamerstukken 2003-2004, 29763: Regeling van een sociale verzekering voor geneeskundige zorg ten behoeve van de gehele bevolking (Zorgverzekeringswet) Nr. 3: Memorie van toelichting (Gesetzesbegründung), S. 10; Schipaanboord, De rol van de consument in de gezondheidszorg, I 2.1-9 in: Breit/Elsinga/Kasdorp/Sanders/Vandermeulen/Weevers, Handboek Structuur en financiering gezondheidszorg, I 2.1-20.

160 Hamilton, Een zorgverzekering voor iedereen, 2005, S. 29.

$161 \mathrm{NZa}$, De tussenstand op de zorgverzekeringsmarkt, 2006, S. 54. 
fen anbieten, was wiederum dazu führt, dass für die Versicherten ein Anreiz gesetzt wird, die Unternehmen zu vergleichen und von ihrem Wahlrecht Gebrauch zu machen und so eine Voraussetzung von Wettbewerb zu schaffen. ${ }^{162}$ Zunächst können Selbstbehalte vereinbart werden, die sich auf $100 €, 200 €, 300 €, 400 €$ oder $500 €$ im Kalenderjahr belaufen dürfen, Art. 19 Abs. 2 Krankenversicherungsgesetz. Daneben gibt es seit 2008 einen verpflichtenden Selbstbehalt, der sich für 2009 auf 155 EUR im Jahr beläuft. ${ }^{163}$ Er löste die verpflichtende Rückzahlung eines Anteils der Prämie im Falle der Nichtinanspruchnahme der Versicherung ab. Die zu erlangende Kürzung durch einen Selbstbehalt belief sich 2008 bei einem Selbstbehalt in Höhe von $100 €$ auf $41 €$ Ersparnis und bei einem Selbstbehalt von $500 €$ auf $202 € .164$

Desweiteren gibt es auch die Möglichkeit von Gruppenversicherungen, von denen viele Niederländer über ihren Arbeitgeber oder über Interessenvertretungen bis hin zu Patientenvereinigungen Gebrauch machen und so in den Genuss einer Prämienreduktion von bis zu 10\% kommen, Art. 18 Krankenversicherungsgesetz. ${ }^{165}$ Tatsächlich wir jedoch nur ein Nachlass von durchschnittlich 7\% gewährt. ${ }^{166}$ Dieses Angebot von Gruppenversicherungen stellt einen zunehmend bedeutsameren Anreiz bei der Wahl des Arbeitgebers dar, die es sowohl dem Arbeitnehmer als auch dem Arbeitgeber über den einkommensabhängigen Beitrag ermöglicht Kosten zu reduzieren. Im Jahr 2006 haben 46\% der Versicherten einen Gruppenvertrag abgeschlossen, während 2005 lediglich $29 \%$ über einen derartigen kollektiven Vertrag versichert waren, wobei 20\% der Bevölkerung über den Arbeitgeber abgesichert sind. 1672007 sind sogar 57\% der Versicherten einer Gruppenversicherung beigetreten. ${ }^{168}$ Dagegen sind die Selbstbehalte bei den Versicherten nicht verbreitet, 96,3\% hatten im Jahr 2006 überhaupt keinen Selbstbehalt vereinbart. 169

\subsubsection{Leistungen als Anreiz}

Ein weiterer Anreiz für die Wahlentscheidung neben dem finanziellen kann auch in den angebotenen Versorgungsformen und damit einhergehend in der Qualität der Versorgung liegen. Solche besonderen Versorgungsformen, mit denen Krankenversicherungen auch werben können, sind zum einen die integrierte Versorgung, dann die DMP`s und erwähnt werden soll auch das in den Niederlanden sehr prägende Hausarztmodell:

162 Vgl. Walser, Erste Ergebnisse der niederländischen Reform des Krankenversicherungssystems, Die BKK 2006, S. $154 \mathrm{ff}$.

163 Im Internet: www.vws.nl.

164 NZa, Monitor Zorgverzekeringsmarkt 2007, S. 12.

165 Ausführlich: Hamilton, Een zorgverzekering voor iedereen, 2005, S. 119 ff.

166 NZa, Monitor Zorgverzekeringsmarkt, 2007, S. 69.

167 NZa, De tussenstand op de zorgverzekeringsmarkt, 2006, S. 14.

168 NZa, Monitor Zorgverzekeringsmarkt, 2007, S. 30.

169 NZa, De tussenstand op de zorgverzekeringsmarkt, 2006, S. 54. 
Die integrierte Versorgung, transmurale zorg, wurde zu Beginn der 90iger Jahre eingeführt und hat seitdem zunehmend an Bedeutung gewonnen. ${ }^{170}$ Dabei ist schon vom Wortsinn her die Versorgung „über die Mauern hinaus“, also über die Krankenhausmauern hinweg zur Verknüpfung der hausärztlichen mit der fachärztlichen Versorgung gemeint. Die Versorgung durch den Hausarzt als Gatekeeper, also mit der Steuerungsfunktion für den Zugang zur fachärztlichen Versorgung, steht dabei weniger im Vordergrund. Der Gedanke, der dieses Versorgungskonzept in der Vergangenheit gefördert hat, liegt in der Kombination von hoher Qualität und gleichzeitiger Effizienz. Denn auch die Niederlande verzeichnen - wie eingangs dargelegt - eine steigende Anzahl älterer und chronisch kranker Versicherter, was mit einer gewissen Kostensteigerung einhergeht. Um die Krankenversicherungsbeiträge nicht weiter anheben zu müssen, wurde eine politische Entscheidung dahingehend getroffen, die bestehenden Ressourcen besser und effizienter zu nutzen. ${ }^{171}$ Man erkannte in den 90iger Jahren, dass eine erhebliche Ineffizienz auf die strikte Trennung der fachärztlichen Versorgung im Krankenhaus von der Versorgung durch niedergelassene Hausärzte und andere Leistungserbringer sowohl in organisatorischer als auch in finanzieller Hinsicht zurückzuführen ist. ${ }^{172}$ Vor diesem Hintergrund wurde eine Vielzahl von unterschiedlichen Projekten initiiert und auch finanziell gefördert, deren Rechtsgrundlage sich in der allgemeinen Vorschrift über den Versorgungsauftrag der Krankenversicherungen, Art. 11 Krankenversicherungsgesetz findet. Eine Spezialnorm gibt es insoweit nicht. Ein Beispiel für derartige Projekte sind die über 90 Verträge, die durch die Stiftung krankenhausverlagerte Versorgung (Stichting Ziekenhuisverplaatste zorg) initiiert worden sind. ${ }^{173}$ Sie betreffen vor allem die Gründung von Netzwerken zur Versorgung von Krebspatienten, Bypässen, Schmerztherapie und Diabetes. Hervorzuheben ist, dass bei diesen Verträgen die initiierende Stiftung den anfallenden Verwaltungsaufwand organisiert hat und so die Gründung der Netzwerke erheblich erleichtert wurde. Ein weiterer Schwerpunkt von Projekten zur integrierten Versorgung liegt in Netzwerken zur Versorgung von Patienten - zumeist nach einem Klinikaufenthalt - zu Hause. Dies meint, dass ein Team aus Gemeindeschwestern, ambulanten Pflegediensten zusammen mit Hausärzten und Fachärzten aus dem Krankenhaus zur Versorgung der Patienten an deren Wohnort tätig werden. In einer Studie von NIVEL (Nederlands Instituut voor onderzoek van de gezondheidszorg, niederländisches Institut für wissenschaftliche Untersuchungen der Gesund-

170 Van der Linden/Rosendal, The Birth of Transmural Care in the 1990 in: van Rooij/Kodner/Rijsemus/Schrijvers, Health and Health Care in the Netherlands, Maarssen 2002, S: 191.

171 Van der Linden/Rosendal The Birth of Transmural Care in the 1990 in: van Rooij/Kodner/Rijsemus/Schrijvers, Health and Health Care in the Netherlands, Maarssen 2002, S. 191.

172 Van der Linden/Rosendal The Birth of Transmural Care in the 1990 in: van Rooij/Kodner/Rijsemus/Schrijvers, Health and Health Care in the Netherlands, Maarssen 2002, S. 192.

173 vgl. Van der Linden/Rosendal The Birth of Transmural Care in the 1990 in: van Rooij/Kodner/Rijsemus/Schrijvers, Health and Health Care in the Netherlands, Maarssen 2002, S. $191 \mathrm{f}$. 
heitsversorgung) wurden 235 transmurale Projekte untersucht und $40 \%$ waren derart ausgestaltet. 174

Der finanzielle Anreiz für die Krankenversicherungen, an solchen Projekten teilzunehmen, liegt in einer speziellen Förderung, die durch den Krankenversicherungsrat aus dem Krankenversicherungsfonds gewährt werden kann. Die Regelung Krankenversicherung (Regeling zorgverzekering) sieht im 6. Kapitel vor, dass Sonderzahlungen für bestimmte Projekte, die mindestens auf ein Jahr ausgelegt sind, möglich sind. Die Förderung und ihre Höhe liegen im Ermessen des Krankenversicherungsrates, wobei die Bedeutung des Projekts für die Bevölkerung einen wichtigen Stellenwert haben soll. ${ }^{175}$

Eine weitere besondere Versorgungsform, die der Versicherte bei seiner Wahlentscheidung berücksichtigen kann, ist das Angebot von multidisziplinären Versorgungsgruppen. Diese befinden sich zur Zeit noch im Experimentierstatus, d.h. es gibt Modellvorhaben im Bereich der Diabetikerversorgung zur Erprobung dieser Versorgungsform bevor ein endgültiger Gesetzesentwurf angefertigt wird. 176

Zur Regelung dieses Versorgungsbedarfs hat das niederländische Gesundheitsministerium im Rahmen eines Gesetzesvorhabens einen Tätigkeitsplan erstellt ${ }^{177}$, der auf der Grundlage des Berichts der Arbeitsgruppe Diabetes 178 im Auftrag des Gesundheitsministeriums ausgearbeitet worden ist. Dieses Vorhaben sieht im Wesentlichen drei Schritte vor:

- Bildung von multidisziplinären Diabetesversorgungsgruppen (Diabeteszorggroepen, DZG);

- Ketten-DBC`s sollen zu einer guten und effizienten Versorgung beitragen;

- Einrichtung eines Wissenszentrums Diabetes.

Wenn sich diese Modellvorhaben als erfolgreich erweisen sollten, ließe es sich mit entsprechenden Anpassungen auch auf andere Bereiche der chronischen Erkrankungen übertragen.

Die multidisziplinären Diabetesversorgungsgruppen, die bereits bestehen, haben eigene Rechtspersönlichkeit und auch die, die geplant sind, sollen derart ausgestaltet sein. Dies ist nahezu zwingend erforderlich, um eine sinnvolle Zusammenarbeit und somit Versorgung der Diabetiker, aber auch anderer chronischer Krankheiten bei entsprechen-

174 Beusmans/Zutphen, Vormen van transmurale zorg in: Spreeuwenberg/Pop/Beusmans/Winkens/Zutphen, Handboek transmurale zorg, 2000, S. $118 \mathrm{f}$.

175 In diesem Zusammenhang ist auch die besondere Förderung von Gesundheitszentren zu erwähnen. Darunter wird ein durch eine Einrichtung verwalteter Zusammenarbeitsverband verstanden, bei dem ausgehend von einem gemeinsamen Versorgungsort integrale Versorgung geliefert wird. Da diese aber ohne die Beteiligung von Krankenhäusern stattfindet, wird trotz ihrer Bedeutung, in diesem Rahmen nicht weiter auf sie eingegangen.

176 Van den Bos, Zorg, opvang en begeleiding: van onderzoeksprogramma naar praktijk in: Groenewegen/van den Bos/van Megchelen, Zorg, opvang en begeleiding van chronisch zieken, 2004, S. 1 ff.

177 Plan van aanpak Diabeteszorg beter, Kamerstukken 2005 22894, „Plan van aanpak Diabeteszorg beter", Nr. 1.

178 Taakgroep Diabetes. 
den Programmen, zu gewährleisten, denn nur so kann die Diabetesversorgungsgruppe selbst als Vertragspartner der Krankenversicherung agieren und es müssen nicht alle einzelnen Leistungserbringer involviert werden. Es ist somit deutlich, dass die Diabetesversorgungsgruppe als solche das gebundene Rechtssubjekt ist. Darüber hinaus ist die eigene Rechtspersönlichkeit auch eine wichtige Voraussetzung für die Ketten$D B C$ `s, die vorgesehen sind, denn nur mit eigener Rechtspersönlichkeit kann die Diabetesversorgungsgruppe auch Finanzverantwortung übernehmen.

Die multidisziplinären Versorgungsgruppen basieren auf Verträgen, für die es keine spezielle Rechtsgrundlage im Krankenversicherungsgesetz gibt. Dies ist auch nicht notwendig, da Verträge mit den Leistungserbringern bei einer Krankenversicherung mit Sachleistungsversorgung gerade das gesetzlich vorgesehene Mittel bilden, um der Versorgungspflicht der Krankenversicherungen nachzukommen. ${ }^{179}$ Dies folgt aus Art. 12 Abs.1 Krankenversicherungsgesetz und Art. 25 Abs.2 Krankenversicherungsgesetz. Auch die vertragliche Kooperation von Leistungserbringern ist zulässig, insbesondere existiert insofern kein berufsrechtliches Verbot. ${ }^{180}$ Denkbar wäre es jedoch, dass nach Abschluss der Modellversuche und bei einer gesetzlichen Regelung doch eine klarstellende Vorschrift erlassen wird, so dass auch der Wille des Gesetzgebers ersichtlich ist.

Neben der Einrichtung der multidisziplinären Versorgungsgruppen ist die Finanzierung der Diabetesversorgungsgruppen durch sog. Keten-DBC's das Herzstück des Reformvorhabens. Diese Keten-DBC`s sind Sonderfälle der DBC`s, also der Diagnose Behandeling Combinaties. Diese lösen seit 2005 das bis dahin geltende funktionsgerichtete System ${ }^{181}$ mit einem Gesamtbudget, aus dem alle Krankenhauskosten gezahlt werden müssen, $a b$ und ersetzt sie durch ein Budget für die Behandlung eines Patienten mit einer bestimmten Krankheit, also einer Fallpauschale. ${ }^{182}$ Am 01.01.2005 sind die DBC's als Finanzierungsgrundlage eingeführt worden, so dass die Beteiligten ab dem 01.02.2005 diesbezüglich Verträge schließen konnten. ${ }^{183}$

Zur Finanzierung der multidisziplinären Versorgungsgruppen soll eine Fallpauschale eingeführt werden, die derart ausgestaltet ist, dass sie - zunächst abgesehen von der Krankenhausversorgung - die gesamte Behandlung der Diabetespatienten umfasst - ein

179 Hamilton, Een zorgverzekering voor iedereen, 2005, 98f; Hermans, Zorgverzekeringswet, 2006, S. 30.

180 Leenen, Gezondheidszorg en recht, Deel II, 4. Aufl. 2002, S. 59 ff.

181 Functiegerichte budgetiering, FB-Systematik.

182 Maarse/Groot/van Merode/Mur-Veeman/Paulus, Marktwerking in de ziekenhuiszorg, een analyse van de Mogelijkheiden en effecten, 2002, S. S. 43.

183 Durch das WTG ExPres und das HOZ sind die erforderlichen Änderungen des damals noch geltenden Krankenkassengesetz (Art. 44 ff Krankenkassengesetz) und des WTG (insbesondere Art. 10 a WTG) eingeführt worden. Wet van 9 december 2004 tot wijziging van de Ziekenfondswet, de Algemene Wet Bijzondere Ziektekosten en enkele andere wetten, in verband met herziening van het overeenkomstenstelsel in de sociale ziektekostenverzekering alsmede enkele andere wijziging (Wet herziening overeenkomstenstelsel zorg (HOZ), Stb. 2005, 27 und Wet van 9 december 2004 tot wijziging van de Wet tarieven gezondheidszorg in verband met experimenten, prestatiebekostiging en einige andere maatregelen (WTG ExPres), Stb. 2005, 24. 
sog. Keten-DBC. Der Begriff „Kette“ nimmt dabei Bezug auf die Versorgungsreihe vom Hausarzt über den Diätassistenten und die pflegerische Versorgung zu Hause. Da die multidisziplinären Versorgungsgruppen eine eigene Rechtspersönlichkeit besitzen, ist es möglich, sie insgesamt durch eine Fallpauschale pro behandeltem Versicherten zu honorieren. Die Keten-DBC`s sind eine Neuerung, die in Verbindung mit der Versorgung der Diabetiker eingeführt werden und nach und nach auch für die Versorgung anderer chronischer Erkrankungen zur Verfügung stehen sollen. ${ }^{184}$ Die DiabetesFallpauschale soll nur die umfasste Behandlung abstecken, aber keinen Preis hierfür veranschlagen. 185 Die Preise sollen zwischen den Versicherern und den jeweiligen Versorgungsgruppen frei verhandelbar sein. Dies könnte dann auch Auswirkungen auf den Preiswettbewerb zwischen den verschiedenen Diabetesversorgungsgruppen im Verhältnis zu den Versicherern haben. Das Risiko, dass sich ein verschärfter Preiswettbewerb auf die Qualität der Versorgung der chronisch Kranken auswirken könnte, wird dadurch begrenzt, dass die Teilnehmer der Diabetesversorgungsgruppen an den Diabetes Zorgstandaard gebunden sein sollen. Neben der Honorierung der Diabetesversorgungsgruppen als Gesamtheit, die über Keten-DBC`s erfolgen soll, stellt sich die Frage nach der internen Verteilung der Pauschale auf die Mitglieder der Diabetesversorgungsgruppen, die wohl im Innenverhältnis geregelt werden wird.

Interessant an diesem Konzept ist die Finanzverantwortung, die die Diabetesversorgungsgruppen über die Fallpauschalen erhalten. Unabhängig davon, ob sie einen schweren, zeitintensiven oder einen schnell zu behandelnden Patienten, der nach Anleitung vielleicht auch zu Hause einige Behandlungen selbst durchführen kann, versorgen, erhalten sie die gleiche Summe, die sie mit der Versicherung ausgehandelt haben. Hierdurch werden erhebliche Anreize gesetzt, um bei Management und Prozessführung auf die Kosten zu achten und vielleicht auch die Selbstbehandlung der Patienten zu fördern. Dies kommt den Wünschen der Patienten entgegen, die sich lästige Wege zum Arzt ersparen, und es führt zu einer Kostenreduzierung der Diabetesversorgungsgruppen. ${ }^{186}$ Hierin liegt also für die Versicherten unter Umständen ein interessanter Aspekt bei der Wahl der Krankenversicherung.

\subsubsection{Zusatzversicherungen}

Neben der Basisversicherung können die Versicherten sich aber auch für eine $\mathrm{Zu}-$ satzversicherung entscheiden. Die Versicherer haben 137 verschiedene Zusatzversicherungen auf den Markt gebracht, die von 93\% der Versicherten auch gewählt werden. Gerade die Policen hinsichtlich der zahnärztlichen Leistungen erfreuen sich großer Be-

184 Plan van aanpak Diabeteszorg beter, Kamerstukken 2005 22894, „Plan van aanpak Diabeteszorg beter", Nr. 1, S. 13.

185 Plan van aanpak Diabeteszorg beter, Kamerstukken 2005 22894, „Plan van aanpak Diabeteszorg beter", Nr. 1, S. 11.

186 Bos/Groenewegen, Zorg, opvang en begeleiding: van onderzoeksprogramma naar praktijk in: Groenewegen/Bos/Megchelen, Zorg, opvang en begeleiding van chronisch zieken, 2004, S. 4. 
liebtheit. 187 Die Versicherten müssen keine zusätzlichen Gesundheitsprüfungen ablegen, bevor sie solche Zusatzversicherungen abschließen können. Zwar gilt der Annahmezwang des Krankenversicherungsgesetzes nicht für die Zusatzversicherungen, jedoch haben sich die Versicherer freiwillig verpflichtet, allen Versicherten ohne extra Prüfung einen Vertrag anzubieten, lediglich für bestimmte Zahnarzttarife werden zum Teil Wartezeiten vorgesehen. ${ }^{188}$ Die vertragliche Bindung der Basisversicherung an die Zusatzversicherung ist nach Art. 120 Krankenversicherungsgesetz verboten und wird von der NZa geahndet. 189

Die Prämien für Zusatzversicherungen variieren je nach Inhalt und Versicherung erheblich, sie belaufen sich auf 5 EUR bis 77 EUR im Monat. ${ }^{190}$

\section{Das Verhältnis zwischen Krankenversicherung und Krankenhaus}

Das Verhältnis der Krankenhäuser zu den Krankenversicherungen wird zum einen von der Frage des Kontrahierungszwangs oder der Kontrahierungsfreiheit der Parteien bestimmt und zum anderen vom Inhalt der geschlossenen Verträge, wobei wiederum zwischen der Leistung und dem Entgelt zu unterscheiden ist.

\subsection{Entwicklung der Kontrahierungsfreiheit zwischen Krankenhäusern und Kran-} kenversicherern

Von vornehmlicher Bedeutung für das Konkurrenzverhältnis zwischen Krankenhäusern ist die Kontrahierungsfreiheit oder aber auch der Kontrahierungszwang zwischen den Krankenversicherungen und den Krankenhäusern. Hier hat sich in den Niederlanden in den vergangenen Jahren ein grundlegender Wandel vollzogen, der bislang noch nicht abgeschlossen ist.

Nach dem ehemaligen Krankenkassengesetz, das bis 2006 galt, unterlagen die Leistungsverträge einer detaillierten gesetzlichen Regulierung. Es gab sog. Musterübereinkommen, die durch den Krankenversicherungsrat aufgestellt oder zumindest genehmigt werden mussten und von denen nicht abgewichen werden durfte. Zusätzlich waren die Krankenkassen verpflichtet, mit jedem Krankenhaus zu kontrahieren, das an sie herantrat, Art. 47 Abs. 1 Krankenkassengesetz. Mit dem Gesetz zur Reform des Übereinkommensystems in der Gesundheitsversorgung (Wet herziening overeenkomstenstelsel zorg, Wet HOZ,) ${ }^{191}$ wurden die Modellübereinkommen als Grundlagen für die indivi-

187 NZA, De tussenstand op de zorgverzekeringsmarkt, 2006, S. 32.

188 NZA, De tussenstand op de zorgverzekeringsmarkt, 2006, S. 12.

189 Ausführlich: unten II.5.3.

190 NZA, De tussenstand op de zorgverzekeringsmarkt, 2006, S. 12.

191 Stb. 2005, 27; Kamerstukken II 2002/2003-2004/2005, 28994, Nr. 1-23; Kamerstukken I 2004/05, 28994, Nr. A-J; ausführlich: de Groot, Het overeenkomstenstelsel in revisie, TvG 2004, S. 184-207. 
duellen Leistungsverträge abgeschafft. In diesem Zuge wurde zunächst für ca. $10 \%$ der Leistungen und später für $20 \%$ der Leistungen, das B-Segment, der Kontrahierungszwang aufgehoben. Im A-Segment, dem weit größeren Bereich der Leistungen, bestand er allerdings auch 2005 noch. Weitere Änderungen gab es 2006 mit dem Inkrafttreten des Krankenversicherungsgesetzes, das die Regulierung der Leistungsverträge noch weiter einschränkt. Der Kontrahierungszwang wurde grundsätzlich aufgehoben, was bedeutet, dass es allen Krankenversicherern und allen Krankenhäusern frei steht, mit wem sie Verträge abschließen wollen. Durch ministerielle Verordnung kann für bestimmte Einrichtungen aber doch wieder ein Kontrahierungszwang festgesetzt werden, Art. 12 Abs. 2 Krankenversicherungsgesetz. Bislang wurde hiervon jedoch kein Gebrauch gemacht und es ist wohl auch keine derartige Verordnung in Vorbereitung. 192 Die Krankenversicherungen können es sich also aussuchen, für welche Leistungen, sie mit welchen Krankenhäusern kontrahieren möchten. Auf der anderen Seite steht es aber auch den Krankenhäusern frei, lediglich mit einer Auswahl von Versicherungen Leistungsverträge abzuschließen.

\subsection{Vertragsinhalt}

Inhaltlich sind die Verträge zunächst dadurch gekennzeichnet, dass die Krankenversicherer, zumindest bei Sachleistungspolicen, die Versorgung ihrer Versicherten mit sämtlichen Leistungen der Basisversicherung sicherstellen müssen. Etwaige zusätzliche Leistungsangebote stehen ihnen im Rahmen der Zusatzversicherungen frei.

Neben der Regelversorgung sind insbesondere die Verträge der integrierten Versorgung zu nennen wie sie bereits dargestellt worden sind. ${ }^{193}$

\subsection{Tarifgestaltung}

Bis 2005 sind alle Tarife hoheitlich durch den Rat für Tarife festgelegt oder zumindest genehmigt worden. Danach sind die Leistungen der Krankenhausversorgung, wie oben bereits angesprochen, in zwei Bereiche unterteilt worden: das A- (ca. 80\% der Krankenhausversorgung) und das B-Segment (derzeit ca. 20\% der Krankenhausversorgung). Für das A-Segment gelten weiterhin feste Tarife, die durch den Rat für Tarife im Gesundheitswesen aufgestellt oder genehmigt werden. Dagegen sind im B-Segment die Tarife - jedenfalls ihre Kostenkomponente, der Honoraranteil dagegen nicht - frei verhandelbar. ${ }^{194}$ Durch diese Verhandelbarkeit wird den Beteiligten ein erhöhter Spiel-

192 Rijken, De diagnosebehandelingcombinatie (DBC) als instrument voor concurrentie tussen ziekenhuizen, Zorg \& Financiering 2006, S. 8 (15); ausführlich: de Groot, De zorgverzekeraar: spin in het web?, TvG 2005, S. 46.

193 Oben II 2.1.2.

194 Rijken, De diagnosebehandelingcombinatie (DBC) als instrument voor concurrentie tussen ziekenhuizen, Zorg \& Financiering 2006, S. 8 (13). 
raum eingeräumt und so ein auf Wettbewerb orientiertes Verhalten jedenfalls im BSegment ermöglicht. Im A-Segment dagegen findet keine Konkurrenz statt. 195

\section{Wettbewerb zwischen den Krankenhäusern}

\subsection{Rechtsform}

Die niederländischen Krankenhäuser sind weit überwiegend als privatrechtliche Stiftungen ohne Gewinnerzielungsabsicht organisiert, Art. 2, 285 ff Bürgerliches Gesetzbuch. Diese Organisationsform resultiert aus der Entwicklung der Krankenhäuser aus caritativen Zusammenschlüssen, die Patienten zu Hause versorgt haben. ${ }^{196}$ Die Stiftungen zeichnet vor allem die fehlende Gewinnerzielungsabsicht aus. Daneben gibt es aber auch Vereine (verenigingen) und GmbH`s (besloten vernootschap). 197

Da es sich hierbei aber nicht um eine speziell auf Krankenhäuser oder andere einen öffentlichen Zweck verfolgende Einrichtungen ausgerichtete Rechtsform handelt, finden sich zahlreiche Sondervorschriften für Krankenhäuser etwa im Zulassungsgesetz für Krankenhäuser über unabhängige Aufsicht und transparente Verwaltungsstruktur. Die Stiftung sieht strukturell nicht die Verantwortung den Patienten gegenüber vor oder deren Einflussnahme. Hierfür sind spezielle gesetzliche Vorgaben erforderlich. Darüber hinaus wird die Rechtsform der Stiftung aber auch den Veränderungen, die Krankenhäuser in der Vergangenheit durchgemacht haben, nicht mehr gerecht. Die Einrichtungen sind durch Konzentrationsbewegungen stark vergrößert und erfordern entsprechende Verwaltungen und Management. Die Voraussetzung an Qualität nehmen immer mehr zu und zu gleicher Zeit wächst auch der finanzielle Druck auf Krankenhäuser, die immer mehr Konkurrenz ausgesetzt sind. Insgesamt fordern die Veränderungen in Richtung auf Organisation und Neufassung von Prozessabläufen vermehrte Anpassungen, denen man in den Niederlanden durch die Schaffung einer neuen Rechtsform für Unternehmen, die einen öffentlichen Zweck verfolgen, begegnen möchte. Dazu hat die Projektgruppe „Rechtsform gesellschaftliches Unternehmen“ im Auftrag des niederländischen Justizministeriums einen ersten Bericht erstellt. 198 Neben Krankenhäusern soll die neue Rechtsform auch für Schulen und Wohnkooperationen zugänglich sein, darüber ist eine weitere Ausweitung des Anwendungsbereichs denkbar. Soweit es sich um Einrichtungen des sog. semi-öffentlichen Sektors handelt. ${ }^{199}$ Diskutiert werden zur Zeit

195 Rijken, De diagnosebehandelingcombinatie (DBC) als instrument voor concurrentie tussen ziekenhuizen, Zorg \& Financiering 2006, S. 8 (11).

196 Vandermeulen, Ziekenhuizen: medisch bedrijven, S. III 2.1-1 in: Breit/Elsinga/Kasdrop/Sanders/Vandermeulen/Weevers, Handboek Structuur en financiering gezondheidszorg, Bd. 3.

197 Ausführlich: Maarse/Okma, The privatisation paradox in Dutch health care in: Maarse, Privatisation in European Health Care, 2004, S. 109 f.

198 Rapport van de projectgroep Rechtsvorm maatschappelijke onderneming, 2006.

199 Rapport van de projectgroep Rechtsvorm maatschappelijke onderneming, 2006, S. 9. 
insbesondere die Regelung der Gewinnerzielungsabsicht der neuen Rechtsform, sowie der Einfluss der Patienten. Die genannte Projektgruppe befürwortet eine privatrechtliche Rechtsform ohne Gewinnerzielungsabsicht, so dass weiterhin die Verfolgung der öffentlichen Ziele, bei Krankenhäusern also die Sicherstellung der qualitativ hochwertigen Behandlung der Patienten, im Vordergrund steht. Insofern soll die Zielrichtung also nach außen, nämlich auf die Verfolgung des öffentlichen Zwecks, gerichtet sein und nicht wie bei Kapitalgesellschaften nach innen, nämlich auf die Gewinnerzielung der Anteilseigner. Kritik erfahren diese Vorhaben von der Interessenvertretung der Krankenhäuser, der Nederlandse Vereniging van Ziekenhuizen. ${ }^{200}$ Diese vertritt die Auffassung, dass eine neue Rechtsform nicht erforderlich sei. Zwar sei die Stiftung überholt, aber durch die bv (entspricht der deutschen $\mathrm{GmbH}$ ) und der nv (entspricht der deutschen AG) stünden ausreichend Möglichkeiten zur Verfügung, die insbesondere auch ein wettbewerbliches Handeln mit Gewinnerzielungsabsicht ermöglichten, die den Entwicklungstrend des Krankenversicherungsgesetz fortführen würden. ${ }^{201}$

Ein weiteres Element der neuen Rechtsform soll nach der Projektgruppe die Möglichkeit sein, Tochtergesellschaften zu gründen. Insofern soll eine Anlehnung an die Vorschriften über die Gesellschaft, Art. 2:24a BW, erfolgen. Hinsichtlich der Verwaltung und Aufsicht soll die neue Rechtsform sich an die Vorschriften der Kapitalgesellschaften anlehnen, was aufgrund des unternehmerischen Handelns für notwendig erachtet wird. ${ }^{202}$ Ein Aufsichtsrat muss also eingerichtet werden und ebenso ein Verwaltungsrat für die ordentliche Verwaltung. Daneben sollen die Betroffenen, also vornehmlich die Patienten durch eine extra Versammlung ähnlich einer Aktionärsversammlung beteiligt werden. In diesem Rahmen soll ein Jahresplan vorgestellt und besprochen werden, sowie damit verbundene Risiken. ${ }^{203}$

Insgesamt kann festgestellt werden, dass man sich in den Niederlanden einig ist, dass hinsichtlich der Rechtsform für Unternehmen mit öffentlichem Zweck, also auch den Krankenhäusern, Handlungsbedarf besteht, dass aber die Ausgestaltung der neuen Rechtsform, insbesondere die Möglichkeit der Gewinnerzielungsabsicht, umstritten ist.

\subsection{Besonderheiten der selbständigen Behandlungszentren}

Selbständige Behandlungszentren sind 1998 durch das Gesetz Krankenhausversorgung (Wet ziekenhuisvoorzieningen) ${ }^{204}$ eingeführt worden. Die Möglichkeit der Einrichtung solcher selbständigen Behandlungszentren ist geschaffen worden, um flexibler

200 Ebenso: Linders, Wet toelating zorginstellingen, Houten 2006, S. 13.

201 Stellungnahme im Internet unter: www.nivra.nl/etalage.asp.

202 Rapport van de projectgroep Rechtsvorm maatschappelijke onderneming, 2006, S. 17.

203 Rapport van de projectgroep Rechtsvorm maatschappelijke onderneming, S. 18.

204 Wet van 25 maart 1971, houdende regelen ter bevordering van doelmatige voorzieningen ter zake van ziekenhuisen en andere inrichtingen voor gezondheidszorg, Es soll durch das Zulassungsgesetz für Krankenhäuser, das zur Zeit im Entwurf vorliegt, abgelöst werden. 
auf kurzfristige Behandlungsengpässe eingehen zu können, also der niederländischen Wartezeitproblematik zu begegnen. Zwar haben sich dir Wartezeiten in der Periode von 2005 bis 2006 verkürzt, jedoch gibt es immer noch Leistungen, bei denen sich die durchschnittliche Wartezeit über der als akzeptabel angesehenen Wartezeit befindet, so beispielsweise bei Knieoperationen. ${ }^{205}$ So kommt es, dass die meisten selbständigen Behandlungszentren sich auf Leistungen spezialisiert haben, die typischer Weise auf den Wartelisten der Krankenhäuser stehen, wie beispielsweise die bereits genannten Knieoperationen. ${ }^{206}$ Selbständige Behandlungszentren sind vor allem durch Umwandlung von Privatkliniken entstanden. ${ }^{207}$ Diese Umwandlung setzt die Genehmigung durch den Rat Bau Krankenhäuser (College bouw ziekenhuisvoorzieningen) voraus. Damit ist das Selbständige Behandlungszentrum befugt, Leistungen zu Lasten der Basisversicherung zu erbringen. Da es sich nicht um ein Krankenhaus handelt, darf jedoch auch keine Aufnahme der Versicherten über 24 Stunden hinaus erfolgen. 208 Sie stellen also kleinere und flexiblere Einrichtungen dar, die Versorgungsengpässe ausgleichen sollen und so die Nachteile der schwerfälligen Krankenhausplanung ausgleichen.

Darüber hinaus lässt sich jedoch auch feststellen, dass durch die selbständigen Behandlungszentren der Wettbewerb, insbesondere bei den Krankenhausleistungen, über die die Beteiligten frei verhandeln dürfen, deren Tarife also nicht hoheitlich festgelegt werden, gefördert wird. ${ }^{209}$ Dies zeigt sich schon in der Anzahl der selbständigen Behandlungszentren, die in diesem Bereich tätig sind. So waren es 2005 nur 37 solcher Zentren, 2007 aber bereits 68.210 Trotzdem werden nach einer Untersuchung der niederländischen Gesundheitswettbewerbsbehörde von Krankenhäuser doch in erster Linie andere Krankenhäuser als Konkurrenten angesehen und nur selten und lediglich in Bezug auf einzelne Leistungen auch selbständige Behandlungszentren.211

\subsection{Krankenhausplanung}

Die Zugangsmöglichkeiten der einzelnen Krankenhäuser zum Krankenhausmarkt bestimmen sich ganz wesentlich nach der Krankenhausplanung. Hier werden die Rahmenbedingungen auch für das wirtschaftliche Handeln des Krankenhauses wie beispielsweise die Bettenzahl, Expansionsmöglichkeiten festgelegt. Das niederländische Krankenhauswesen wird durch ein komplexes System der Krankenhausplanung be-

205 NZa, Monitor Ziekenhuiszorg 2007, S. 38.

206 Nobels, Prijsconcurrentie tussen ziekenhuis en ZBC, 2005, S. 28; Tweede Kamer, Vaststelling van het ministerie van Volksgezondheid, Welzijn en Sport voor het jaar 2004; Brief minister met informatie over onder meer wettelijk kader privé-kliniken en behandelcentra, 2003, Nr. 24.

207 Nobels, Prijsconcurrentie tussen ziekenhuis en ZBC, 2005, S. 28.

208 Nobels, Prijsconcurrentie tussen ziekenhuis en ZBC, 2005, S. 28.

209 NZa, Monitor Ziekenhuiszorg 2007, S. 16.

$210 N Z a$, Monitor Ziekenhuiszorg 2007, S. 16.

211 NZa, Monitor Ziekenhuiszorg 2007, S. 17. 
stimmt, das in staatlicher Hand liegt und zur Zeit neu geordnet wird. Während sich bislang die gesetzliche Grundlage für die Krankenhausplanung im Gesetz über Krankenhausleistungen ${ }^{212}$ befand, ist nach neuer Rechtslage das Zulassungsgesetz für Krankenhäuser ${ }^{213}$ maßgebend, das 2006 in Kraft getreten ist.

Das Verfahren nach dem Gesetz über Krankenhausleistungen sah die Verantwortlichkeit für die Krankenhausplanung in erster Linie bei den Provinzen. Der Gesundheitsminister wies diese lediglich an, die Pläne aufzustellen und er bestimmte auch, für welches Gebiet und welche Art von Krankenhäusern, Art. 4 S. 1 Gesetz über Krankenhausleistungen. Das maßgebliche Gebiet für diese Pläne sind die Gesundheitsregionen (regio `s), Nr. 1.3 Richtlinien nach Artikel 3 Gesetz über Krankenhausleistungen 214. Das Verfahren und die Inhalte der Krankenhauspläne sind ausgesprochen detailliert in diesen Richtlinien geregelt. So enthalten sie Vorschriften vom Aufbau des Planes, der zunächst den status quo enthalten soll, sodann die einzelnen Phasen beschreiben soll, um das angestrebte Ziel zu erreichen und ein dritter Teil soll die genauen Ausführungsbestimmungen enthalten, um die einzelnen Phasen umzusetzen, Nr. 1.4 Richtlinien nach Artikel 3 Gesetz über Krankenhausleistungen. Inhaltlich enthalten diese Richtlinien auch Vorschriften hinsichtlich der Bettenanzahl der Einrichtungen. So ist nach Nr. 2.2 Richtlinien nach Artikel 3 Gesetz über Krankenhausleistungen ein Durchschnitt von 2,8 Betten pro 1000 Einwohner anzustreben. Ebenso sind konkrete Funktionseinheiten angegeben, die die Kapazität der in den Einrichtungen tätigen Spezialisten angeben, Nr. 2.3 Richtlinien nach Artikel 3 Gesetz über Krankenhausleistungen.

In den letzten Jahren hat die Planerstellung in der Praxis stark an Bedeutung verloren. 215 Der Gesundheitsminister hat keine Aufforderungen an die Provinzen erteilt. Stattdessen wurden Anträge auf Bau oder Erweiterung eines Krankenhauses direkt nach den Richtlinien nach Artikel 3 Gesetz über Krankenhausleistungen beurteilt. Insofern ist ein fließender Übergang zur neuen Rechtslage nach Zulassungsgesetz für Krankenhäuser entstanden:

Das Zulassungsgesetz für Krankenhäuser soll im Rahmen der Gesundheitsreform das Gesetz über Krankenhausleistungen ersetzen. ${ }^{216}$ Es ist am 22.09.2004 durch die Zweite Kammer des niederländischen Parlaments angenommen worden. In der ersten Kammer fand die Beratung am 11.10.2005 statt, so dass das Gesetz zusammen mit dem Krankenversicherungsgesetz 2006 in Kraft treten konnte. Diese Neufassung ist durch die

212 Wet ziekenhuisvoorzieningen, WZV.

213 Wet toelating zorginstellingen Zulassungsgesetz für Krankenhäuser .... .

214 Richtlijnen ex artikel 3 van de Wzv voor het ontwerpen van plannen: tevens beoordelingskader bij toepassing van artikel 29 eerste lid van de Wzv.

215 Einleitung zum Text der Richtlijnen/beleidsregels ex artikel 3 WZV im Internet unter: www.bouwcollege.nl/smartsite.shtml?id=559.

216 Im Hinblick auf die erforderliche terminologische Klarheit sei darauf hingewiesen, dass der Gesetzesentwurf zunächst Wet exploitatie zorginstellingen hieß, wie auch noch die Überschrift der amtlichen Gesetzesbegründung lautet, im Laufe des Gesetzgebungsverfahrens aber umbenannt wurde in Zulassungsgesetz für Krankenhäuser. 
Reform des Gesundheitssystems von einem angebotsgesteuerten System, bei dem die Kapazitäten normativ durch den Staat festgelegt werden, in ein nachfrageorientiertes, bei dem die Beteiligten, also die Versicherten, die Krankenhäuser und die Krankenversicherungen die Kapazitäten und damit auch die Investierungsmaßnahmen maßgeblich bestimmen, erforderlich geworden. ${ }^{217}$ Der Staat soll lediglich die Rahmenbedingungen vorgeben, innerhalb derer die Parteien (Versicherungen und Einrichtungen) handeln können. ${ }^{218}$ Der Übergang zu dem reformierten System soll stufenweise erfolgen, so dass vielfältig auf gesetzliche Instrumente gewählt wurden, die sich leicht an eine veränderte Situation anpassen lassen. Ein Beispiel hierfür ist, dass das Zulassungsgesetz für Krankenhäuser mehrfach auf das vom Gesundheitsministerium zu erlassende Leitprogramm verweist. Dies kann schnell und unbürokratisch geändert werden und ist somit ein ausgesprochen flexibles Steuerungsinstrument. 219

Für die Krankenhausplanung werden nunmehr keine Pläne durch die Provinzen aufgestellt, sondern das Gesundheitsministerium stellt mindestens alle vier Jahre einen Bericht effektives Gesundheitssystem auf, Art. 3 Abs. 1 Zulassungsgesetz für Krankenhäuser (WTZi) Auf dieser Grundlage legt das Ministerium Richtlinien fest, um Bauanfragen für Krankenhäuser prüfen zu können, Art. 4 Zulassungsgesetz für Krankenhäuser. Eine wichtige Informationsquelle für das Ministerium stellen dabei die Berichte der Regionen (regio `s) dar (regiovisie). ${ }^{220}$ Das Zustandekommen dieser Berichte fällt in den Verantwortungsbereich der Provinzen und der vier großen Städte, die den Provinzen diesbezüglich gleichgestellt sind (Amsterdam, Den Haag, Rotterdam, Utrecht). ${ }^{221}$ Sie stellen Regeln auf, die das Erstellen des Berichts sicherstellen sollen. Hierbei kommt ihnen ein großer Spielraum zu. Zwingend ist jedoch, dass Patienten- und Versichertenorganisationen teilnehmen sowie Leistungserbringer, Krankenversicherer, Gemeinden und die Provinzen selbst. ${ }^{222}$ Diese sollen in eine Diskussion eintreten, an deren Ende ein Bericht steht, der dem Gesundheitsministerium als Informationsquelle dienen kann. Wenn die Beteiligten sich nicht einigen können, ist es möglich, die unter-

217 Kamerstukken II 27659 Nr.3: Herziening van het stelsel van overheidsbemoienis met het aanbod van zorginstellingen (Wet exploitatie zorginstellingen): Memorie van toelichting (Gesetzesbegründung) S. 4.

218 Wet exploitatie zorginstellingen: Memorie van toelichting (Gesetzesbegründung), (Fn. 217) S.

219 De Groot, Zorgbehoefte en capaciteitstekorten in zorginstellingen: Wie is verantwoordelijk?, in: Hubben/van Zenden, Het stelsel voorbij? Sturingsperikelen in de gezondheidszorg en jurisprudentie-overzicht, 2002, S. 49 (56).

220 Kamerstukken II 27659 Nr.3: Herziening van het stelsel van overheidsbemoienis met het aanbod van zorginstellingen (Wet exploitatie zorginstellingen): Memorie van toelichting (Gesetzesbegründung ) S. 36.

221 Kamerstukken II 27659 Nr.3: Herziening van het stelsel van overheidsbemoienis met het aanbod van zorginstellingen (Wet exploitatie zorginstellingen): Memorie van toelichting (Gesetzesbegründung ) S. 14.

222 Kamerstukken II 27659 Nr.3: Herziening van het stelsel van overheidsbemoienis met het aanbod van zorginstellingen (Wet exploitatie zorginstellingen): Memorie van toelichting (Gesetzesbegründung ) S. 14. 
schiedlichen Auffassungen darzustellen und auf diese Weise dem Ministerium mitzuteilen. ${ }^{223}$

Da diese Berichte für das Ministerium jedoch nicht verbindlich sind, sondern lediglich eine Informationsquelle, muss man hinsichtlich der verstärkten Nachfrageorientierung des neuen Systems skeptisch sein. Letztlich entscheidet das Gesundheitsministerium über die Kriterien, die an den Bau neuer und die Erweiterung bereits bestehender Krankenhäuser angelegt werden. Es ist jedoch ein Schritt auf einen höheren Einfluss der Einrichtungen, insbesondere auf ihre Kapazitäten und Investierungsmaßnahmen gemacht worden; der Staat wird sich mehr und mehr aus der Krankenhausplanung zurückziehen, den Krankenhäusern und Versicherungen mehr Freiräume und damit verbunden Verpflichtungen übertragen und somit die Steuerung ein Stück weit dem Wettbewerb überlassen. 224

\subsection{Zulassungsverfahren}

Ebenfalls eine Zugangsvoraussetzung zum Markt der Krankenhausversorgung stellt die Zulassung dar, die jede Einrichtung, die Leistungen der Gesundheitsversorgung anbietet, vom Krankenversicherungsrat haben muss, Art. 5 Abs. 2 Zulassungsgesetz für Krankenhäuser. Das Gesundheitsministerium erteilt selbst die Genehmigung, Art. 5 Abs. 3 Zulassungsgesetz für Krankenhäuser, wenn die Einrichtung zu einem Katalog solcher Einrichtungen in einem ausführenden Beschluss gehört und die angestrebte Art des Baus dort aufgezählt ist. Nach Art. 5.2 a) Ausführungsbeschluss Zulassungsgesetz für Krankenhäuser ${ }^{225}$ gehören Krankenhäuser mit Ausnahme militärischer Krankenhäuser zu diesen Einrichtungen, die eine Zulassung durch das Gesundheitsministerium bedürfen, wenn die Art des Baus in Art. 5.3 Ausführungsbeschluss Zulassungsgesetz für Krankenhäuser aufgeführt ist. Hier sind alle größeren Baumaßnahmen genannt, so z.B. die Errichtung einer neuen Einrichtung, ein Neubau, der einen Altbau ersetzt, eine Erweiterung eines bestehenden Gebäudes, wenn die Kosten höher sind als der Betrag, der nach dem Gesetz über die Tarife im Gesundheitswesen für Instandhaltungskosten bereit steht, ein ergänzender Bau, der die Ausweitung der Bettenanzahl bezweckt. Insgesamt decken die Aufzählungen derart große Bereiche ab, dass es der Grundsatz und nicht die Ausnahme sein dürfte, dass die Zulassung durch das Gesundheitsministerium und nicht durch den Krankenversicherungsrat erteilt wird. Da dieser aber auch dem Gesundheitsministerium untersteht und es keinerlei Einflussnahme von Interessenvertretungen oder

223 Kamerstukken II 27659 Nr.3: Herziening van het stelsel van overheidsbemoienis met het aanbod van zorginstellingen (Wet exploitatie zorginstellingen): Memorie van toelichting (Gesetzesbegründung ) S. 14.

224 Kamerstukken II 27659 Nr.3: Herziening van het stelsel van overheidsbemoienis met het aanbod van zorginstellingen (Wet exploitatie zorginstellingen): Memorie van toelichting (Gesetzesbegründung) S. 4.

225 Besluit van houdende uitvoering van einige bepalingen van de Wet toelating zorginstellingen (Uitvoeringsbesluit Zulassungsgesetz für Krankenhäuser). 
von regionalen Gruppierungen zulässt, ist der Unterschied nicht derart erheblich wie es auf den ersten Blick den Anschein hat. Der Krankenversicherungsrat ist eine öffentlichrechtliche Einrichtung, die Rechtspersönlichkeit besitzt, Art. 58 Abs. 1 Krankenversicherungsgesetz, und untersteht dem Gesundheitsministerium. So kann das Gesundheitsministerium ein Reglement hinsichtlich seiner Arbeitsweise aufstellen, Art. 62 Krankenversicherungsgesetz. Ebenso benennt und entlässt der Gesundheitsminister den Vorsitzenden und die übrigen Mitglieder des Krankenversicherungsrates, Art. 59 Abs. 2 Krankenversicherungsgesetz. Die Benennungen richten sich nach Sachkenntnis und Erfahrung, Art. 59 Abs. 3 Krankenversicherungsgesetz.

Die Erteilung der Zulassung erfolgt nach einem gesetzlich geregelten Verfahren: Wenn ein Antrag auf Zulassung beim Gesundheitsministerium oder beim Krankenversicherungsrat gestellt wird, wird zunächst der Rat für den Bau von Krankenhäusern ${ }^{226} \mathrm{zu}$ Rate gezogen, Art. 7 Abs. 2 Zulassungsgesetz für Krankenhäuser. Der Rat für den Bau von Krankenhäusern ist eine öffentlich-rechtliche Einrichtung, die Rechtspersönlichkeit besitzt, Art. 19 Abs. 1 Zulassungsgesetz für Krankenhäuser. Ebenso wie auch der Krankenversicherungsrat ist der Rat für den Bau von Krankenhäusern dem Gesundheitsministerium unterstellt, das den Vorsitzenden und die übrigen Mitglieder benennt und entlässt, Art. 20 Abs. 2 Zulassungsgesetz für Krankenhäuser. Das Gesundheitsministerium muss dem Arbeitsprogramm, das der Rat für den Bau von Krankenhäusern jährlich aufstellt, ebenso wie dem Finanzplan und den Verwaltungskosten zustimmen, Art. 23, 24, 26 Zulassungsgesetz für Krankenhäuser.

Die Voraussetzungen, die der Rat für den Bau von Krankenhäusern prüft, muss er schriftlich festlegen und durch das Gesundheitsministerium bewilligen lassen, Art. 10 Abs. 1 Zulassungsgesetz für Krankenhäuser. Das Gesundheitsministerium verweigert die Bewilligung, wenn die Voraussetzungen nicht zu einem effektiven, für jedermann zugänglichen und ausgewogenen System der Gesundheitsversorgung passt, Art. 10 Abs. 2 Zulassungsgesetz für Krankenhäuser. Was ein derartiges System ausmacht, geht aus dem Bericht hervor, den das Gesundheitsministerium nach Art. 3 Abs. 1 Zulassungsgesetz für Krankenhäuser alle vier Jahre aufstellt.

Wenn das Gesundheitsministerium eine Zulassung erteilt hat, ist in einem zweiten Schritt eine Genehmigung durch den Rat für den Bau von Krankenhäusern erforderlich, Art. 11 Abs. 1 Zulassungsgesetz für Krankenhäuser. Es erteilt die Genehmigung, wenn die vorgenannten Kriterien gegeben sind, Art. 11 Abs. 2 Zulassungsgesetz für Krankenhäuser.

Insgesamt ist zu ersehen, dass der Krankenhaussektor durch eine erhebliche staatliche Einflussnahme und Steuerung geprägt wird, die - zumindest derzeit noch - bis hin zur konkreten Bestimmung der Bettenanzahl eines Krankenhauses reicht. Durch diese starke Steuerung wird der betroffene Markt stark gelähmt, was nicht im Einklang mit den Zielen der Reformbestrebungen steht. Die Kräfte des Marktes sollen sich stärker

226 College bouw zorginstellingen (Cbz). 
verwirklichen können, die Beteiligten sollen selbstverantwortlich handeln, so dass ein nachfrageorientierter Markt entsteht. ${ }^{227}$ Die Umsetzung dieser Ziele soll schrittweise erfolgen, um durch diese grundlegenden Änderungen keine Versorgungsengpässe oder anderweitige Umsetzungsprobleme zu riskieren. Ein Schritt betrifft dabei die Auflockerung des bislang strikten und umfassenden Zulassungserfordernisses für Instandhaltungs- und Erweiterungsmaßnahmen. Nach dem Zulassungsgesetz für Krankenhäuser (Art. 5 Abs. 3) in Verbindung mit dem Ausführungsbeschluss zum Zulassungsgesetz für Krankenhäuser (Art. 5.3 c) ist für Instandhaltungsmaßnahmen dann keine Zulassung durch das Gesundheitsministerium erforderlich, wenn die damit verbundenen Kosten nicht höher sind als diejenigen im Gesetz über Tarife im Gesundheitswesen für Instandhaltungsmaßnahmen festgestellten. Hierdurch entsteht ein gewisser Freiraum für Krankenhäuser, auch Maßnahmen unabhängig vom Gesundheitsministerium durchzuführen. Eine Einflussnahme der Krankenhäuser auf ihre Kapazitäten ist hiermit zwar noch nicht gegeben, jedoch kann davon ausgegangen werden, dass entsprechende Regelungen noch folgen werden. ${ }^{228}$ Denn nur durch die eigene Steuerung können Einrichtungen zum wirtschaftlichen Handeln angeregt werden, womit auch eine flexible Reaktion auf einen veränderten Bedarf der Versicherten einhergeht. Damit könnte erheblichen Wartezeiten, die ein schon seit längerem akutes Problem in der niederländischen Gesundheitsversorgung darstellen, begegnet werden.

In die gleiche Richtung des flexibleren und wirtschaftlichen Handelns in eigener Regie geht die Auflockerung des strikten Verbots der Gewinnerzielungsabsicht für Krankenhäuser und sonstige Einrichtungen, Art. 5 Abs. 4 Zulassungsgesetz für Krankenhäuser. Auch hier wurde wiederum die stufenweise Neuordnung gewählt, indem die Einrichtungen, für die eine Gewinnerzielungsabsicht erlaubt sein soll, durch Beschluss bestimmt werden sollen, Art. 5 Abs. 4 Zulassungsgesetz für Krankenhäuser. Der Ausführungsbeschluss zum Zulassungsgesetz für Krankenhäuser sieht in Art. 3.1 nun gerade vor, dass Krankenhäuser nicht zu der Kategorie der vom Verbot der Gewinnerzielungsabsicht befreiten Einrichtungen gehören, Insofern hat es also bislang noch keine Änderungen gegeben. Aber auch hier ist beabsichtigt, den Kreis der von dieser Regelung befreiten Einrichtungen, mit der Zeit zu erweitern. ${ }^{229}$ Desweiteren könnte eine erlaubte

227 Kamerstukken II 27659 Nr.3: Herziening van het stelsel van overheidsbemoienis met het aanbod van zorginstellingen (Wet exploitatie zorginstellingen): Memorie van toelichting (Gesetzesbegründung ) S. 1.

228 Kamerstukken II 27659 Nr.3: Herziening van het stelsel van overheidsbemoienis met het aanbod van zorginstellingen (Wet exploitatie zorginstellingen): Memorie van toelichting (Gesetzesbegründung ) S. 7, 17.

229 Die ursprüngliche Gesetzesbegründung geht noch von einem strikten Verbot der Gewinnerzielungsabsicht aus, Kamerstukken II 27659 Nr.3: Herziening van het stelsel van overheidsbemoienis met het aanbod van zorginstellingen (Wet exploitatie zorginstellingen): Memorie van toelichting (Gesetzesbegründung ) S. 19 f; Von der Einführung einer Gewinnerzielungsabsicht und ihrer späteren Ausweitung geht jedoch aus: Beleidsvisie Wet toelating zorginstelllingen (Zulassungsgesetz für Krankenhäuser) vom 3. juni 2005 S. 2 f. 
Gewinnerzielungsabsicht auch über das Einfallstor einer neuen Rechtsform für Krankenhäuser ermöglicht werden, wie oben ${ }^{230}$ bereits erläutert wurde.

\subsection{Finanzierung}

Die Kosten für die Krankenhausversorgung stellen mit ca. $30 \%$ einen substantiellen Anteil an den Gesamtkosten der Gesundheitsversorgung der Bevölkerung dar. ${ }^{231}$ Diese Zahl ist in den letzten 15 Jahren mehr oder weniger konstant geblieben, obwohl es in dem Bemühen um Kostensenkung zu einer nennenswerten Konzentration im Krankenhaussektor gekommen ist. ${ }^{232}$ Hier sind vor allem auch viele kleine Krankenhäuser geschlossen worden. ${ }^{233}$

Vor diesem Hintergrund ist es von grundlegender Bedeutung, auf welche Weise die Krankenhausversorgung finanziert wird.

Ein Einschnitt hat in der Krankenhausfinanzierung 1983 stattgefunden, als in dem Bestreben um Kostenbeherrschung die Budgetierung eingeführt wurde. Für jedes Krankenhaus wurde im Vorfeld eine Pauschale festgesetzt, mit der es seine Ausgaben decken musste. Mehrausgaben gingen zu Lasten des Krankenhauses und Mehreinnahmen durften den krankenhauseigenen Reserven hinzugefügt werden. Im Jahr 1988 hat es eine grundlegende Änderung der Budgetierung hin zu einem funktionsgerichteten System (functiegerichte budgetiering, FB-Systematik) gegeben, das im Wesentlichen auch heute noch gilt. 234

Im Rahmen der FB-Systematik wird zwischen vier Kostenarten unterschieden ${ }^{235}$ :

- Locatiegebonden kosten, diese beziehen sich auf die Kapitallasten, den Unterhalt der Gebäude und die Nutzung des Gebäudes.

- Beschikkbarheitskosten, also diejenigen festen Kosten, die für das Bereithalten der Versorgung aufgewendet werden und insofern nicht variieren. Gemessen werden diese Kosten an der Anzahl der Einwohner im Einzugsgebiet eines Krankenhauses. Sie machen ca. $10 \%$ des Krankenhausbudgets aus.

- Capaciteitsgebonden kosten, die semi-feste Kosten umfassen, die für das Bereithalten der Versorgung aufgewendet werden und nur in geringem Maße variieren.

230 II 3.1.

231 Maarse/Groot/van Merode/Mur-Veeman/Paulus, Marktwerking in de ziekenhuiszorg, een analyse van de Mogelijkheiden en effecten, 2002, S. $23 \mathrm{f}$.

232 Maarse/Groot/van Merode/Mur-Veeman/Paulus Marktwerking in de ziekenhuiszorg, een analyse van de Mogelijkheiden en effecten, 2002, S. $24 \mathrm{f}$.

233 Vandermeulen, Ziekenhuisen: medisch bedrijven in: Breit/Elsinga/Kasdrop/San-ders/Vandermeulen/Weevers, Handboek Structuur en financiering gezondheidszorg, Bd. 3 2005, III 2.1-2.

234 Insgesamt zur FB-Systematik: Maarse/Groot/van Merode/Mur-Veeman/Paulus Marktwerking in de ziekenhuiszorg, een analyse van de Mogelijkheiden en effecten, 2002, S. 29 ff; Kamerstukken II Nr. 27490 Nr. 2: Bekostiging ziekenhuiszorg, Rapport, Beilage 1, S. 24 ff.

235 Vandermeulen, Ziekenhuisen: medisch bedrijven in: Breit/Elsinga/Kasdrop/San-ders/Vandermeulen/Weevers, Handboek Structuur en financiering gezondheidszorg, Bd. 3 2005, III 2.1-17. 
Maßstab für diese Kosten sind die Anzahl der Betten und der Spezialisteneinheiten. Sie machen ca. $20 \%$ des Krankenhausbudgets aus.

- Productiegebonden kosten, variable Kosten, die abhängig sind von den Vereinbarungen zwischen den Krankenhäusern und den Krankenversicherungen, die vom CTG bewilligt werden. Sie umfassen ca. $40 \%$ des Krankenhausbudgets.

Für die Kosten pro Bett und Spezialisteneinheit sowie für diejenigen pro Einwohner im Einzugsgebiet setzt der Rat für Tarife im Gesundheitswesen jährlich einen Tarif fest. Insgesamt sind die Kosten der Krankenhausversorgung also einerseits von den hoheitlichen Festsetzungen des Rats für Tarife im Gesundheitswesen und andererseits von den Verhandlungen mit den Krankenversicherern abhängig. 236

In den letzten Jahren hat die Budgetierung im Krankenhaussektor immer mehr Kritik erfahren, so dass es Bestrebungen für eine Reform in diesem Bereich gibt. ${ }^{237}$

Hauptkritikpunkt ist zumeist die Diskrepanz zwischen den abgesprochenen Leistungen und den tatsächlich erbrachten. ${ }^{238}$ Zwar sind die Absprachen zwischen den Krankenhäusern und den Krankenversicherern der Ausgangspunkt für die Budgets, aber die Krankenhäuser haben immer mehr neue Versorgungsformen integriert, durch die das Budget umgangen wird, wie beispielsweise die integrierte Versorgung.

Ein weiteres Argument ist der fehlende Bezug zwischen den Tarifen des FB-Systems und den tatsächlichen Kosten, der sich vor allem aus den vielfältigen Kürzungen ergibt. 239 Die Folge hiervon ist, dass für die Krankenhäuser kein ausreichender Anreiz für eine effiziente Versorgung besteht.

Schließlich wird kritisiert, dass die FB-Systematik neuen und effizienteren Versorgungsformen entgegensteht. 240 Auch wenn es Krankenhäusern gelingt, Leistungen kostengünstiger anzubieten, etwa weil sie verstärkt auf moderne Versorgungsformen zurückgreifen, haben sie hierdurch keinen Vorteil. Sie unterliegen trotzdem genauso wie Krankenhäuser, die nicht derart effizient arbeiten, der generellen Kürzung bei Über-

236 Nachdem das Budget festgesetzt worden ist, muss auch die Finanzierung dieses Budgets geregelt werden. Dies geschieht über die Festsetzung der Tarife, die das Krankenhaus in Rechnung stellen kann. Diese werden landesweit festgestellt, gelten also für alle Krankenhäuser, wenn sie wohl auch nicht für alle Bedeutung entfalten werden, da nicht jedes Krankenhaus alle Leistungen anbietet. Insgesamt gibt es ca. 1.600 solcher Tarife.

Eine Besonderheit stellt der Pflegetarif dar. Diese werden anders als die übrigen Tarife unmittelbar aus dem festgestellten Budget abgeleitet. Vom festgestellten Budget werden die übrigen Tarife in Abzug gebracht und der Rest durch die Pflegetage dividiert, so dass sich der Pflegetarif ergibt. Da die Einnahmen aus den Tarifen sich zwischen den einzelnen Krankenhäusern unterscheiden, ergeben sich auch unterschiedliche Pflegetarife.

Bei einer Überschreitung des macro-Budgets kann der Rat für Tarife im Gesundheitswesen auf Anweisung des Gesundheitsministers die Budgets kürzen, indem für alle Krankenhäuser die Tarife verringert werden, eine sog. "generelle Kürzung".

237 Kamerstukken II Nr. 27490 Nr. 2: Bekostiging ziekenhuiszorg, Rapport, Beilage 1.

238 Kamerstukken II Nr. 27490 Nr. 2: Bekostiging ziekenhuiszorg, Rapport, Beilage 1, S. 11.

239 Kamerstukken II Nr. 27490 Nr. 2: Bekostiging ziekenhuiszorg, Rapport, Beilage 1, S 11.

240 Kamerstukken II Nr. 27490 Nr. 2: Bekostiging ziekenhuiszorg, Rapport, Beilage 1, S. 12. 
schreitung des macro-Budgets. Insofern fehlt es an Anreizen für das Einsetzen von neuen und effizienten Versorgungsformen.

Vor diesem Hintergrund sind die betroffenen Parteien ${ }^{241}$ seit 1994 damit beschäftigt, ein neues Finanzierungssystem zu erarbeiten. Dieses soll auf der Grundlage von Diagnose Behandeling Combinaties (DBC), funktionieren, d.h. die FB-Systematik mit einem Gesamtbudget, aus dem alle Krankenhauskosten gezahlt werden müssen, soll schrittweise durch ein Budget für die Behandlung eines Patienten mit einer bestimmten Krankheit, also einer Fallpauschale, abgelöst werden. ${ }^{242}$ Am 01.01.2005 sind nun die DBC's als Finanzierungsgrundlage eingeführt worden, von denen es derzeit ca. 30.000 gibt. 243

Die Gesundheitswettbewerbsbehörde kann in Form von Richtlinien Leistungsbeschreibungen mit und ohne Tariffestsetzungen aufstellen, wozu beispielsweise auch DBC`s gehören, Art. 10a i.V.m. Art. 11 Gesetz über Tarife im Gesundheitswesen. Diese haben dann landesweit Geltung. Um die Aktualität der DBC`s zu gewähren, wurde im Juli 2004 eine Stiftung gegründet, die sich als unabhängiges Organ ausschließlich mit der Aktualisierung der DBC`s beschäftigt und so der Gesundheitswettbewerbsbehörde Vorschläge unterbreiten kann. ${ }^{244}$ Sie kann aber nicht selbst DBC's ändern, das obliegt ausschließlich der Gesundheitswettbewerbsbehörde.

Seit 2005 wird der Gesundheitsmarkt hinsichtlich de Finanzierung hat in ein sog. Aund ein B-Segment unterteilt. Im A-Segment bleibt es bei der FB-Budgetierung oder soweit vorhanden bei festen Tarifen für die jeweiligen DBC's, die von der Gesundheitswettbewerbsbehörde festgesetzt werden. ${ }^{245}$ Dagegen werden die Preise im BSegment, das circa $20 \%$ der Krankenhausleistungen umfasst, zwischen den Krankenhäusern und den Krankenversicherern frei ausgehandelt. 246 Die Folge sind Unterschiede in der Preisgestaltung der Krankenhausleistungen, wodurch die Konkurrenz um Verträge mit den Krankenversicherungen verschärft werden könnte. Für das Jahr 2006 ist

241 Berufsverband der Spezialisten (Orde van Medisch Spezialisten), der Krankenhausverband (Nederlandse Vereniging van Ziekenhuisen) und der Dachverband der Krankenversicherer (Zorgverzekeraars Nederland).

242 Maarse/Groot/van Merode/Mur-Veeman/Paulus, Marktwerking in de ziekenhuiszorg, een analyse van de Mogelijkheiden en effecten, 2002, S. 43; Zuurbier/Krabbe-Alkemade, Onderhandelen over DBC`s, 2004.

243 Durch das WTG ExPres und das HOZ sind die erforderlichen Änderungen des Krankenkassengesetz(Art. 44 ff Krankenkassengesetz) und des WTG (insbesondere Art. 10 a WTG) eingeführt worden. Wet van 9 december 2004 tot wijziging van de Ziekenfondswet, de Algemene Wet Bijzondere Ziektekosten en enkele andere wetten, in verband met herziening van het overeenkomstenstelsel in de sociale ziektekostenverzekering alsmede enkele andere wijziging (Wet herziening overeenkomstenstelsel zorg (HOZ), Stb. 2005, 27 und Wet van 9 december 2004 tot wijziging van de Wet tarieven gezondheidszorg in verband met experimenten, prestatiebekostiging en einige andere maatregelen (WTG ExPres), Stb. 2005, 24.

244 CTG/ZAio, Visiedocument ziekenhuiszorg, Analyse en aanbevelingen voor concurrentie in het Bsegment, 2005, S. 26.

245 Nobels, Prijsconcurrentie tussen ziekenhuis en ZBC, 2005, S. 30.

246 Nobels, Prijsconcurrentie tussen ziekenhuis en ZBC, 2005, S. 30. 
zu ersehen, dass im Vergleich zum Vorjahr keine Kostensteigerung im B-Segment zu verzeichnen war. ${ }^{247}$ Es ist jedoch abzuwarten, ob dies ein bleibendes Ergebnis sein wird und ob es sich zu Lasten der anderen Leistungsbereiche auswirkt.

\subsection{Staatlicher Einfluss}

Die Finanzierung der Krankenhäuser durch die FB-Systematik, die schrittweise durch das DBC-System abgelöst wird, wurde bereits oben 248 eingehend erläutert. Offen geblieben ist jedoch die Beteiligung des Staates. Durch das ehemalige Gesetz über Krankenhausleistungen wurde die Angebotsseite der Krankenhausversorgung stark hoheitlich gesteuert. Dies sollte durch das Inkrafttreten des Zulassungsgesetzes für Krankenhäuser 2006 an die Gesamtentwicklung im Gesundheitswesen, die den Beteiligten größere Freiräume verschafft, angepasst werden. Die Krankenhäuser sollten einen größeren Einfluss, aber auch eine größere Verantwortung, hinsichtlich der Investierungsbeschlüsse erhalten. ${ }^{249}$ Der Staat sollte lediglich Rahmenvorgaben machen. Statt eines Budgets, das ex ante erteilt wird und unter Umständen nach Ablauf eines Kalenderjahres nachkalkuliert wird, werden die Kapitallasten wie die Abschreibungen von Baumaßnahmen in die DBC's einbezogen. Dies sind ca. $10 \%$ des jährlichen Umsatzes. ${ }^{250}$ Während einer Übergangszeit werden die Unterkunftskosten noch nachträglich ausgeglichen, später soll dies jedoch entfallen. ${ }^{251}$ In dieser Phase werden die Krankenhäuser dann völlig risikotragend sein. Entsprechend wird dann auch das Genehmigungsverfahren vor dem Rat für den Krankenhausbau schrittweise entfallen. Um einem Insolvenzrisiko vorzubeugen und die Finanzierung durch Banken zu erleichtern, ist die Bildung von Rücklagen vorgesehen. Daneben gibt es aber auch noch einen Garantiefonds ${ }^{252}$ für den Gesundheitssektor, der in solchen Fällen ebenfalls für Ausgleich sorgt. ${ }^{253}$ Dieser Prozess soll 2012 abgeschlossen sein. 254

Der Vorteil des angestrebten Systems liegt in der Flexibilität der Krankenhäuser, die viel einfacher als gegenwärtig auf Veränderungen bei der Nachfrage eingehen können. Der Nachteil wird aber sein, dass Kapitalgeber ausgesprochen vorsichtig mit ihren In-

247 NZa, Monitor Ziekenhuiszorg 2007, S. 7.

248 S. $18 \mathrm{ff}$.

249 Linders, Wet toelating zorginstellingen, 2006, S. 10.

250 Linders, Wet toelating zorginstellingen, 2006, S. 12.

251 Linders, Wet toelating zorginstellingen, 2006, S. 12; ausführlich hierzu: Kamerstukken 2004/05, 27659, Nr. 52: Kapitaallastenbrief.

252 Waarboorgfonds.

253 Linders, Wet toelating zorginstellingen, 2006, S. 13.

254 Rijken, De Diagnosebehandelingcombinatie (DBC) als instrument voor concurrentie tussen ziekenhuizen, Zorg \& Financiering 2006, S. 8 (17); Scheerder, Integrale tarieven en kapitaallasten, Zorg \& Financiering, 2005, Nr. 4 S. 11-19. 
vestitionen umgehen werden, wenn die Deckung der Kapitallasten nicht mehr durch ein garantiertes Budget sichergestellt ist. ${ }^{255}$

\subsection{Wettbewerbswidrige Absprachen zwischen Krankenhäusern}

Mit zunehmendem Wettbewerb zwischen den Krankenhäusern wird auch die Frage bedeutsam, ob und in wieweit die gemeinschaftliche Tätigkeit von verschiedenen Krankenhäusern am Wettbewerbsrecht gemessen wird. Krankenhäuser werden in den Niederlanden heute als wirtschaftlich handelnde Unternehmen eingestuft und unterliegen insofern dem Wettbewerbsrecht. ${ }^{256}$ Nun widersprechen aber nicht alle kollektiven Verhandlungen und Absprachen dem Wettbewerbsgesetz, vielmehr haben sich durch die Beschlüsse der niederländischen Wettbewerbsbehörde gewisse Richtlinien herausgebildet. Hinsichtlich der Krankenhäuser galt in der Vergangenheit, dass sie aufgrund des hohen Maßes an staatlicher Regulierung nicht tatsächlich miteinander konkurrieren können, so dass das Wettbewerbsgesetz nicht anwendbar war. ${ }^{257}$ In zunehmendem Maße erkennt die Wettbewerbsbehörde aber, dass sich das Krankenhauswesen und seine staatliche Regulierung in Bewegung befinden und wendet das Wettbewerbsrecht an. Das gelte insbesondere, wenn die Preise zur Verhandelbarkeit freigegeben sind und der Kontrahierungszwang für Krankenhäuser abgeschafft wird. ${ }^{258}$

Ein typisches Beispiel sind Fusionsbestrebungen zwischen Krankenhäusern, die von der Wettbewerbsbehörde immer wieder am Wettbewerbsgesetz gemessen werden. So ist die Wettbewerbsbehörde eingeschritten, als die stichting Ziekenhuis Walcherern und die stichting Oosterscheldeziekenhuizen - zwei Allgemeinkrankenhäuser - eine gemeinsame Holding gründen wollten, die diese die Verwaltung für beide Unternehmen übernehmen sollte. ${ }^{259}$ Die beiden Krankenhäuser werden nach der Beurteilung der Wettbewerbsbehörde nicht auf unterschiedlichen Märkten aktiv, insbesondere auch nicht in regionaler Hinsicht, weil die Reisezeiten zwischen den Häusern, aber auch von den jeweiligen Einzugsgebieten zu den Krankenhäusern relativ kurz seien. Sie sind die einzigen Anbieter von klinischer Versorgung in der Region Midden-Zeeland. Hinzukommt

255 Vandermeulen, Ziekenhuizen: medisch bedrijven in: Breit/Elsinga/Kasdrop/San-ders/Vandermeulen/Weevers, Handboek Structuur en financiering gezondheidszorg, Bd. 3, III 2.1-24.

256 Gaasbeek in: van de Gronden/Mortelmans, Mededinging en niet-economische belangen, 2001, S. 66f.

257 Besluiten d-g NMa van 14 maart 2002 in der Sache 2877/Sint Antonius Ziekenhuis - Mesos Medisch Centrum, van 24 juli 2001 in der Sache 2589/Diaconessenhuis Eindhoven - Sint Joseph Ziekenhuis und vom 5 juni 2998 in der Sache 165/Sophia Ziekenhuis - Ziekenhuis/Verpfleeghuis de Weezenlanden.

258 Besluit van de d-g NMa van 14 maart 2002 in der Sache 2877/Sint Antonius Ziekenhuis - Mesos Medisch Centrum, Rn. 10.

259 Besluit van de Raad van Bestuur van de Nederlandse Mededingingsautoriteit als bedoeld in artikel 37 van de Mededingingswet, Nummer 5196/47, in zaak 5196/ Ziekenhuis Walcheren - Stichting Oosterscheldeziekenhuizen. 
dass nach den Ausführungen der Wettbewerbsbehörde die Parteien nicht hinreichend belegt hätten, dass die gemeinsame Holding erhebliche Effizienzvorteile brächte, die auch den Patienten zugute käme. ${ }^{260}$

\section{Wettbewerb der Krankenversicherungen untereinander}

Das Verhältnis der Krankenversicherungen untereinander wird in wettbewerblicher Hinsicht wesentlich von der Krankenversicherungsreform 2006, also dem Inkrafttreten des Krankenversicherungsgesetzes, geprägt. Die relevanten Elemente sind die Konkurrenz um Versicherte, wettbewerbliche Folgen aus dem Nebeneinander von streng regulierter Basis- und freierer Zusatzversicherung, der Risikostrukturausgleich sowie Konzentrationsbewegungen der Krankenversicherungen untereinander.

\subsection{Konkurrenz um die Versicherten}

Seit dem Bericht der Kommission Decker in 1987261 werden vermehrt Wettbewerbselemente in das Gesundheitssystem implementiert. Dabei wird dem Wettbewerb kein Selbstzweck beigemessen, sondern er wird als Mittel zur Erreichung des grundsätzlichen Ziels der Gesundheitspolitik, einer für jeden zugängliche Gesundheitsversorgung bei erfolgreicher Kostenbeherrschung angesehen. ${ }^{262}$ Da es schwierig ist, Wettbewerb von Patientenseite einzuführen oder zu verstärken, da diese im Verhältnis zu den Krankenhäusern ein Informationsdefizit aufweisen und darüber hinaus auch noch örtlich gebunden sind, ist der Ausgangspunkt der vergangenen Reformen die Seite der Krankenversicherer. Diesen kommt eine Position zu, die stark und unabhängig genug ist, um wettbewerblich agieren zu können. Ihre Stellung bietet die Möglichkeit, aktiv Leistungen „einzukaufen“ und dabei entsprechend verantwortungsvoll auszuwählen, soweit das System die Möglichkeiten hierfür bietet. Sie verhandeln mit den Krankenhäusern über die Leistungen, die diese bereitstellen und die Beträge, die dies hierfür erhalten. Wie oben bereits erläutert, sind die Krankenversicherer bislang jedoch noch verpflichtet, mit allen Krankenhäusern, die dies wünschen, Verträge zu schließen. Aber auch im Verhältnis zu den Versicherten sind Spielräume für die Krankenversicherungen geschaffen worden, die Wettbewerb ermöglichen. So haben sie Gestaltungsmöglichkeiten bei den Leistungen, die sie anbieten, soweit diese über das Standardleistungspaket hinausgehen, und sie dürfen den pauschalen Anteil der Prämie selbstständig festsetzen.

260 Zaak 5196/ Ziekenhuis Walcheren - Stichting Oosterscheldeziekenhuizen (Fn. 259) S. 21.

261 Ausführlich dazu: Kötter, Von alten und neuen Rezepten, Radikalkuren und Wechselbädern - die Reformen des niederländischen Gesundheitssystems, ZIAS 1998, $391 \mathrm{ff}$.

262 Gaasbeek, Mededingingswet en de Zorgsector in :van de Gronden/Mortelmans, Mededinging en niet-economische belangen, 2001, S. 63 . 
Hierdurch sind Möglichkeiten geschaffen worden, um miteinander um Versicherte zu konkurrieren.

Ein wichtiges Wettbewerbsparameter ist die Aufhebung der Dualität zwischen gesetzlicher und privater Vollversicherung durch die grundlegende Reform des Krankenversicherungssystems 2006 mit der Folge, dass alle Krankenversicherungsunternehmen um die Versicherten konkurrieren und nicht lediglich innerhalb der gesetzlichen Krankenversicherung oder innerhalb der privaten Krankenversicherung. Ebenfalls die Organisation der Krankenversicherung als private Unternehmen, nämlich Schadenversicherungen, die dem Gesetz über die Aufsicht über Versicherungsunternehmen von 1993 (Wet toezicht verzekeringsbedrijf 1993) unterworfen sind, soll der Förderung von Wettbewerb zwischen den Unternehmen dienen, wobei aber nicht verkannt werden darf, dass die niederländischen Krankenversicherungen strengen öffentlich-rechtlichen Vorgaben zur Erreichung des sozialen Zwecks der Krankenversicherung unterliegen, so dem Annahmezwang und dem festgelegten Leistungsumfang der Basisversicherung. ${ }^{263}$ Mit der Neuordnung der Krankenversicherungsorganisation wollte die niederländische Gesetzgeber vor allem sein vornehmlichstes Ziel verfolgen, nämlich durch die Förderung von Wettbewerb zwischen den Krankenversicherungsunternehmen eine möglichst effiziente und patientenfreundliche Versorgung der Bevölkerung zu erreichen. ${ }^{264}$

Die Entscheidung, ob ein Versicherungsunternehmen, das Krankenversicherungsgesetz ausführen will und entsprechend eine Basisversicherung anbieten möchte, liegt in erster Linie allein bei diesem Unternehmen. Zur Zeit agieren 32 Krankenversicherungsunternehmen auf dem niederländischen Markt. sie müssen lediglich die folgenden Voraussetzungen erfüllen:

- Es muss der gesetzlich vorgeschriebenen Versorgungspflicht nachkommen, die Verwaltung muss so ausgestaltet sein, dass sie den Risikoausgleich zwischen den verschiedenen Krankenversicherungsunternehmen erlaubt,

die Krankenversicherung wird im gesamten Gebiet der Niederlande angeboten (Ausnahme: die Versicherung hat weniger als 850.000 Versicherte),

den Versicherten wird ein redlicher Einfluss in die Ausführung der Krankenversicherung gewährleistet.

Die Konkurrenz zwischen den Krankenversicherungen wird durch das Krankenversicherungsgesetz in erster Linie durch verschiedene Möglichkeiten für die Krankenversicherer erreicht, sich gegenüber den Versicherten voneinander zu unterscheiden, so dass ihnen eine wirkliche Auswahlentscheidung mit verschiedenen Varianten offen steht. Eines der wichtigsten Unterscheidungskriterien ist die pauschale Prämie, die die Krankenversicherungen eigenständig festsetzen dürfen. Nach einer Umfrage war für 33\% der

263 Kamerstukken 2003/2004, 29763 Nr. 3: Regeling van een sociale verzekering voor geneeskundige zorg ten behoeve van de gehele bevolking (Zorgverzekeringswet), Memorie van toelichting (Gesetzesbegründung) S. 25.

264 Kamerstukken II 29763 Nr. 3: Regeling van een sociale verzekering voor geneeskundige zorg ten behoeve van de gehele bevolking (Zorgverzekeringswet) - Memorie van toelichting, S. 25. 
Versicherten für ihren Wechsel dies finanzielle Kriterium ausschlaggebend. ${ }^{265} \mathrm{Im}$ Jahr 2006 gab es eine Spanne der pauschalen Prämien von 990 EUR bis zu 1.172 EUR im Jahr. ${ }^{266}$ Dass hierin von den Versicherten durchaus ein Kriterium zum Wechsel der Krankenversicherung gesehen wird, zeigt unter anderem die hohe Wechselbereitschaft. Im Jahr 2006 haben 18\% der Niederländer ihre Krankenversicherung gewechselt, während 2004 lediglich 2,4\% der gesetzlich Versicherten gewechselt haben und 8,6\% der privat Versicherten. 267 Insofern ist eine deutliche Steigerung zu erkennen.

Aber neben der Prämie können sich die Versicherungen auch durch die angebotenen Leistungsarten unterscheiden. Zwar ist der Leistungsinhalt gesetzlich vorgeschrieben, aber die Art und Weise der Erbringung steht den Krankenversicherungen frei, nämlich ob sie Kostenerstattung, Sachleistung oder sogar eine Mischung hiervon anbieten wollen, Art. 11 Abs. 1 Krankenversicherungsgesetz. Hier ließ sich im letzten Jahr ein deutlicher Trend zu den Kostenerstattungstarifen verzeichnen, obwohl diese gegenüber den Sachleistungspolicen etwas teurer sind. ${ }^{268}$ Erklären lässt sich dies wohl durch den Umstand, dass in den Niederlanden vor der Reform 2006 in der gesetzlichen Krankenversicherung keine Kostenerstattungstarife angeboten wurden und damit eine freiere Wahl des behandelnden Arztes verbunden ist.

Daneben sind auch mögliche Selbstbehalte ein denkbares Kriterium für die Versicherten. Allerdings sind sie nicht sehr beliebt bei den Versicherten. 96,3\% haben im Jahr 2006 eine Basisversicherung ohne Selbstbehalt gewählt. ${ }^{269}$ Lediglich innerhalb von Gruppenversicherungen kommen Selbstbehalte etwas häufiger vor. Hierüber wird also kein nennenswerter Wettbewerb stattfinden.

Nicht zu unterschätzen ist aber auch der wettbewerbliche Vorteil, den sich Krankenversicherungsunternehmen durch das Angebot von Zusatzversicherungen zu der Basisversicherung verschaffen können. Zwar darf das Angebot einer Zusatzversicherung nach dem Krankenversicherungsgesetz nicht vom Abschluss einer Basisversicherung abhängig gemacht werden, aber viele Versicherte neigen aus Praktikabilitätsgründen doch dazu, alle Krankenversicherungen bei einem Unternehmen abzuschließen. Kurz nach Inkrafttreten kam es immer wieder (bei 1/8 der Verträge) zu Verstößen gegen dieses Kopplungsverbot in Verträgen der Krankenversicherungen, aber hiergegen ist die

265 NZai.o., De tussenstand op de zorgverzekeringsmarkt, 2006, S. 12.

266 NZai.o., De tussenstand op de zorgverzekeringsmarkt, 2006, S. 12; ausführlich: Walser, Ziel erreicht? Erste Ergebnisse der niederländischen Reform des Krankenversicherungssystems, Die BKK 2006, S. 394, 396.

267 NZai.o., De tussenstand op de zorgverzekeringsmarkt, 2006, S. 16; ausführlich: Walser, Erste Ergebnisse der niederländischen Reform des Krankenversicherungssystems, Die BKK 2006, S. 394, 396.

268 NZai.o., De tussenstand op de zorgverzekeringsmarkt, 2006, S. 12.

269 NZai.o., De tussenstand op de zorgverzekeringsmarkt, 2006, S. 54. 
Gesundheitswettbewerbsbehörde eingeschritten, weil es die Mobilität der Versicherten auf dem Krankenversicherungsmarkt beeinträchtigt. ${ }^{270}$

Es ist also zu sehen, dass die Krankenversicherungsunternehmen verschiedene Möglichkeiten haben, sich voneinander zu unterscheiden und so in Konkurrenz um die Versicherten zu treten. Dagegen ist es nicht möglich, dass Versicherer sich junge und gesunde Versicherte aussuchen. Insoweit gilt der Annahmezwang des Art. 3 Abs. 1 Krankenversicherungsgesetz. Darüber hinaus erfolgt ein Risikoausgleich zwischen den Versicherungen.

Diesen rechtlichen Unterscheidungsmöglichkeiten steht aber eine erhebliche Konzentration auf dem Krankenversicherungsmarkt entgegen, die auch eingehend von der niederländischen Gesundheitswettbewerbsbehörde untersucht worden ist. ${ }^{271}$ Die Anzahl der Versicherer hat sich von 33 Krankenversicherern 2006 aufgrund von Fusion auf 32 im Jahr 2007 verringert. ${ }^{272}$ Genau wie im Vorjahr lassen sich die Krankenversicherer auch 2007 in 14 Konzerne unterteilen, wobei die fünf größten Konzerne über 80 \% des Marktes bestimmen. ${ }^{273}$

\subsection{Risikostrukturausgleich}

Um den Krankenversicherungsunternehmen den Anreiz zur Risikoselektion zu nehmen, findet in den Niederlanden ein sehr ausdifferenzierter Risikoausgleich statt, Art. 32 ff Krankenversicherungsgesetz und Kapitel 3 des Beschlusses Krankenversicherung (Besluit zorgverzekering). Der Umfang beläuft sich auf eine Größenordnung von ca. 15 Mrd. EUR. ${ }^{274}$ Dieser Risikoausgleich gliedert sich in eine vor- und eine nachgelagerte Komponente. ${ }^{275}$ Bereits bei der Verteilung der Geldmittel durch den Krankenversicherungsrat aus dem Krankenversicherungsfonds, in den im wesentlichen die einkommensabhängigen Beiträge der Versicherten und der Staatszuschuss eingezahlt werden, wird ex ante die Risikostruktur der Krankenversicherungsunternehmen berücksichtigt mit der Zielsetzung, dass diese ihre Organisation und Verwaltung so effizient gestalten, dass sie den Versicherten niedrige Prämien anbieten können, um so viele Versicherte für sich zu gewinnen. Dabei werden jährlich die Schätzungen der Gesamtausgaben aus dem Staatshaushalt hinsichtlich der Kosten des Krankenversicherungsgesetzes sowie ein Risikomodell herangezogen. Mit diesem statistischen Modell wird eine Einschätzung der voraussichtlichen Kosten eines Krankenversicherers vorgenommen, wobei die erforderli-

270 NZai.o., De tussenstand op de zorgverzekeringsmarkt, 2006, S. 12; ausführlich: Walser, Ziel erreicht? Erste Ergebnisse der niederländischen Reform des Krankenversicherungssystems, Die BKK 2006, S. 394, 396.

$271 \mathrm{NZa}$, Monitor Zorgverzekeringsmarkt, S. $19 \mathrm{ff}$.

272 NZa, Monitor Zorgverzekeringsmarkt, S. 21.

273 NZa, Monitor Zorgverzekeringsmarkt, S. 22.

274 Beereport, De Zorgverzekeringswet en de Wet op de zorgtoeslag, Houten 2006, S. 80.

275 Ausführlich: Hamilton, Een zorgverzekering voor iedereen, 2005, S. 140 ff; Beereport De Zorgverzekeringswet en de Wet op de zorgtoeslag, Houten 2006, S. 80 ff. 
chen Daten der Versicherten zur Verfügung stehen (Arzneimittelverschreibungen, Alter, Geschlecht, Wohnort etc.). Durch die Kriterien Arzneimittelverschreibungen und Krankenhauseinweisung erhält man die Morbiditätsorientierung des Ausgleichs. Diese erfolgt zum einen durch Berücksichtigung der Arzneimittelverschreibungen, die in eine Arzneimittelkostengruppe (Famaciekostengroup, FKG), eingeordnet werden. Zum anderen tragen auch die Diagnosekostengruppen (diagnosekostengroepen, DKG) zur Morbiditätsorientierung bei. Sie basieren im Wesentlichen auf den Krankenhauseinweisungen in der Vergangenheit und sollen zu einem Ausgleich für chronisch kranke Versicherte führen.

Im Nachhinein erfolgt eine Kompensation, wenn die Schätzungen zu Ungenauigkeiten geführt haben. Diese soll zukünftig eingeschränkt werden, so dass das Kostenrisiko vermehrt bei den Versicherern liegt. ${ }^{276}$ Gemäß Art. 34 Krankenversicherungsgesetz soll die generelle Nachberechnung bis 2011 eingestellt werden. Gerade für die Krankenhausleistungen wird die Einhaltung dieses Zeitrahmens aber von der Flexibilisierung der Finanzierung insbesondere der Ausweitung des B-Segments abhängen.

\subsection{Zusatzversicherungen}

Neben der durch das Krankenversicherungsgesetz reglementierten Basisversicherung dürfen die Krankenversicherungsunternehmen aber auch Zusatzversicherungen anbieten, bei deren inhaltlicher und finanzieller Gestaltung sie noch freier sind, da lediglich die Vorschriften des Bürgerlichen Gesetzbuches über Versicherungen gelten, nicht aber die Regelungen des Krankenversicherungsgesetzes. Da die Krankenversicherer nunmehr alle Gewinn erzielen dürfen - den Krankenkassen vor 2006 war dies untersagt ist der Tätigkeitsbereich der Zusatzversicherungen durchaus interessant.

Die niederländische Gesundheitswettbewerbsbehörde hat ein besonderes Augenmerk auf die Verträge, die für die Zusatzversicherungen abgeschossen werden. Hier hat es zum Teil Klauseln gegeben, die den Abschluss der Zusatzversicherung an eine bestehende Basisversicherung vorgesehen haben, was gegen Art. 120 Krankenversicherungsgesetz verstößt. 277 Nach entsprechenden Hinweisen von der Gesundheitswettbewerbsbehörde sind diese Klauseln gestrichen worden.

\subsection{Konzentration}

Ziel der jüngsten Reform des Krankenversicherungssystems war die Stärkung des Wettbewerbs zwischen den Beteiligten des Krankenversicherungssystems. Demzufolge gewinnt auch die Aufsicht über das Verhalten der Akteure an Bedeutung, so im Bereich

276 Hamilton, Een zorgverzekering voor iedereen, 2005, S. 141; Beereport, De Zorgverzekeringswet en de Wet op de zorgtoeslag, Houten 2006, S. 86.

$277 N Z a$, De tussenstand op de zorgverzekeringsmarkt, 2006, S. 33. 
von Konzentrationsbildung und Fusionen zwischen den Krankenversicherungsunternehmen. Diese obliegen - wie bereits erläutert ${ }^{278}$ - der Zuständigkeit der niederländischen Wettbewerbsbehörde. Der Markt umfasste zu Beginn des Jahres 200633 Krankenversicherungsunternehmen, die das Krankenversicherungsgesetz ausführen. Dabei ist die Konzentration aber doch höher als man zunächst annehmen sollte, denn die Unternehmen sind in 14 Konzernen zusammengefasst, wobei zu den drei größten Konzernen (Menzis, Achmea und VGZ-IZA-Trias) 14 Versicherungsunternehmen gehören. ${ }^{279}$ Diese Konzentration wird von der Gesundheitswettbewerbsbehörde noch nicht als bedenklich eingestuft. 280

Erst am 9. Oktober 2006 hat die Wettbewerbsbehörde über die Meldung einer weiteren Konzentration entschieden. ${ }^{281}$ Hierbei kam sie zu dem Schluss, dass zwar eine Zunahme von Verfügungsgewalt (zeggenschap) festzustellen sei, die auch unter die Aufsicht der Wettbewerbsbehörde falle, aber dass nichts darauf hinweise, dass eine ökonomische Machtposition i.S.d. Wettbewerbsgesetz erreicht oder angestrebt werde. Es ging in dieser Entscheidung um den Zusammenschluss der größeren Krankenversicherungsunternehmen Delta Lloyd N.V., Onderlinge Waarborgmaatschappij Menzis Zorgverzekeraar U.A., und Onderlinge Waarborgmaatschappij Agis Zorgverzekeringen U.A. zu einer gemeinsamen Unternehmung, die das Krankenversicherungsgesetz ausführen sollte. In dem neu zu schaffenden Unternehmen sollten die drei Gründungsmitglieder ab 2008 in allen Entscheidungen von wirtschaftlich-strategischer Bedeutung ein Vetorecht haben. Aus diesem Vetorecht folgert die Wettbewerbsbehörde eine Verfügungsgewalt der drei Unternehmen i.S.d. Wettbewerbsgesetzes. Nach einer detaillierten Untersuchung der Marktes und des Einflusses der drei Unternehmen auf diesen Markt, kommt die Wettbewerbsbehörde jedoch zu dem Ergebnis, dass diese Verfügungsgewalt nicht zu einer ökonomischen Machtposition führen wird, die dem Wettbewerbsgesetz widersprechen würde. In ihre Erwägungen hat die Wettbewerbsbehörde auch einbezogen, dass zeitgleich über die Fusion von $V G Z$ und Univé entschieden wird, die voraussichtlich auch zulässig ist. ${ }^{282}$ Die beiden neuen Unternehmen werden dann zusammen mit Achmea und $C Z / O Z$ die vier größten Anbieter von Krankenversicherungen sein, die einen Marktanteil von $87 \%$ halten werden. Dies könnte zusammen zu einer ökonomischen Machtposition führen, die dem Wettbewerbsgesetz widersprechen könnte. Die Wettbewerbsbehörde prüft die Wahrscheinlichkeit einer solchen anhand von vier Kriterien:

- Einfachheit der Koordination hinsichtlich der Verständigung,

278 Oben I. 4.4.

279 Walser, Ziel erreicht? Erste Ergebnisse der niederländischen Reform des Krankenversicherungssystems, Die BKK 2006, S. 394.

$280 N Z a$, Monitor Ziekenhuiszorg 2007, S. 17f.

281 Besluit van de Raad van Bestuur van de Nederlandse Mededingingsautoriteit als bedoelt in artikel 37, eerste lid, van de Mededingingswet, Nummer 5682/47, zaak 5682/Delta Lloyd - Agis - Menzis.

282 Zaak 5682/Delta Lloyd - Agis - Menzis (Fn. 281) S. 16 f. 
- Kontrolle der Unternehmen,

- Disziplinierungsmechanismus bei abweichendem Verhalten,

- keine Beeinträchtigung der angestrebten Resultate durch Außenstehende.

Nach diesen Kriterien verneint die Wettbewerbsbehörde zu diesem Zeitpunkt die Wahrscheinlichkeit des Auftretens einer ökonomischen Machtposition. Das Argument hierbei ist, dass es nach der grundlegenden Reform und der laufenden Etablierung des neuen Systems keine stabile Marktsituation gibt, so dass die Koordination und Kontrolle auf Schwierigkeiten stößt. Die Disziplinierungsmaßnahmen und der Einfluss Dritter würden dann außer Frage stehen. ${ }^{283}$

\section{Zusammenfassung der Ergebnisse bezogen auf die Funktion und Rolle des Wettbewerbs}

Insgesamt lässt sich für die Niederlande erkennen, dass sich die Steuerung im Gesundheitswesen und ganz besonders im Bereich der Krankenhäuser im Wandel befindet. Während das System bis 2005 noch von einer starken normativen Regulierung und einem erheblichen staatlichen Einfluss geprägt war, was sich in der detaillierten Krankenhausplanung bis hin zur Festlegung der Bettenzahl der einzelnen Krankenhäuser sowie in der Finanzierung nach staatlichen Vorgaben und durch ein staatliches Organ festgesetzt zeigte, verschiebt sich diese normative Regulierung mehr und mehr zu einer Steuerung durch Wettbewerb, wobei der hoheitliche Einfluss nur in geringem Maße abnimmt, aber mehr kontrollierend und rahmensetzend geprägt ist, was sich vor allem in der Tätigkeit der Gesundheitswettbewerbsbehörde, aber auch der Wettbewerbsbehörde zeigt.

Im Verhältnis der Versicherten zum Krankenhaus ließ sich in den letzten Jahren keine größere Entwicklung verzeichnen. Auch wenn sich die Versicherten mehr über die Qualität eines Krankenhauses informieren, so wird ihr Recht auf Wahl des Krankenhauses durch faktische Zwänge, wie der regionalen Verteilung der Krankenhäuser, weitgehend bestimmt, so dass keine großen Entscheidungsspielräume verbleiben und die Krankenhäuser demzufolge nicht um die Versicherten konkurrieren müssen.

Weit interessanter sind die wettbewerblichen Entwicklungen im Verhältnis des Versicherten zu der Krankenversicherung. Durch unterschiedliche Preisgestaltungen und verschiedene Ausformungen der Versicherungsangebote sowie der Möglichkeit von Zusatzversicherungen haben die Versicherten die Wahl, so dass die Versicherungsunternehmen um die Versicherten konkurrieren. Die ersten Auswertungen der Reform haben gezeigt, dass die Versichertenmobilität nach der Reform ausgesprochen hoch war und die Krankenversicherungen auch tatsächlich unterschiedliche Policen anbieten.

283 Zaak 5682/Delta Lloyd - Agis - Menzis (Fn. 281) S. 17, 18. 
Im Verhältnis der Krankenversicherungen zu den Krankenhäusern zeigen sich vor allem infolge der Freigabe der Preisverhandlungen bei einem Teil der Leistungen und der Aufhebung des Kontrahierungszwanges verstärkte wettbewerbliche Elemente, die in diesem Bereich zumindest zu einer Kostenstabilität geführt haben. Auch hier hat der Staat den Beteiligten mehr Verantwortung übertragen und beschränkt sich auf eine kontrollierende Funktion oder auch eine ersetzende, wenn die Verhandlungen der Parteien völlig scheitern.

Auch hinsichtlich des Verhältnisses der Krankenhäuser untereinander hat es in den Niederlanden starke Bestrebungen gegeben, zu einem stärker wettbewerbsorientierten System zu gelangen. So wurde die Krankenhausplanung in der Vergangenheit weitgehend von den Regionen (regio `s) übernommen. Sie wird aber immer mehr freigegeben. Bereits 2005 hat man die DBC's eingeführt und die Tarifverhandlungen im B-Segment freigegeben. 2008 ist eine Erweiterung des B-Segments geplant, so dass man eine schrittweise Ausweitung dieses freieren, mehr den Marktkräften überlassenen Feldes erreicht und der Staat sich auf eine kontrollierende Funktion beschränkt, aber weiterhin die normativen Rahmenvorgaben festlegt, in denen der Wettbewerb stattfinden soll. Das Ziel sind dabei privatrechtlich agierende Krankenhäuser als Wirtschaftsunternehmen, vielleicht in einer neuen Rechtsform, die weniger normative Vorgaben erlaubt und die hinsichtlich ihrer Planung, der Investitionen und Leistungsverträge weitgehend frei und eigenverantwortlich agieren können. Dies bildet wohl hinreichende Voraussetzungen, um Wettbewerb zwischen den einzelnen Krankenhäusern stattfinden zu lassen. Die Kehrseite ist aber, dass diesen Einrichtungen zur gleichen Zeit auch die finanzielle Verantwortung übertragen werden soll. Da es in der Vergangenheit, in der der Staat diese Verantwortung noch weitestgehend getragen hat, erhebliche Problemen mit den Kosten und der Finanzierung des Gesundheitssystems gegeben hat, erscheint es zumindest nicht völlig unproblematisch, dass die einzelnen Krankenhäuser diese Aufgabe so viel besser erfüllen können sollen und wenn ihnen dies geling, zu wessen Lasten sich diese Änderungen auswirken werden.

Schließlich hatte die Reform von 2006 auch erhebliche Auswirkungen auf das Verhältnis der Krankenversicherer untereinander. Durch die vielfältigen Möglichkeiten für die Gestaltung von Versicherungsverträgen ist eine Voraussetzung für eine Verstärkung des Wettbewerbs geschaffen worden. Eine wichtige Aufgabe fällt dabei der Gesundheitswettbewerbsbehörde zu, die die gesetzeskonforme Vertragsgestaltung mit den dargestellten Problemen überwacht. Ob sich hier tatsächlich eine Wettbewerbsverstärkung auch langfristig verzeichnen lassen wird, muss abgewartet werden. Zur Zeit lässt sich eher eine Konzentration feststellen, die allerdings von der Gesundheitswettbewerbsbehörde noch nicht als bedenklich eingestuft wird.

Die staatliche Steuerung soll zukünftig vermehrt durch Wettbewerb anstatt normativ stattfinden. Diese Entwicklung hat mit der Einrichtung der Gesundheitswettbewerbsbehörde bereits begonnen. Das Agieren von Krankenhäusern wird mittlerweile am Wett- 
bewerbsgesetz gemessen und je weiter die privatrechtliche, wirtschaftlich ausgerichtete Organisation und Handlungsfreiheit zunimmt, desto mehr Handeln wird auch mit wettbewerbsrechtlichen Maßstäben zu prüfen sein. 


\section{Literatur}

Beerepoot, C.C., De Zorgverzekeringswet en de Wet op de zorgtoeslag, Houten 2006.

Boot, Jan Maarten/Knapen, M.H.J.M., Nederlandse Gezondheidszorg, Houten 2005.

Breit, J.G./Elsinga, E./Kasdrop, J.P./Sanders, F.B.M./Vandermeulen, L.J.R./Weevers, K., Handboek Structuur en financiering gezondheidszorg Bd. 3, Maarsen 2005.

Centraal Bureau voor de Statistiek, Gezondheid en zorg in cijfers, Den Haag 2007.

College bouw ziekenhuisvoorzieningen, Curatieve Basiszorg: Vraag, Aanbod en infrastructuur, 2005.

CTG/Zaio, Visiedocument ziekenhuiszorg, Analyse en aanbevelingen voor concurrentie in het Bsegment, Utrecht 2005.

De Groot, G.J., De zorgverzekeraar: spin in het web?, TvG 2005, S. $41 \mathrm{ff}$.

De Groot, G.J., Het overeenkomstenstelsel in revisie, TvG 2004, S. 184 ff.

De Groot, G.J., Zorgbehoefte en capaciteitstekorten in zorginstellingen: Wie is verantwoorderlijk?, In: Hubben/van Zenden, Het stelsel voorbij? Sturingsperikelen in de gezondheidszorg en jurisprudentie-overzicht, Lelystad 2002, S. 49 ff.

Gaasbeek, P.B., Mededingingswet en de Zorgsector, in: van de Gronden/Mortelmans, Mededinging en nieteconomische belangen, Utrecht 2001, S. $63 \mathrm{ff}$.

Greß, Stefan, Das Beispiel Niederlande, Frankfurt am Main 2002.

Groenewegen, P.P./van den Bos, G.A.M./van Megchelen, P., Zorg, opvang en begeleiding van chronisch zieken, Assen 2004.

Hamilton, Geert Jan, Zorgverzekering, Deventer 2005.

Hamilton, Geert Jan, Kabinet kiest voor wettelijke geregelde privaatrechtelijke zorgverzekering, Zorg\&Finanziering 2004, S. 12 ff.

Hamilton, Geert Jan, Een zorgverzekering voor iedereen, Deventer 2005.

Hermans, H.E.G.M., Zorgverzekeringswet, Den Haag 2005.

Hermans, H.E.G.M./van Donk, R.N., Herziening overeenkomstenstelsel zorg, Houten 2004.

Korsten, L.E.J., Memo Mededinging 2004/05, 1. Aufl., Deventer 2004.

Kötter, Ute, Von alten und neuen Rezepten, Radikalkuren und Wechselbädern - die Reformen des niederländischen Gesundheitssystems, ZIAS 1998, S. 391 ff.

Kronenburg-Willems, E.J., Sociale Zekerheid, Deventer 2006.

Lapre', R.M./Rutten, F./Schut, F.T., Algemene economie van de gezondheidszorg, Maarsen 2001.

Leenen, Hannie, Rechtenvan mensen in de gezondheidszorg, Teil 1 Houten 2000.

Linders, J.J.M., Wet toelating zorginstellingen, Houten 2006.

Maarse, Hans, Marktwerking in de ziekenhuiszorg, Maastricht 2002.

Maarse, Hans/Groot,W./Merode, F./Mur-Veeman, I./Paulus, A., Marktwerking in de ziekenhuiszorg, Maastricht 2002.

Maarse, Hans, Privitisation in European Health Care, Maarsen 2004.

Mackenbach, J.P./van der Maas, F.J., Volksgezondheid en gezondheidszorg, 1. Aufl., Maarssen 2005.

Ministerie van Volksgezondheid, Welzijn en Sport, Beleidsvisie Wet toelating zorginstellingen, Den Haag 2005.

Nederlandse Mededingingsautoriteit, Concurrentie in de ziekenhuissector, Den Haag 2004.

Nederlandse Zorgautoriteit, Monitor ziekenhuiszorg 2007, Den Haag 2007. 
Nederlandse Zorgautoriteit, Consultatiedocument Aanmerkelijke Marktmacht (AMM) in de Zorg 2006. Nederlandse Zorgautoriteit, De tussenstand op de zorgverzekeringsmarkt, Den Haag 2006.

Nobels, Carlijn, Prijsconcurrentie tussen ziekenhuis en ZBC, Rotterdam 2005.

Nolen, M.F., Rechtsbescherming van Verzekerden in de nieuwe Zorgverzekeirngswet, Zorg\&Financiering 2004, S. $10 \mathrm{ff}$.

Noordam, Frits M., Socialezekerheidsrecht, 7. Aufl. Deventer 2004.

Noordam, Frits M., Hoofdzaken Socialezekerheidsrecht, 1. Aufl., Deventer 2004.

Okma, Kieke, Studies of Dutch Health Politics, Poicies and Law, Utrecht 1997.

Okma, Kieke, The privatisation paradoxon in dutch health care in: Maarse, Privatisation in European Health Care, 2004, S. 109 ff.

Pruijssers, N./Siebers, J.W.J./Kolsteren, G.T.F.A./Mulder, A./Van Scherpenzeel, A., Sociale verzekeringswetten Bd. 7, AWBZ, 7. Aufl. Deventer 2004.

Raad van State, Advies Zvw, Den Haag 2004.

Rijken, F.J., De diagnosebehandelingcombinatie (DBC) als instrument voor concurrentie tusssen ziekenhuizen, Zorg\&Financiering 2006, S. 8 ff.

Scheerder, R.L.J.M., Integrale tarieven en kapitallasten, Zorg\&Financiering, 2005, S. $11 \mathrm{ff}$.

Scherder, R.T.J.M., De Wet Marktordening Gezondheidszorg, Zorg\&Finanziering 2005, S. 25 ff.

Scherpenisse, A.M.C./Verbeek, G., Gezondheidszorg, Houten 2002.

Schrijvers, G., Een kathedral van zorg, Maarsen 2001.

Spreeuwenberg,C./Pop, P./Beusmans, G.H.M.I./Winkens, R.A.G./Zutphen, H./, Handboek transmurale zorg, Maarsen2000.

Steyger, H.E., Marktwerking in oprichting: de bevoeggdheden van zorgautoriteit en NMa en de werking in de praktijk, TvG 2006, S. 2 ff.

Van de Gronden, J.W./Mortelmans, K.J.M., Mededingind en niet.economische belangen, Utrecht 2001.

Van der Kooij, P.A.C.E./Mulder, S.J.A., Hoofdzaken mededingingsrecht, 1. Aufl., Deventer 2001.

Van der Most, J.M., De Zorgverzekeringswet en de selfverzekerde burger, TvG 2005, S. 17 ff.

Van der Most, J.M., Funktiegerechte verstrekkiung-omschrijving, TvG 1991, S. 464 ff.

Van der Most, J.M., Vraaggestuurde zorg als recht vanuit verzekeringsperspectief (ZFW en AWBZ), TvG 2003, S. 2 ff.

Van Rooij, F.B./Kodner, D./Rijsemus, T./Schrijvers, G., Health and Health Care in the Netherlands, Maarsen 2002.

Van Saase, L./Pruijssers, N., De nieuwe Zorgverzekeringswet, Deventer 2005.

Van Schooneveld, E., De Zorgverzekeringswet en de Wet op de zorgtoeslag in vogelflucht, TvG 2005, S. $3 \mathrm{ff}$.

Van Westerlaak, Marc, De zorgverzekeringswet toegepast, Deventer 2005.

Walser, Christina, Die aktuellen Reformen der niederländischen Krankenversicherung - Anregungen für Deutschland?, ZFSH/SGB 2004, S. $410 \mathrm{ff}$.

Walser, Christina, Neue Krankenversicherung der Niederlande, ZRP 2005, S. 273 ff.

Walser, Christina, Nach der Gesundheitsreform in den Niederlanden: eine neue Krankenversicherung für jeden, SozSich 2006, S. 87 ff.

Walser, Christina, Erste Ergebnisse der niederländischen Reform des Krankenversicherungssystems, Die BKK 2006, S. 154 ff.

Wansink, H./Blom, R.J./van Garderen-Groenveld, A.S.J./van Ardenne-Dick, M.M.R./Kalkman, W.M.A., Juridisch Zakboek Bd. III, Deventer, Looseblattwerk, Stand Oktober 2008. 


\section{Christina Walser}

Zuurbier, Joost/Krabbe-Alkemade, Yvonne, Onderhandelen over DBC`s, Maarsen 2004. 


\title{
Kommentar zum Bericht über die Niederlande aus ökonomischer Sicht
}

\author{
Hans Maarse
}

1. Einführung $\quad 340$

2. Patienten haben freie Krankenhauswahl $\quad 340$

3. Wahlfreiheit für Verbraucher bei der Krankenversicherung 342

4. Das Verhältnis zwischen Krankenhaus und Versicherungsgesellschaft 345

5. Wettbewerb zwischen den Krankenhäusern 348

6. Der Wettbewerb auf dem Krankenversicherungsmarkt 353

Literatur 356 